FABRICIO SHIGUERU CATAE

\title{
CLASSIFICAÇÃO AUTOMÁTICA DE TEXTO POR MEIO DE SIMILARIDADE DE PALAVRAS: UM ALGORITMO MAIS EFICIENTE
}

\footnotetext{
Dissertação apresentada à Escola Politécnica da Universidade de São Paulo para obtenção do Título de Mestre em Engenharia Elétrica.
}

São Paulo

2012 


\section{CLASSIFICAÇÃO AUTOMÁTICA DE TEXTO POR MEIO DE SIMILARIDADE DE PALAVRAS: UM ALGORITMO MAIS EFICIENTE}

Dissertação apresentada à Escola Politécnica da Universidade de São Paulo para obtenção do Título de Mestre em Engenharia Elétrica.

Área de concentração:

Sistemas Digitais

Orientador:

Prof. Dr. Ricardo Luis de Azevedo da Rocha

São Paulo 


\section{FICHA CATALOGRÁFICA}

\section{Catae, Fabricio Shigueru}

Classificação automática de texto por meio de similaridade de palavras: um algoritmo mais eficiente / F.S. Catae. -- São Paulo, 2012.

$93 \mathrm{p}$.

Dissertação (Mestrado) - Escola Politécnica da Universidade de São Paulo. Departamento de Engenharia de Computação e Sistemas Digitais.

1. Algoritmos 2. Classificação automática de texto 3. Reconhecimento de padrões I. Universidade de São Paulo. Escola Politécnica. Departamento de Engenharia de Computação e Sistemas Digitais II. t. 
Dedico este trabalho aos meus pais, que fizeram de tudo para que esse dia chegasse. 


\section{Agradecimentos}

Gostaria de agradecer a oportunidade ao professor Dr. José Jaime da Cruz, o principal responsável por toda essa história. Seu incentivo foi fundamental para que eu tivesse a coragem necessária de entrar no programa de pós-graduação.

Agradeço a experiência a todas as pessoas que conheci durante o mestrado:

- Ao meu orientador, professor Dr. Ricardo Luis de Azevedo da Rocha, por compartilhar seu conhecimento com muita paciência, além de desempenhar o papel de psicólogo e motivador durante a reta final do trabalho;

- Ao professor Dr. Jorge Kinoshita pelas caminhadas filosóficas à tarde, que me ajudaram a enxergar a vida sob outra perspectiva;

- Ao professor Dr. João José Neto pelas conversas dentro e fora do laboratório sobre os mais diversos assuntos;

- Ao professor Dr. Hae Yong Kim pelos ensinamentos em processamento de imagem e vídeo, que me recordaram os primeiros anos de graduação na Poli;

- Ao professor Dr. Flávio Soares Corrêa da Silva pelos valiosos conselhos que me fizeram repensar todo o trabalho;

- Aos companheiros Celso Crivelaro, Elisângela Rodrigues, Iúri Chaer, Luís Dalla Valle, Reginaldo Inojosa e Ricardo Guiraldelli por me acompanharem nas matérias, nos almoços e nos happy hours.

Esse é um bom momento para agradecer às pessoas que me acompanham:

Aos colegas de trabalho, por toda genialidade e amizade: Daniel Takao Santos, Douglas Santos, Eduardo Nakahara, Fabio Gentile, Luiz Felipe Pimenta, Renata Festa, Silvio Pavarino, Tatiana Pauli, Thiago Caserta, Thiago Iacopini e Wellington Rampazo; 
Aos colegas Sérgio Ramos e Marco Aurélio pelas altas risadas no escritório com as discussões (desorientadas) sobre algoritmos;

À companheira Ana Paula pelo seu jeito de "menininha" e sua preocupação com as pessoas (além de ser minha atual chefa);

Ao casal Aline e Tognini, amigos de longa data, distantes fisicamente, mas sempre mantendo contato para não esquecer os dias de Rock Band e Networking;

À Tatiana por acreditar em mim e estar sempre pensando longe em conhecer novos destinos de viagem;

À Carmen, Sandra, Clara, Mitsuro, Cristhiane, Herbert e a toda família do beisebol pelos agitados finais de semana;

À Rubiana e ao Paulo Teixeira pelos cafés da manhã, almoços, cafés da tarde, jantas, reuniões de trabalho, planos PIDM, apostas, piadas sem graça e tudo mais que constitui uma amizade duradoura;

Ao meu filho Gustavo Yudi por toda animação e energia positiva, com aquele jeito único de criança, despojado, sempre me lembrando das prioridades da vida.

Finalmente, gostaria de agradecer aos meus familiares, a meus pais e a meu irmão por vivermos sempre juntos e dividirmos os momentos de alegria e tristeza. Estou muito feliz por nossa união. 


\section{Resumo}

A análise da semântica latente é uma técnica de processamento de linguagem natural, que busca simplificar a tarefa de encontrar palavras e sentenças por similaridade. Através da representação de texto em um espaço multidimensional, selecionam-se os valores mais significativos para sua reconstrução em uma dimensão reduzida. Essa simplificação lhe confere a capacidade de generalizar modelos, movendo as palavras e os textos para uma representação semântica. Dessa forma, essa técnica identifica um conjunto de significados ou conceitos ocultos sem a necessidade do conhecimento prévio da gramática. $\mathrm{O}$ objetivo desse trabalho foi determinar a dimensionalidade ideal do espaço semântico em uma tarefa de classificação de texto. A solução proposta corresponde a um algoritmo semi-supervisionado que, a partir de exemplos conhecidos, aplica o método de classificação pelo vizinho mais próximo e determina uma curva estimada da taxa de acerto. Como esse processamento é demorado, os vetores são projetados em um espaço no qual o cálculo se torna incremental. Devido à isometria dos espaços, a similaridade entre documentos se mantém equivalente. Esta proposta permite determinar a dimensão ideal do espaço semântico com pouco esforço além do tempo requerido pela análise da semântica latente tradicional. Os resultados mostraram ganhos significativos em adotar o número correto de dimensões.

Palavras-chave: Algoritmos; Classificação automática de texto; Reconhecimento de padrões. 


\section{Abstract}

The latent semantic analysis is a technique in natural language processing, which aims to simplify the task of finding words and sentences similarity. Using a vector space model for the text representation, it selects the most significant values for the space reconstruction into a smaller dimension. This simplification allows it to generalize models, moving words and texts towards a semantic representation. Thus, it identifies a set of underlying meanings or hidden concepts without prior knowledge of grammar. The goal of this study was to determine the optimal dimensionality of the semantic space in a text classification task. The proposed solution corresponds to a semi-supervised algorithm that applies the method of the nearest neighbor classification on known examples, and plots the estimated accuracy on a graph. Because it is a very time consuming process, the vectors are projected on a space in such a way the calculation becomes incremental. Since the spaces are isometric, the similarity between documents remains equivalent. This proposal determines the optimal dimension of the semantic space with little effort, not much beyond the time required by traditional latent semantic analysis. The results showed significant gains in adopting the correct number of dimensions.

Keywords: Algorithms; Automatic text classification; Pattern Recognition. 


\section{SUMÁRIO}

1 INTRODUÇão 1

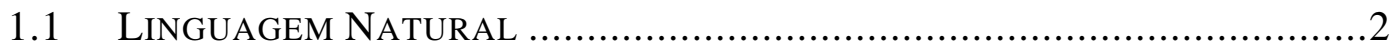

1.1.1 Aquisição de Linguagem .............................................2

1.1.2 Análise da Semântica Latente ........................................... 3

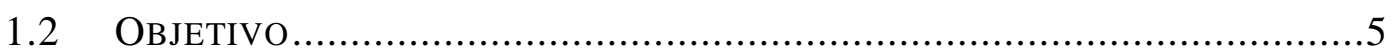

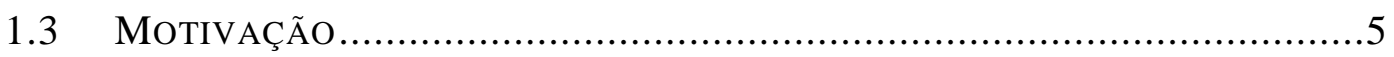

1.4 ORGANIZAÇÃO DO DOCUMENTO ..........................................

2 Modelagem de Dados 9

2.1 Classes e Atributos ............................................................. 9

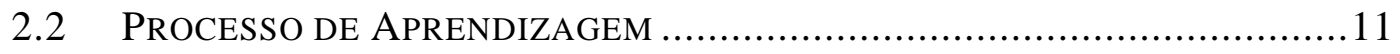

2.3 ClassifiCAdores De TEXTO ................................................... 13

2.3.1 Árvore de Decisão .......................................................14

2.3.2 Naïve Bayes ........................................................15

2.3.3 Classificação pelos k vizinhos mais próximos ....................16

2.3.4 Rocchio ............................................................... 17

2.3.5 Máquina de Vetores de Suporte .....................................18

2.4 MÉTRICAS DE AvaLIAÇÃO.................................................... 19

2.4.1 Precisão, Cobertura e Medida F ......................................20

2.4.2 Taxa de Acerto e Erro ....................................................21

2.4.3 Valores Médios (Macro e Micro) .....................................21

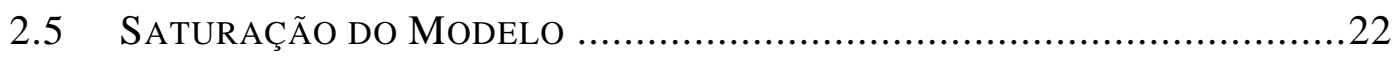

2.5.1 Princípio da Navalha de Occam ....................................23

2.5.2 Limitação do Modelo ................................................24

3 ESPAÇO SEMÂNTICO

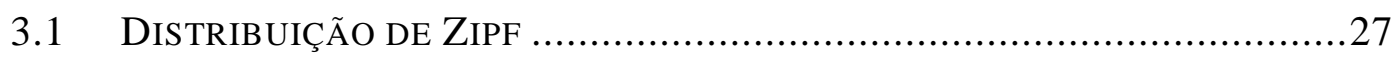




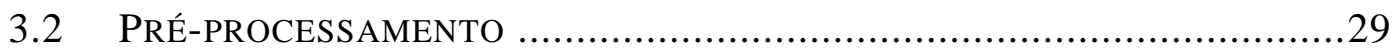

3.2.1 Segmentação ......................................................29

3.2.2 Reconhecimento de Termos ........................................29

3.2.3 Lematização ..................................................... 30

3.2.4 Eliminação de Termos Irrelevantes ...................................30

3.3 REPRESENTAÇÃO VETORIAL ................................................... 31

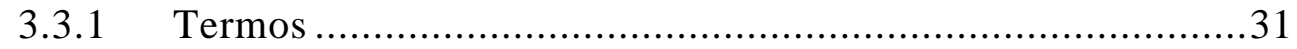

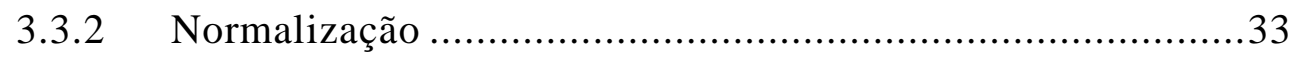

3.3.3 Similaridade ........................................................ 34

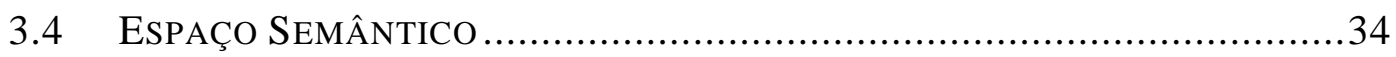

3.4.1 Matriz Termo-Documento ........................................ 37

3.4.2 Decomposição em Valores Singulares ..............................38

3.4.3 Aproximação de Matrizes .................................................38

3.4.4 Projeção no espaço semântico ........................................40

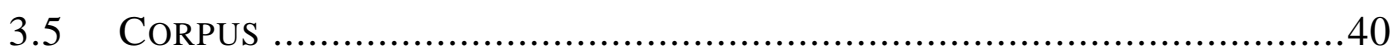

3.5.1 Reuters 21578 ........................................................40

3.5.2 Experimentos ......................................................42

4 Extensão da Matriz Termo-Documento 45

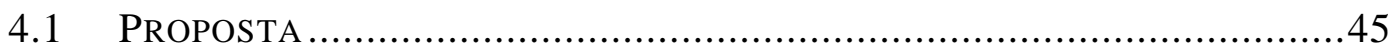

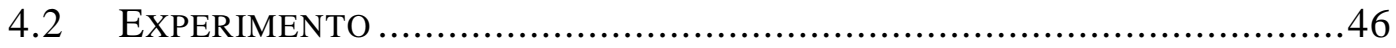

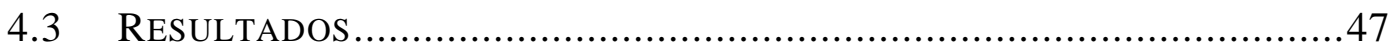

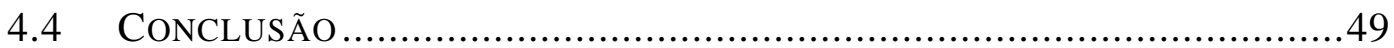

5 Espaços Semânticos por Categoria 50

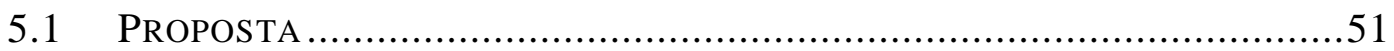

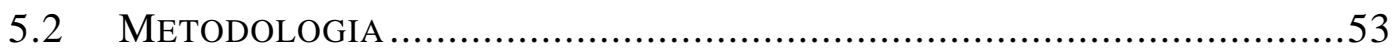

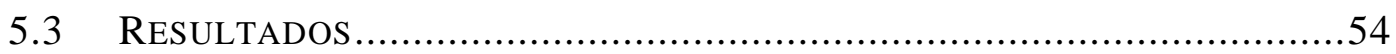

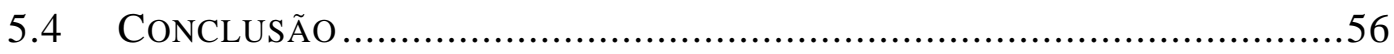

6 Dimensão IdeAL

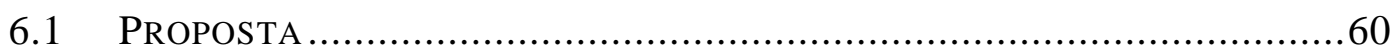

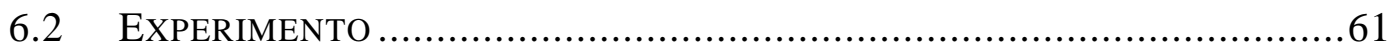


6.3 Resultados Preliminares ..................................................62

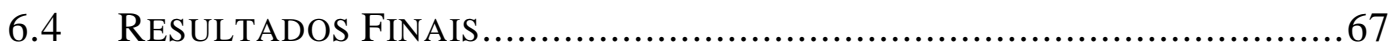

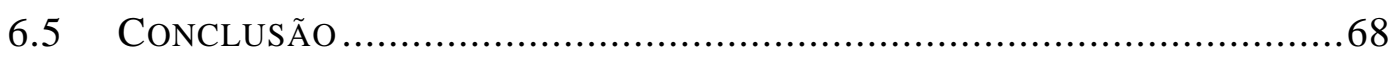

7 Algoritmo Mais Eficiente

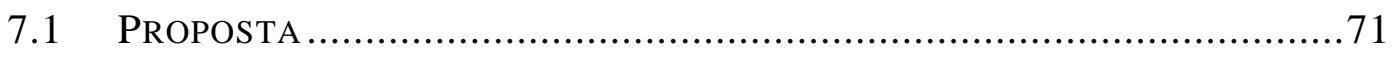

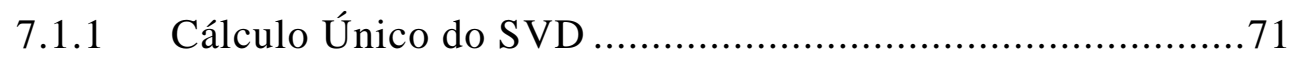

7.1.2 Projeção da Matriz Termo-Documento ..............................71

7.1.3 Cálculo Incremental da Similaridade ..............................75

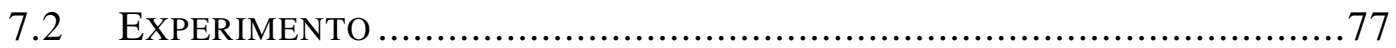

7.3 Resultados PreliminaRes .................................................... 78

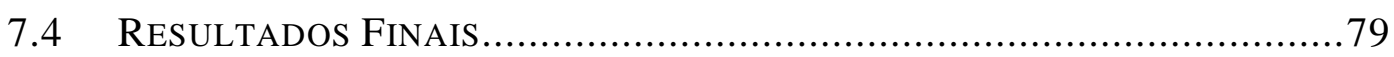

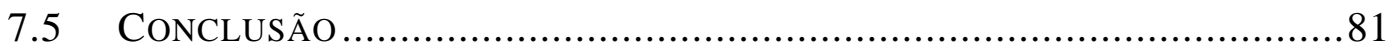

8 ConsideraÇões Finais

8.1 CONTRIBUiÇÕES DA PESQUISA ..................................................... 83

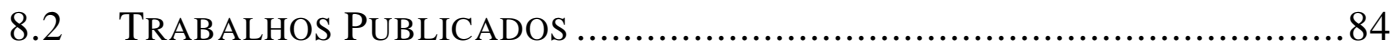

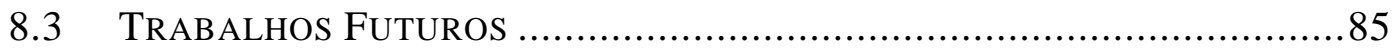

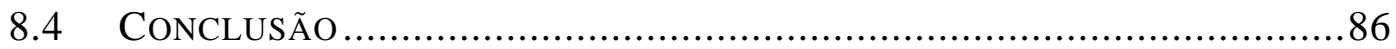

$\begin{array}{lr}\text { REFERENCIAS } & \mathbf{8 9}\end{array}$ 


\section{LISTA DE FigURAS}

Figura 2.1 - Representação das regras em autômato ............................................... 11

Figura 2.2 - Processo de aprendizagem de novas regras ....................................... 12

Figura 2.3 - Classificação pelo vizinho mais próximo .............................................. 16

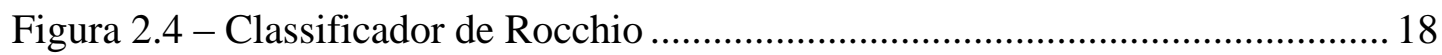

Figura 2.5 - Classificador usando Máquina de Vetores de Suporte .......................... 19

Figura 2.6 - Exemplo do fenômeno de overfitting de dados .................................... 23

Figura 2.7 - Árvore de decisão desbalanceada ................................................... 25

Figura 2.8 - Overfitting devido à limitação do modelo ........................................... 25

Figura 3.1 - Distribuição de termos e relevância........................................................ 28

Figura 3.2 - Representação de termos no espaço vetorial .......................................... 36

Figura 3.3 - Representação de termos no espaço semântico ..................................... 37

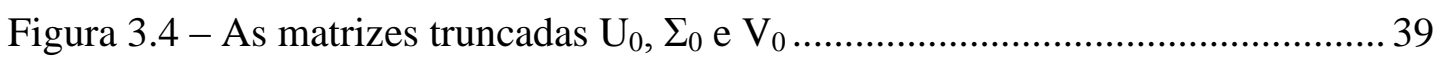

Figura 5.1 - Comparação entre o ESC e os diferentes métodos ...............................57

Figura 6.1 - Influência do número de dimensões ................................................... 59

Figura 6.2 - Taxa de acerto $\mathrm{T}(\mathrm{k})$ do conjunto de treinamento ..................................... 61

Figura 6.3 - Curvas $\mathrm{T}(\mathrm{k})$ e $\mathrm{P}(\mathrm{k})$ em relação aos dados $\mathrm{P} 1$........................................ 63

Figura 6.4 - Curvas $\mathrm{T}(\mathrm{k})$ e $\mathrm{P}(\mathrm{k})$ em relação aos dados P2 e P3 ................................. 64

Figura 6.5 - Desempenho dos conjuntos de dados com distribuição aleatória........... 66

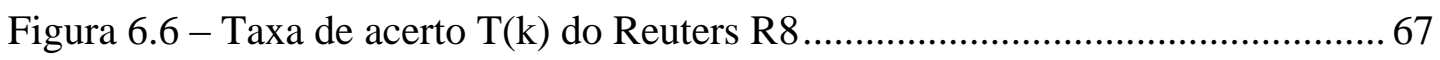

Figura 6.7 - Determinando a dimensão ideal em Reuters R8 …….......................... 69

Figura 6.8 - Avaliação da aleatoriedade usando os dados R8-E .............................. 69

Figura 6.9 - Diferença percentual entre $\mathrm{T}(\mathrm{k})$ e $\mathrm{P}(\mathrm{k})$ em Reuters R8 ......................... 69

Figura 7.1 - Tempo gasto pelos métodos simples e otimizado (segundos) ................78

Figura 7.2 - Comparação dos tempos em escala logarítmica .................................. 79

Figura 7.3 - Tempo gasto nas etapas SVD e Matriz................................................ 80 


\section{LISTA DE TABELAS}

Tabela 2.1 - Tabela de contingência da categoria Ci.............................................. 20

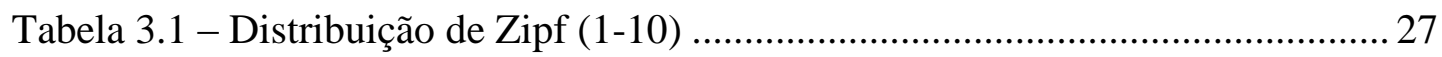

Tabela 3.2 - Distribuição de Zipf (10-15000) …...................................................... 27

Tabela 3.3 - Distribuição de documentos no corpus R8 ............................................ 43

Tabela 4.1 - Comparativo de desempenho da matriz estendida ............................... 48

Tabela 5.1 - Desempenho da técnica Categorização por projeção ............................ 54

Tabela 5.2 - Desempenho do Espaço Semântico por Categoria (Resumo) ................ 55

Tabela 5.3 - Detalhamento do desempenho do Espaço Semântico por Categoria .... 55

Tabela 5.4 - Comparação de desempenho do Espaço semântico por categoria .........56

Tabela 5.5 - Projeção de um documento da classe "earn" ..........................................58

Tabela 6.1 - Distribuição de documentos por assunto (P1).....................................6 65

Tabela 6.2 - Distribuição de documentos por assunto (P2).....................................65

Tabela 6.3 - Distribuição de documentos por assunto (P3).................................... 65

Tabela 6.4 - Desempenho da classificação do Reuters R8 usando LSA .................... 67

Tabela 7.1 - Comparação de tempo dos métodos simples e otimizado..................... 79

Tabela 7.2 - Tempo gasto pelos métodos simples e otimizado no Reuters R135 ..... 80 


\section{INTRODUÇÃO}

Quando o linguista Noam Chomsky introduziu a expressão "Problema de Platão", questionava-se sobre como que os seres humanos sabem o que sabem e qual a relação do conhecimento com as experiências adquiridas. Essa dúvida foi levantada ao observar a forma como as crianças aprendem a manipular a linguagem, criando desde sentenças simples a complexas, frente à quantidade de informação a que estão expostas.

Um dos mistérios da cognição é como que as pessoas obtêm tanto conhecimento quanto se comparado à quantidade de informação. Esse é um problema envolvendo diversas áreas: filosofia, psicologia, linguística, computação, entre outras. A formalização matemática de que determinadas linguagens não podem ser aprendidas com base em dados finitos reforça esse argumento (JAIN, 1986).

Chomsky (1991) acredita que a linguagem é aprendida a partir de uma capacidade inata do ser humano, de forma que existem regras pré-definidas e que necessitam de pequenas alterações com base nas experiências da vida. Não é exatamente uma aquisição de linguagem. É, na realidade, um ajuste nos parâmetros. Embora essa proposta seja discutível, ainda pode ser considerada uma explicação razoável de como as crianças se tornam, com tão pouca informação, mestres da língua. Observa-se que a aquisição de linguagem é uma capacidade que independe do local, região ou cultura e ocorre sempre por volta da mesma idade.

A aquisição de linguagem é um assunto relacionado com o estudo do processamento de linguagem natural, que aborda a modelagem computacional, a representação de conhecimento e a aprendizagem de máquina. O desafio é transformar uma cadeia de símbolos em conceitos com a mesma facilidade que fazemos naturalmente. 
O artigo "Uma solução para o problema de Platão" de Landauer e Dumais (1997) sugere uma hipótese para explicar porque determinados domínios de conhecimento possuem fracos laços de inter-relação direta, dificultando a assimilação da linguagem pela máquina. Na realidade, os conceitos permeiam as palavras de um texto, mas estão escondidos. Essa hipótese foi levantada através de experimentos utilizando a análise da semântica latente: um modelo multidimensional que não requer conhecimento prévio para analisar uma grande quantidade de dados e, depois, é capaz de gerar uma representação que captura a similaridade entre textos e palavras.

\subsection{Linguagem Natural}

Enquanto que a linguagem se desenvolve espontaneamente como uma aptidão do ser humano, uma máquina requer representações formais que facilitem seu armazenamento e manipulação.

\subsubsection{Aquisição de Linguagem}

A aquisição de linguagem ainda é uma questão que intriga os pesquisadores. É difícil imaginar que, com tão pouca informação, seja desenvolvida uma linguagem dinâmica e criativa, sempre agregando novos vocábulos e mudando de forma ao longo do tempo. No campo da linguística, refere-se ao problema da pobreza de estímulo, no qual a quantidade de estímulos é insuficiente para que ocorra o aprendizado da língua e suas regras.

Como as crianças podem adquirir a linguagem falada em tão pouco tempo? Elas não ficam em classes de aula em uma relação aluno-professor. Conseguem aprender a fala sem a necessidade de estudar as regras gramaticais. Mesmo sem saber ler ou escrever, são capazes de identificar palavras isoladas para adivinhar o significado da frase. Basta ligar a televisão e a criança sabe "ler" quando aparece o título do seu desenho predileto. 
Crianças maiores de 6 a 8 anos, que já conhecem o alfabeto e sabem formar sílabas, divertem-se com jogos eletrônicos mesmo quando o texto está escrito em uma língua estrangeira. Essas experiências não constituem a capacidade de compreender um texto por completo. Por outro lado, demonstram que conseguem adquirir parte do vocabulário e agregar ao seu conhecimento.

$\mathrm{Na}$ hierarquia de Chomsky, uma linguagem formal é descrita por meio de regras. Será que há um sistema de regras no cérebro dos humanos? Ao contrário de um conjunto de normas rígidas, a linguagem natural surge como uma capacidade inerente de comunicação do cérebro humano. Uma conversa fluente entre duas

pessoas pode, por exemplo, não seguir estritamente as estruturas sintáticas e gramaticais.

Segundo a proposta de Chomsky (1965), os seres humanos são dotados de um dispositivo especializado de aquisição de linguagem, sendo responsável por trabalhar melhor os estímulos recebidos. Pressupõe-se a existência de regras, compondo uma Gramática Universal, que precisam apenas de ajustes em seus parâmetros.

\subsubsection{Análise da Semântica Latente}

O ditado popular "para bom entendedor, meia palavra basta" é um exemplo de que as sentenças geradas a partir da linguagem natural não são tão aleatórias, mas elas possuem determinado grau de previsibilidade. Afinal, meia palavra basta. Acreditase, portanto, que as palavras similares estejam presentes no mesmo contexto, seja no escopo de uma frase, um parágrafo ou um documento.

A linguagem natural apresenta um grande desafio em relação ao processo de aprendizado por máquina. Apesar disso, há resultados convincentes obtidos através da representação em espaço vetorial (MANNING, RAGHAVAN e SCHÜTZE, 2008).

A análise da semântica latente é um método baseado na álgebra linear (DUMAIS, FURNAS, et al., 1988; DEERWESTER, DUMAIS, et al., 1990). A proposta inicial era validar se esse mecanismo conseguia reproduzir, em partes, o conhecimento humano. Em um experimento usando a técnica da análise da 
semântica latente, indexaram-se 30473 artigos da enciclopédia americana Grolier. Em seguida, o mecanismo foi submetido a 80 questões de múltipla escolha de um exame da língua inglesa, Test Of English as a Foreign Language (TOEFL). O resultado foi uma taxa de $64,4 \%$ de acerto contra uma média de $64,5 \%$ dos candidatos (LANDAUER e DUMAIS, 1997).

Através da decomposição de matrizes e projeção de vetores, a técnica reduz a complexidade do espaço vetorial, que representa as informações, e o transforma em um espaço semântico. Nessa nova representação, é possível inferir as relações de similaridade entre palavras.

Entretanto, as principais limitações da análise da semântica latente são:

- Falta de algoritmo para determinar a dimensão ideal do espaço semântico. Por exemplo, nas primeiras coleções de documentos do Text REtrieval Conference (TREC), Dumais $(1993 ; 1994 ; 1995)$ determinaram-se os parâmetros na base da tentativa e erro. Os experimentos adotam valores empíricos entre 100 a 500 dimensões (BRADFORD, 2008).

- Cálculos com matrizes de larga escala $m \times n$, onde $m$ é o número de termos e $n$, documentos. Esses valores são usualmente grandes, tornando as operações de multiplicação e de decomposição em valores singulares quase inviáveis. Como forma alternativa, a técnica de projeção aleatória tem sido aplicada para reduzir o tamanho da matriz ao custo de perda de precisão (PAPADIMITRIOU, TAMAKI, et al., 1998; BINGHAM e MANNILA, 2001).

- A classificação prévia dos dados de treinamento é desconsiderada, pois a análise da semântica latente é considerada um mecanismo de aprendizagem não-supervisionado (TORKKOLA, 2001). Isso significa que o algoritmo pode não ser o mais adequado para uma tarefa de classificação de documentos. 


\subsection{Objetivo}

O escopo do trabalho é aplicar a análise da semântica latente em uma tarefa simples: classificação de documento em categorias pré-definidas. Essa técnica é amplamente conhecida na área de classificação de dados (SEBASTIANI, 2002), não sendo necessário repetir os experimentos para avaliar os resultados. A proposta é ir além dos experimentos tradicionais e procurar por um algoritmo mais eficiente.

Definimos eficiência por:

- Melhorar a qualidade dos resultados obtidos

- Reduzir o tempo e os recursos consumidos

- Tornar o algoritmo escalável em relação ao volume

O principal objetivo do trabalho é estudar a questão da dimensionalidade do espaço semântico. A determinação da dimensão ideal com base da tentativa e erro é inviável, pois requer repetir o experimento para um intervalo de dimensões ou adotar valores tradicionais na esperança que sejam adequados. Nesse trabalho, avaliamos uma proposta para determinar a dimensão ideal.

Além disso, busca-se melhorar os aspectos da categorização em relação à escalabilidade do algoritmo conforme se aumenta a quantidade de documentos. Uma forma de atingir esse objetivo é adotar espaços semânticos independentes para cada uma das categorias.

O trabalho adicionalmente sugere uma estratégia para levar em consideração a classificação prévia dos dados de treinamento. Dessa forma, a análise da semântica latente se transforma em um mecanismo de aprendizagem semi-supervisionado e pode obter melhores resultados.

\subsection{Motivação}

A inspiração do trabalho nasceu a partir do desejo de criar um mecanismo de indexação que incorporasse os detalhes linguísticos. A proposta era combinar a 
análise da semântica latente ao preditor de Solomonoff, dando continuidade à pesquisa de Chaer (2010).

O preditor de Solomonoff com convergência de $1 / n$ sobre o número de amostras é uma ideia promissora. Entretanto, há o problema de percorrer todo o Universo de algoritmos, dificultando a aplicação prática e direta do dispositivo dentro do escopo desse trabalho. Por isso, voltamos os esforços ao propósito inicial: melhorar a qualidade do algoritmo da análise da semântica latente.

O artigo "Uma solução para o problema de Platão" comenta sobre a importância da escolha correta de parâmetros (LANDAUER e DUMAIS, 1997, p. 220):

"A ideia base do modelo assume a escolha correta da dimensionalidade."

Na conclusão, Landauer e Dumais (1997, p. 234) evidenciam que o número de dimensões afetou diretamente o resultado do experimento:

"O desempenho do modelo no teste de sinônimo teve forte dependência da dimensionalidade do espaço representado, no qual se encaixavam as palavras. $O$ desempenho foi péssimo quando se limitou somente à coocorrência local (muitas dimensões); foi bem quando assumiu por volta de 300 dimensões; novamente ruim ao tentar representar todo seu conhecimento em menos de 100 dimensões. A partir daí, concluímos que a determinação da dimensão pode melhorar significativamente a extração e representação de conhecimento em pelo menos um domínio de aprendizagem humana."

Em uma pesquisa bibliográfica, a melhor referência encontrada sobre o ajuste de dimensão foi "Um estudo empírico do número de dimensões para aplicações de larga escala usando a análise da semântica latente” (BRADFORD, 2008). Nas palavras do autor, os resultados obtidos indicam uma "ilha de estabilidade" no intervalo de 300 a 500 dimensões, com pouca variação de resultado fora dessa faixa. 
Dado o desconhecimento de um método mais preciso para ajustar corretamente o número de dimensões do espaço semântico, consideramos esse desafio como um ótimo ponto de partida para o trabalho.

\subsection{Organização do Documento}

O capítulo 1 realiza uma breve introdução sobre a aquisição de linguagem natural e suas dificuldades. O objetivo principal e os secundários são definidos em conjunto com a motivação do trabalho.

No capítulo 2, apresenta-se uma noção básica sobre aprendizagem de máquina e a criação da "inteligência" usando amostras de eventos passados. O capítulo inicia com um exemplo de classificação de dados para mostrar que, ao contrário de regras bem definidas, a máquina pode absorver conhecimento para depois realizar inferências sobre eventos futuros. São abordadas as métricas de avaliação e os classificadores de texto mais comuns. Na última parte, alerta-se sobre o perigo da saturação do modelo, conhecido também como o fenômeno de overfitting.

No capítulo 3, é descrito o modelo de espaço vetorial amplamente utilizado em recuperação de informação. Esse modelo permite a representação dos documentos associados às palavras usando vetores multidimensionais. O capítulo apresenta a distribuição de Zipf, que fundamenta o processamento estatístico de linguagem. Os passos de pré-processamento de texto para converter em vetores são discutidos. Em seguida, é detalhado o fundamento matemático por trás da técnica de análise da semântica latente: a decomposição de matriz em valores singulares. Ao final do capítulo, é apresentado o corpus da Reuters e os conjuntos utilizados nos experimentos: a coleção de documentos da Reuters R8 e R135, as amostras de dados P1 a P5 e suas variantes.

No capítulo 4, é observado que a análise da semântica latente depende apenas das informações de documentos e termos, ignorando as categorias. A ideia é incluir novas linhas com dados de documentos previamente classificados, associando as 
categorias aos documentos. Assim, propõe-se o experimento de extensão da matriz termo-documento.

No capítulo 5, observa-se que as palavras podem possuir diferentes significados dependendo do contexto. Dado a existência de vários domínios de conhecimento, discutimos a possibilidade de criar diferentes espaços semânticos independentes. $\mathrm{O}$ experimento utiliza a projeção de documentos nos diferentes subespaços que definem uma categoria.

No capítulo 6, é investigado o desafio de definir a dimensão ideal para a análise da semântica latente. Esse parâmetro influencia diretamente na qualidade do resultado final. Propõe-se a hipótese de que os dados de treinamento podem ser usados para prever o comportamento do teste. O experimento realizado comprova essa hipótese e aponta para uma forma de determinar a dimensionalidade correta.

No capítulo 7, continua a discussão sobre o problema da dimensão ideal. Entretanto, o foco é a questão do tempo de processamento. Nesse capítulo, o algoritmo é revisto e são sugeridas otimizações para ganho de desempenho.

No capítulo 8, são apresentadas as considerações finais e ideias para os trabalhos futuros. 


\section{MODELAGEM DE DADOS}

Ao observar uma revoada de pássaros voando no céu, imaginamos que sejam todos da mesma espécie. Entretanto, sabemos que existem características que os diferenciam entre eles: formato dos olhos, tom das penas, tamanho das asas. Assim como existem outras que são particularidades da classe: proporção do tamanho da asa em relação ao corpo, formato do bico e dos pés. Dada uma espécie, enumeramos uma série de atributos.

Nesse cenário, definimos o problema de classificação como a questão inversa: a partir dos atributos de uma ave, seria possível descobrir qual a sua espécie?

\subsection{Classes e Atributos}

Em uma tarefa de classificação, é fornecido um conjunto de indivíduos que podem ser descritos por meio de seus atributos. Cada indivíduo pertence a uma ou mais classes, sendo que aqueles de mesma classe compartilham características em comum. $\mathrm{O}$ ato de classificar significa associar os conjuntos de atributos às classes correspondentes. Por exemplo, no estudo de aves migratórias definimos os atributos e classes:

\section{Atributos:}

- $\mathrm{ASAS}=\{$ ATROFIADAS, DESENVOLVIDAS $\}$

- $\mathrm{BICO}=\{$ CURTO, LONGO $\}$

- $\mathrm{CORPO}=\{$ PEQUENO, GRANDE $\}$

\section{Classes:}

- EspéCIE MigratóRIA $=\{S I M, N \tilde{O} O\}$ 
Usando como base o estudo das espécies, as regras são criadas de forma a associar a morfologia ao comportamento de migração. Uma das hipóteses é que somente as aves com asas desenvolvidas, bico longo e corpo grande são migratórias. Assim, usamos regras para classificar indivíduos de acordo com seus atributos.

\section{Regras:}

\begin{tabular}{ccc} 
AsAS, BICO, CORPO (ATRIBUTOS) & & MIGRATÓRIA \\
\hline DESENVOLVIDAS , CURTO , PEQUENO & $\longrightarrow$ & NÃO \\
DESENVOLVIDAS , LONGO, PEQUENO & $\longrightarrow$ & NÃO \\
DESENVOLVIDAS , CURTO , GRANDE & $\longrightarrow$ & NÃO \\
DESENVOLVIDAS , LONGO, GRANDE & $\longrightarrow$ & SIM \\
ATROFIADAS , CURTO , PEQUENO & $\longrightarrow$ & NÃO \\
ATROFIADAS , LONGO , PEQUENO & $\longrightarrow$ & NÃO \\
ATROFIADAS , CURTO , GRANDE & & NÃO \\
ATROFIADAS , LONGO , GRANDE & & NÃO
\end{tabular}

O processo pode ser aplicado para os diferentes tipos de aves a partir de sua descrição. Por exemplo, observamos que o avestruz e o pinguim são aves não migratórias, mas o pelicano é migratório. Essas novas regras foram incorporadas em um diagrama de apoio a decisão, representadas através de um autômato de estados finitos (Figura 2.1).

\begin{tabular}{|c|c|c|}
\hline ESPÉCIE & & ( ASAS, BiCo, CORPo)(Migratória) \\
\hline AVESTRUZ & $=$ & ( ATROFIADAS , CURTO , GRANDE )(NÃO) \\
\hline Pinguim & $=$ & ( ATROFIADAS , CURTO , PEQUENO )(NÃO) \\
\hline PELICANO & $=$ & ( DESENVOLVIDAS , LONGO, PEQUENO )(SIM) \\
\hline
\end{tabular}




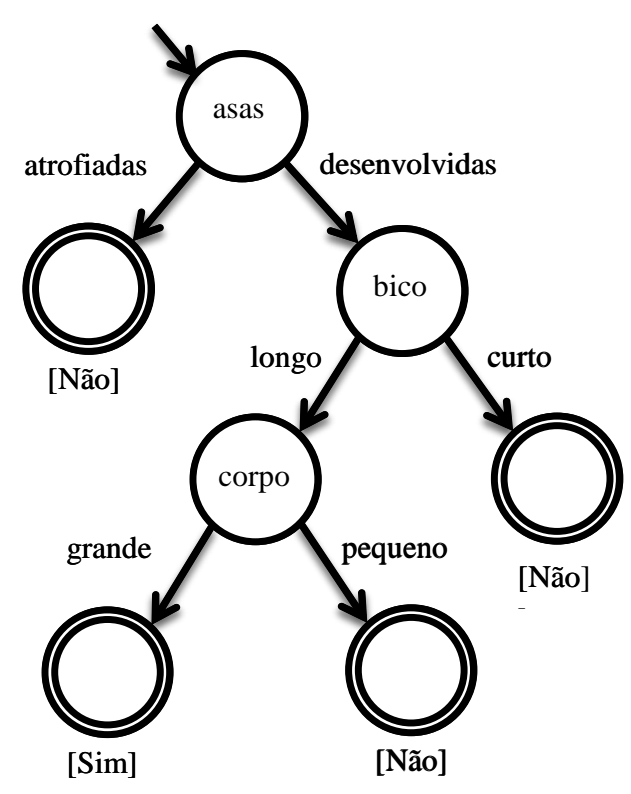

Figura 2.1 - Representação das regras em autômato

Um indivíduo é classificado em migratório "sim" ou "não" com base em seus atributos. Nesse exemplo, as características estão relacionadas com as asas, o bico e o tamanho do corpo das aves.

Estamos interessados em determinar a classe das aves com relação ao comportamento migratório. Isso corresponde a verificar qual o estado final do autômato ao seguir as transições com base nos atributos A, B e C (Asas, Bico e Corpo). Em seu último estado, o autômato indica "sim" ou "não". Essa seria uma versão primitiva de um programa de computador que classifica aves a partir de seus atributos.

\subsection{Processo de Aprendizagem}

Com o passar do tempo, novas regras de classificação podem surgir por conta de situações não consideradas inicialmente. Essas mudanças se refletem na alteração do autômato, forçando a criação de uma nova estrutura de classificação. O processo de aprendizagem permite que um autômato incorpore as mudanças em sua própria estrutura de forma incremental. Consideramos, como exemplo, a classificação de uma andorinha seguindo as regras anteriormente definidas. 


\section{ANDORINHA $=($ DESENVOLVIDAS, CURTO, PEQUENO $)$}

Apesar das migrações sazonais das andorinhas serem um fato conhecido, $\mathrm{O}$ classificador define, por regras, que as características de (A) asas desenvolvidas, (B) bico curto e (C) corpo pequeno correspondem à classe de aves não migratórias (Figura 2.1). Esse comportamento pode ser corrigido durante um estágio denominado de etapa de aprendizagem, em que se ajustam os estados e as transições do autômato. Quando uma estrutura reage às mudanças impostas a ela e se modifica, há uma adaptação. Essa transformação incorpora informações do meio externo, permitindo o aprendizado incremental.

$\mathrm{Na}$ área de tecnologia adaptativa (NETO, 2001), estudam-se dispositivos que apresentam mudança de comportamento através de alterações em seu próprio núcleo. Um autômato adaptativo é uma extensão do autômato de estados finitos, acrescido de regras de automodificação. Essa capacidade de alteração transforma autômatos de estados finitos, limitados a linguagens regulares, em mecanismos com poder computacional de Máquina de Turing (ROCHA e NETO, 2000).

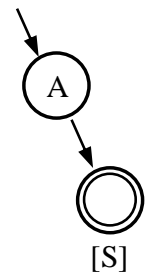

(a)

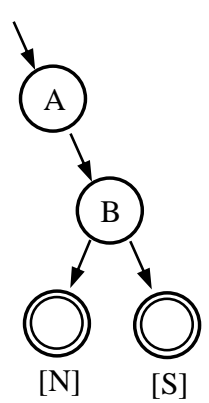

(b)

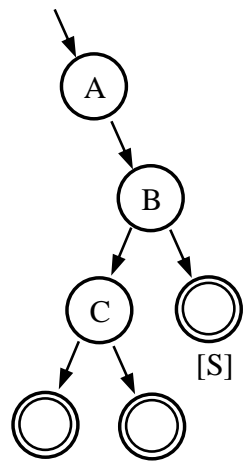

[N]
[S]

(c)

Figura 2.2 - Processo de aprendizagem de novas regras

Um autômato adaptativo é capaz de aprender novas regras usando as amostras de treinamento. (a) Estado inicial: Todas as aves são consideradas como migratórias e existe um único caminho no autômato, que leva à resposta "sim".

(b) Ocorre a inserção de um novo estado. Dependendo do atributo B, o autômato classifica o indivíduo como migratório ou não migratório. (c) Uma nova inserção ocorre no autômato, que passa a verificar a condição do atributo C. As regras foram incorporadas ao modelo através de um mecanismo de aprendizagem. 
A Figura 2.2 apresenta um autômato adaptativo na forma de árvore de decisão (PISTORI, NETO e PEREIRA, 2006). A regra era inicialmente classificar todas as aves como migratórias ("sim”). Em seguida, através das amostras de treinamento, a árvore de decisão pode criar novos ramos e folhas para classificar os indivíduos de acordo com uma combinação de atributos $A, B$ ou $C$.

\subsection{Classificadores de Texto}

Um mecanismo com regras fixas apresenta um grande poder de escala e automação, mas depende de uma tarefa de manutenção manual e custosa. A aprendizagem de máquina é uma forma natural de adquirir informações do meio externo e agrega-las ao modelo.

Um dispositivo inteligente é utilizado para inferir propriedades e atributos sobre informações até então desconhecidos (MITCHELL 1997). Assim, mapeiam-se os dados previamente observados em possíveis casos futuros. Dessa forma, é possível classificar e ordenar um grande volume de dados, tarefa inviável se fosse realizada manualmente.

Os estudos dos campos de recuperação da informação e aprendizado de máquina disfrutam de muitas semelhanças. Entre elas, destacam-se os dispositivos de classificação de dados aplicados a textos. Considerando os métodos mais comuns empregados na tarefa de classificação de texto (MANNING, RAGHAVAN e SCHÜTZE, 2008), todos eles, exceto o de Rocchio, tem origem a partir da aprendizagem de máquina:

- Árvore de decisão

- Naïve Bayes

- Rocchio

- Classificação pelos $k$ vizinhos mais próximos

- Máquina de vetores de suporte

Comparações entre os diferentes métodos têm sido realizadas (DUMAIS, PLATT, et al., 1998; YANG, 1999; HUANG, LU e LING, 2003), porém, não há 
uma resposta sobre qual é o melhor classificador. A seguir, descrevemos sucintamente os classificadores com base em (SEBASTIANI, 2002; MANNING, RAGHAVAN e SCHÜTZE, 2008).

\subsection{1 Árvore de Decisão}

A árvore de decisão é uma estrutura bem conhecida na aprendizagem de máquina (KOTSIANTIS, ZAHARAKIS e PINTELAS, 2007), sendo composta por nós e folhas que se relacionam aos atributos dos dados. O processo de aprendizado permite que uma árvore assimile novas informações e realize inferências sobre a classificação de dados.

Ao contrário dos demais classificadores que usam a representação vetorial de documentos no espaço contínuo, a modelagem de árvores de decisão depende do uso de atributos discretos. Uma generalização do algoritmo é considerar cada palavra como um atributo com dois possíveis valores: positivo e negativo. Um atributo é considerado negativo quando o termo não está presente no documento e, positivo quando o documento faz referencia a ele.

A dificuldade em classificar documentos está relacionada à grande quantidade de atributos. Em geral, o número de palavra é da ordem de dezenas de milhares. Por isso, um passo importante do algoritmo é a seleção dos atributos a serem utilizados na árvore.

Existem diferentes métodos para determinar a forma de crescimento da árvore. O problema de aprendizado ótimo é conhecido como da classe NP-completo (HYAFIL e RIVEST, 1976) e, por isso, os algoritmos são heurísticos. O objetivo é encontrar pontos de mínimos locais, variando entre cálculo de entropia, chi-square ou diferentes medidas. Os métodos ID3 e C4.5 (QUINLAN, 1993) são bastante conhecidos e utilizam o cálculo de entropia. 


\subsubsection{Naïve Bayes}

O classificador Naïve Bayes é utilizado para estimar a probabilidade de um documento pertencer a uma determinada categoria (LEWIS, 1998). Devido à sua eficiência e capacidade de lidar com grande quantidade de dados, tem sido amplamente utilizado em aprendizado de máquina.

Existem variações como o modelo de independência binária (ROBERTSON e JONES, 1976) e outros exemplos apresentados em (LEWIS, 1998), que mudam a forma de distribuição de dados e pesos. Entretanto, seu princípio matemático se mantém apoiado sobre o Teorema de Bayes:

$$
P\left(C_{k} \mid x\right)=P\left(C_{k}\right) \cdot \frac{P\left(x \mid C_{k}\right)}{P(x)}
$$

Considerando as categorias $C_{k}$ e o documento $x$ a ser classificado, desejamos determinar a probabilidade de que $C_{k}$ seja a categoria do documento $X$, denotada por $P\left(C_{k} \mid x\right)$. O nome do classificador, Naïve ("naive" significa tolo), deriva da hipótese de independência dos termos nos documentos, na qual se assume simplificadamente que os termos não possuem relação entre si. Assim, podemos reescrever a probabilidade do documento em função de seus termos $t_{j}$ :

$$
P\left(x \mid C_{k}\right)=\prod_{j}^{t_{j} \in x} P\left(t_{j} \mid C_{k}\right)
$$

Graças a essa suposição, podemos simplificar o cálculo da probabilidade e ainda obter resultados experimentais satisfatórios (DOMINGOS e PAZZANI, 1997). O documento é classificado na categoria que apresentar a probabilidade máxima, desconsiderando o divisor constante $P(x)$ :

$$
C(x)=\underset{C_{k}}{\arg \max }\left(P\left(C_{k}\right) \cdot \prod_{j}^{t_{j} \in x} P\left(t_{j} \mid C_{k}\right)\right)
$$


Podemos estimar as probabilidades com base nos dados de treinamento:

$$
\begin{gathered}
P\left(C_{k}\right) \cong \frac{N_{C k}}{N_{D}} \\
P\left(t_{j} \mid C_{k}\right) \cong \frac{T_{j}^{k}}{\sum_{i=1}^{n}\left(T_{i}^{k}\right)}
\end{gathered}
$$

Onde:

$$
\begin{aligned}
& N_{C k}=\text { número de documentos da categoria } C_{k} \\
& N_{D}=\text { total de documento em todas categorias } \\
& \boldsymbol{T}_{\boldsymbol{i}}^{\boldsymbol{k}}=\text { número de termos } t_{i} \text { na categoria } C_{k}
\end{aligned}
$$

\subsubsection{Classificação pelos $k$ vizinhos mais próximos}

O classificador pelo vizinho mais próximo é um dos mecanismos mais simples de se compreender como funciona. Para classificar um novo objeto, busca-se no conjunto de treino a amostra mais próxima (Figura 2.3). A ideia por trás do algoritmo é "se tem um exemplo idêntico de treinamento, então o classifique com a mesma categoria" e "se não houver, então o mais próximo será a melhor opção".

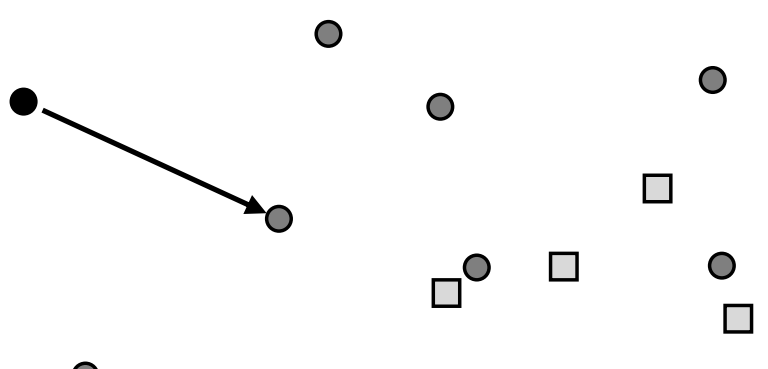

○

Figura 2.3 - Classificação pelo vizinho mais próximo

A generalização do vizinho mais próximo é o "k vizinhos mais próximos". Ao invés de usar apenas o dado mais próximo, expandimos a comparação para os $k$ exemplos mais próximos (MANNING e SCHÜTZE, 1999). 
Esse algoritmo é chamado também de aprendizado baseado em instâncias, uma vez que todas as amostras são mantidas em memória para serem recordadas na classificação. Por isso, esse classificador depende muito da qualidade e quantidade de dados de treinamento.

\subsubsection{Rocchio}

O classificador de Rocchio divide o espaço vetorial em distintas regiões ao redor de centroides (HULL, 1994). A inspiração do algoritmo foi o método de feedback de relevância de Rocchio para recuperação de documento, no qual o usuário pode retroalimentar o processo com informações positivas ou negativas (ROCCHIO, 1971).

$$
(\text { consulta })=(\text { consulta original })+\beta \times\left(\begin{array}{c}
\text { documentos } \\
\text { relevantes }
\end{array}\right)-\gamma \times\left(\begin{array}{c}
\text { documentos } \\
\text { não relevantes }
\end{array}\right)
$$

A equação balanceia os documentos conhecidos e a consulta do usuário. Pela equação, a consulta se move em direção ao centroide dos documentos relevantes, ao mesmo tempo em que se distancia dos documentos irrelevantes. A escolha dos parâmetros $\beta$ e $\gamma$ tem grande influência sobre o resultado.

No caso do classificador de Rocchio, cada categoria apresenta seu próprio centroide ou protótipo definido por $\mu_{C k}$. O centroide da categoria $C_{k}$ é definido positivamente pela média dos documentos pertencentes à categoria e, negativamente pela média dos demais documentos. Portanto, podemos escrever a equação do protótipo da categoria por:

$$
\mu_{C k}=\beta \frac{1}{N_{C k}} \cdot \sum_{d \in C_{k}} d-\gamma \frac{1}{N_{D}-N_{C k}} \cdot \sum_{d \notin C_{k}} d
$$

Onde:

$$
\begin{aligned}
& N_{C k}=\text { número de documentos da categoria } C_{k} \\
& N_{D}=\text { total de documento em todas categorias }
\end{aligned}
$$


Existe um caso particular de $\beta=1$ e $\gamma=0$, no qual os protótipos correspondem a exatamente o centro de massa da categoria.

$$
\mu_{C k}=\frac{\sum_{d \in C_{k}} d}{\left\|C_{k}\right\|}
$$

A classificação é simples e rápida, mas apresenta problemas quando os documentos de uma mesma categoria se encontram espalhados no espaço. Devido ao posicionamento do centro de massa, um documento usado em treinamento pode ser classificado incorretamente no modelo (Figura 2.4).

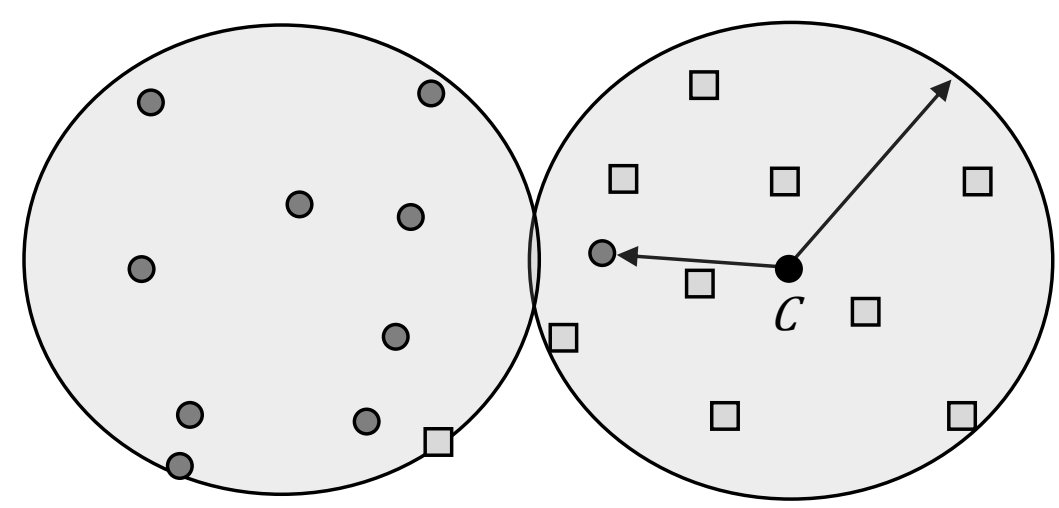

Figura 2.4 - Classificador de Rocchio

Os documentos são classificados com base no centro de massa mais próximo. Isso pode classificar incorretamente algumas amostras de treinamento quando os dados estão muito espalhados.

\subsubsection{Máquina de Vetores de Suporte}

A máquina de Vetores de Suporte (SVM, Support Vector Machine) tem sido utilizada com grande sucesso nos diferentes problemas de aprendizagem de máquina (CORTES e VAPNIK, 1995). O método busca um hiperplano que divida um conjunto de dados no espaço em dois subconjuntos denominados de positivo e negativo. Esse hiperplano pode ser definido pela equação:

$$
w x+b=0
$$

A Figura 2.5 apresenta o vetor $\vec{w}$, ortogonal ao hiperplano, e os vetores de suporte (linhas tracejadas). Quando os conjuntos são linearmente separáveis, então 
essa equação admite múltiplas soluções $(w, b)$. Nesse caso, o objetivo do algoritmo se torna maximizar a distância entre os vetores de suporte. Esse é um problema de otimização quadrática com diferentes formas de ser resolvido (BENNETT e CAMPBELL, 2000).

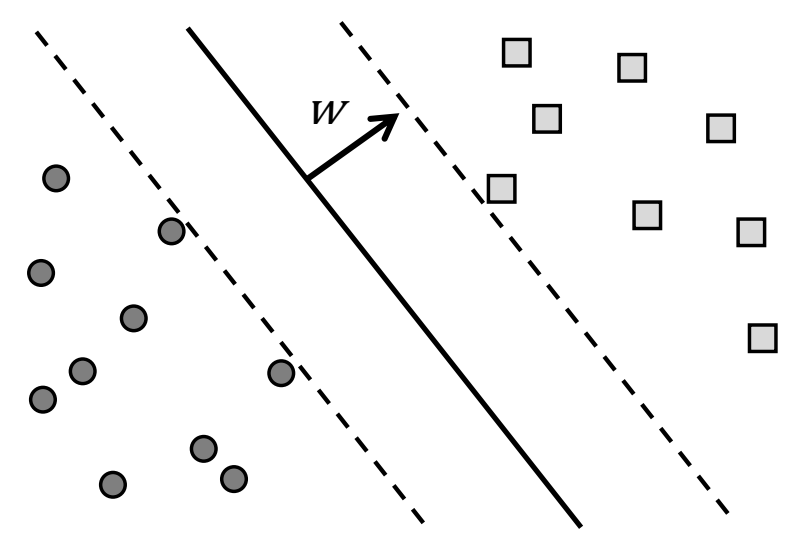

Figura 2.5 - Classificador usando Máquina de Vetores de Suporte

Quando as amostras são linearmente separáveis, existem infinitos hiperplanos que satisfazem a equação. Nesse caso, buscamos a melhor solução: aquela que maximiza a distância entre os vetores de suporte (linhas tracejadas).

Uma vez identificado o hiperplano, a classificação de dados $X$ é feita avaliando se a função $f$ é positiva ou negativa:

$$
f(x)=w x+b
$$

A máquina de vetores de suporte tem sido aplicada com muito sucesso na tarefa de categorização de texto (JOACHIMS, 1998; DUMAIS, PLATT, et al., 1998; DRUCKER, WU e VAPNIK, 1999).

\subsection{Métricas de Avaliação}

A classificação de texto agrupa os documentos relevantes às respectivas categorias. Apesar do processo de classificação ser objetivo em relação à forma de execução, a noção de relevância é um tópico subjetivo (HARTER, 1992). Afinal, os conjuntos de dados foram manualmente classificados por especialistas, que são pessoas e carregam a subjetividade na decisão. 
Entretanto, nos experimentos de classificação automática de texto, a opinião dos especialistas sobre relevância é aceita como correta e indiscutível. Ao final de qualquer experimento, podemos detalhar os resultados em uma tabela de contingência (Tabela 2.1) para cada categoria classificada, comparando a eficácia do classificador contra a "realidade".

\begin{tabular}{c|cc|c|}
\multicolumn{1}{c}{} & \multicolumn{2}{c}{ Especialistas } \\
\cline { 3 - 4 } & Relevante & Irrelevante \\
\cline { 2 - 4 } Classificador & Relevante & $S S_{i}$ & $S N_{i}$ \\
\cline { 2 - 4 } & Irrelevante & $N S_{i}$ & $N N_{i}$ \\
\cline { 2 - 4 } & &
\end{tabular}

Tabela 2.1 - Tabela de contingência da categoria Ci

Distribuição de acertos e erros, validando quais foram os documentos considerados relevantes e irrelevantes pelo classificador frente ao julgamento dos especialistas.

\subsubsection{Precisão, Cobertura e Medida F}

Existem diferentes métricas de avaliação (MANNING, RAGHAVAN e SCHÜTZE, 2008):

- Precisão (precision) - Corresponde à proporção dos documentos corretos em relação ao total de documentos que estão classificados na categoria $C_{i}$. O oposto da precisão é a imprecisão: os documentos classificados de forma incorreta como $C_{i}$.

$$
\text { Precisão }=\frac{S S_{i}}{S S_{i}+S N_{i}}
$$

- Cobertura (recall) - Conhecido também por abrangência ou revocação, essa medida avalia a proporção de documentos corretos em relação ao total de documentos que deveriam ser classificados na categoria $C_{i}$. O oposto da cobertura é a falta de documentos que deveriam ser classificados em $C_{i}$. 


$$
\text { Cobertura }=\frac{S S_{i}}{N S_{i}+S S_{i}}
$$

Introduzida por van Rijsbergen (1979), a medida composta $F$ balanceia os valores de precisão $P$ e cobertura $C$, sendo calculada pela média harmônica:

$$
F=\frac{2 P C}{P+C}
$$

\subsubsection{Taxa de Acerto e Erro}

Embora a precisão, cobertura e medida $F$ sejam utilizadas frequentemente na área de recuperação de dados, a taxas de acerto é uma medida bastante utilizada em aprendizagem de máquina (MITCHELL, 1997).

- Taxa de acerto (accuracy) - Corresponde a porcentagem de acertos da tarefa de classificação.

$$
\text { Taxa de acerto }=\frac{S S_{i}+N N_{i}}{S S_{i}+N N_{i}+N S_{i}+S S_{i}}
$$

- Taxa de erro - Corresponde a porcentagem de erros de classificação.

Taxa de erro $=1-($ Taxa de acerto $)$

\subsubsection{Valores Médios (Macro e Micro)}

Frequentemente é necessário agregar as métricas relativas a todas as categorias em um único número para avaliar o desempenho do classificador no geral. Nesse caso, existem duas formas de calcular a média:

- Média macro - A métrica é calculada para cada categoria localmente e depois é feita a média para todas as categorias. 
- Média micro - Cria-se uma tabela de contingência consolidada com a soma dos resultados de todas as tabelas. Depois a métrica é calculada globalmente usando a tabela consolidada.

É comum observar que as médias macro e micro divergem dependendo do tamanho das categorias. A média micro é dominada pelas categorias maiores, enquanto que a média macro avalia individualmente cada categoria com o mesmo peso.

\subsection{Saturação do Modelo}

Um problema muito comum na modelagem de dados é a presença do fenômeno de saturação do modelo ou overfitting (DIETTERICH, 1995). Como exemplo, tomamos um conjunto de dados coletados durante um experimento conforme ilustrado na Figura 2.6.a. A fim de ajustar uma curva que descreva o comportamento observado, selecionam-se arbitrariamente amostras de dados para serem utilizadas na definição do modelo. Por se tratar de um comportamento aparentemente simples, utilizam-se seis exemplos de treinamento, conforme apresentado na Figura 2.6.b.

Em seguida, aplicamos o método dos mínimos quadrados com polinômios de graus distintos. A Figura 2.6.c apresenta a aproximação dos pontos de amostragem por um polinômio de segundo grau, no qual se observa um resultado visualmente coerente com os dados coletados. Dessa forma, podemos afirmar que o polinômio de segundo grau representou bem o fenômeno observado.

Ao utilizar um polinômio de grau maior, espera-se obter um erro de aproximação igual ou menor. Repetimos o processo de aproximação usando o método dos mínimos quadrados com um polinômio de sexto grau. O resultado apresentado na Figura 2.6.d mostra que o polinômio passa exatamente sobre cada ponto de amostragem, ou seja, o erro nulo de aproximação é nulo. Entretanto, a curva diverge sobre o resultado esperado - inesperadamente, a função apresenta valores negativos. 


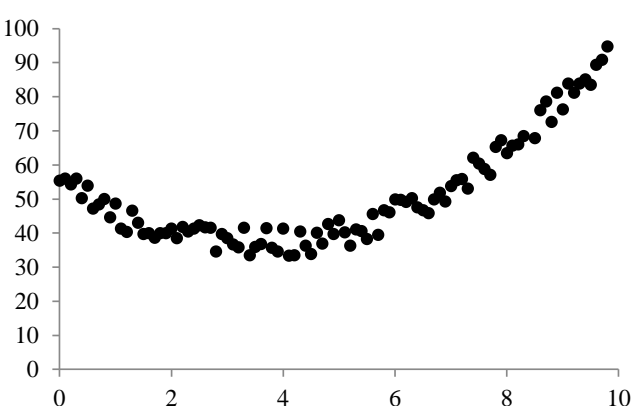

(a)

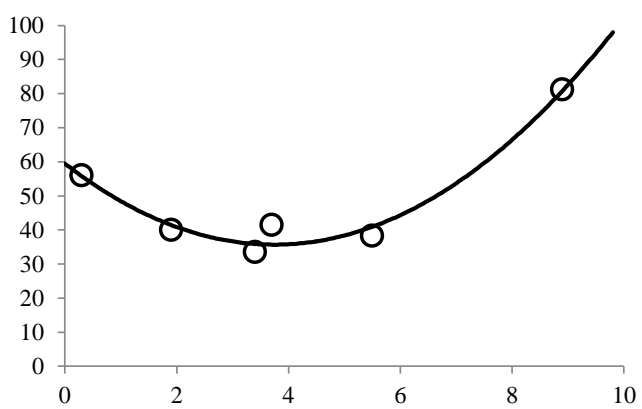

(c)

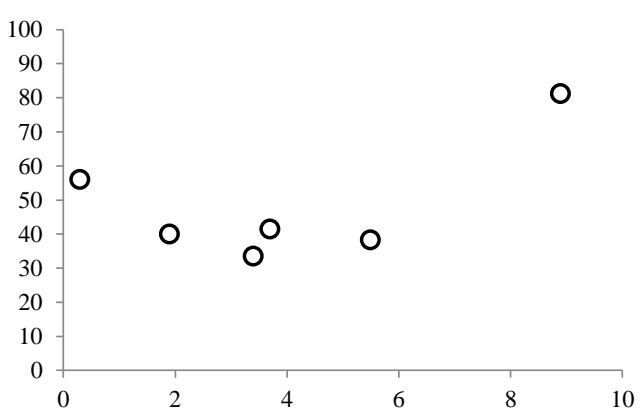

(b)

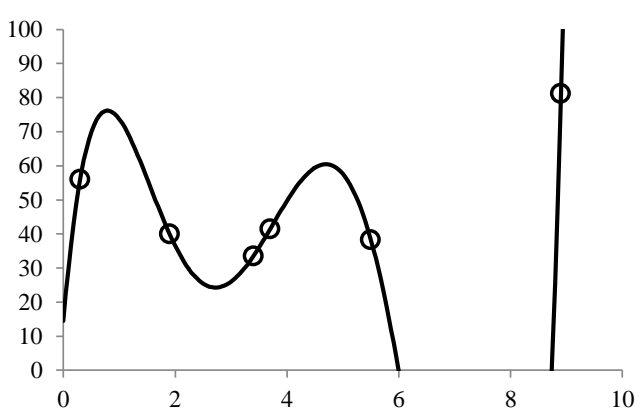

(d)

Figura 2.6 - Exemplo do fenômeno de overfitting de dados

(a) Dados coletados. (b) Amostras de treinamento.

(c) Regressão linear usando um polinômio de grau 2.

(d) Regressão linear usando um polinômio de grau 6 sobre os mesmos pontos, porém, apresentando o fenômeno de overfitting.

Nesse segundo caso, o polinômio de sexto grau não representou bem a realidade. Esse fenômeno denominado de overfitting ocorre quando há um excesso de ajustes do modelo sobre a amostra de dados. Apesar do polinômio de sexto grau eliminar o erro de aproximação completamente, existe um polinômio mais simples que se adequa aos dados.

\subsubsection{Princípio da Navalha de Occam}

O princípio da navalha de Occam é intuitivamente um ótimo fator de decisão para a escolha de modelos:

"Se há diversas possibilidades, opte pela mais simples.

Ela provavelmente é a mais correta". 
De fato, existem inúmeras formas de interpretar o significado da palavra "simples". Em um autômato, a simplicidade pode estar relacionada com o alfabeto usado, o número de ciclos, o número de estados sem transição ou estados finais. A decisão se torna ampla e subjetiva. A fim de complementar o princípio da navalha de Occam e definir o termo "simplicidade", recorremos ao conceito de complexidade algorítmica ou também conhecido como complexidade de Kolmogorov (VITANYI e LI, 2000).

A complexidade corresponde ao tamanho da menor descrição do dado em uma determinada linguagem. Em um autômato de estados finitos, a complexidade algorítmica está associada ao tamanho do menor programa escrito na "linguagem de autômato" para reconstruir a sequência de dados. A grosso modo, um autômato de estados finitos "simples" é aquele que possui o menor número de estados e transições.

Em uma árvore de decisão, o overfitting está associado ao desejo de representar usando um número de nós e de ramos além do necessário (QUINLAN, 1993). Isso significa que o espaço foi subdividido em diversas partes e não há um número suficiente de dados de amostragem para determinar as classes em cada região. A fim de se evitar esse fenômeno, é importante retirar estruturas redundantes. Esse mecanismo é conhecido como poda da árvore (MINGERS, 1989).

Um modelo está saturado quando a complexidade algorítmica do modelo é superior à complexidade intrínseca ao comportamento observado (VITANYI e LI, 2000).

\subsubsection{Limitação do Modelo}

Uma das causas da saturação está relacionada com limitações do modelo em relação às amostras de dados. A Figura 2.7 ilustra uma estrutura de árvore de decisão desbalanceada. O crescimento dessa árvore ocorre frequentemente nos ramos da direita, indicando uma possível saturação do modelo. 


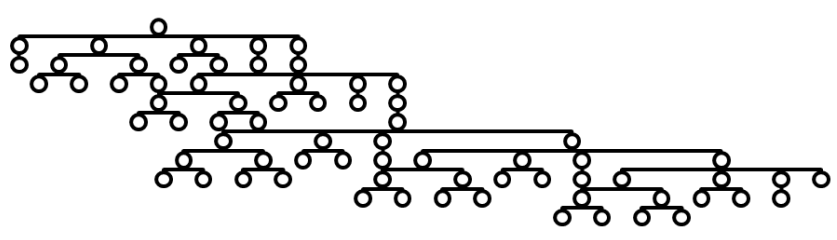

Figura 2.7 - Árvore de decisão desbalanceada

Figura 6. Árvore de decisão desbalanceada com grande quantidade de nós do lado direito, representando um possível comportamento de overfitting.

A Figura 2.8 descreve uma aproximação da borda do círculo por retas horizontais e verticais. A subdivisão sucessiva da região espacial observada corresponde à tentativa de modelar uma figura através de atributos $x$ e $y$, que são as retas horizontais e verticais. Embora os atributos $x$ e $y$ sejam tratados como independentes, sabemos que o objeto descrito segue a equação $x^{2}+y^{2}<r^{2}$. Se a modelagem fosse conduzida substituindo as coordenadas cartesianas $(x, y)$ por coordenadas polares $(\rho, \theta)$, então o modelo seria construído rapidamente com pouca quantidade de amostras de treinamento.

Durante a modelagem do problema, frequentemente se assume que a relação entre os atributos é independente, ou seja, um não depende um do outro. Em muitos casos, a suposição incorreta leva à incapacidade do modelo ser uma boa representação do objeto real. Concluímos, portanto, que a complexidade algorítmica aumenta rapidamente quando o modelo é limitado em relação à representação do comportamento observado.

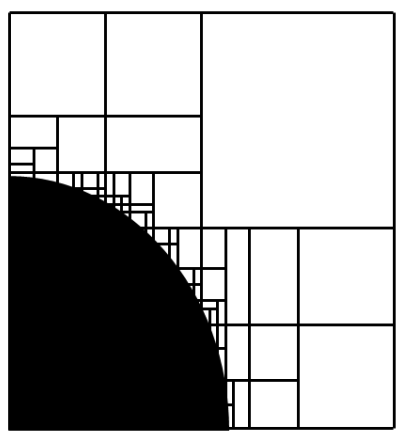

Figura 2.8 - Overfitting devido à limitação do modelo

Aproximação de um círculo por retas horizontais e verticais. Próximo à borda do círculo, há uma série de regiões cada vez menores que subdividem o espaço. Esse comportamento não ocorreria se fossem usadas coordenadas polares. 


\section{ESPaÇo SEMÂNTICo}

Uma palavra é vista como um símbolo, cujo significado é a união de características semânticas e situações distintas nas quais se encontram presentes. $\mathrm{O}$ conjunto de significados constitui o conceito descrito pela palavra (STILLINGS, 1989), que por sua vez serve para definir outras, de forma mais precisa.

As frases ou sentenças são formadas a partir de palavras, que possuem diferentes origens de formação. É interessante observar que novas expressões podem aparecer ao longo do tempo, ou seja, o processo de comunicação é dinâmico. Por outro lado, a construção de sentenças segue regras gramaticais e fundamentais para a compreensão adequada. Seja o objeto ou a ação, a palavra desempenha seu papel dentro da frase de transmitir um ou mais significados.

Quando há a ocorrência de palavras polissêmicas, com dois ou mais significados, o contexto deve ser levado em consideração. Assim, as palavras mais próximas auxiliam a determinação do melhor significado.

- Comi uma manga verde

- Camisa de manga longa

Estudos apontam que a determinação do significado da palavra pode ser feita através de um processo de inferência local, considerando somente a presença das palavras ao redor.

O objetivo desse capítulo é detalhar os passos necessários para chegar até a criação do espaço semântico. Podemos imaginar que as palavras, na forma de símbolos, estão localizadas no espaço vetorial. Os significados e conceitos são resultados da análise da semântica latente. 


\subsection{Distribuição de Zipf}

De acordo com o Princípio do menor esforço de Zipf (1949), ninguém deseja se desgastar mais do que o necessário durante uma conversa. Tanto aqueles que falam, quanto os que escutam, tentam minimizar seus esforços para chegar a um entendimento. $\mathrm{O}$ ouvinte prefere ter um vocabulário amplo e cheio de palavras meticulosas, embora infrequentemente usadas, de tal forma que as mensagens se tornem menos ambíguas. Por outro lado, o esforço da fala é poupado através de um vocabulário comum composto de poucas palavras.

Esse processo resulta em aproximadamente a mesma distribuição de esforços, dando origem à conhecida Lei de Zipf: ordenando os termos $t_{n}$, do maior número de ocorrências para o menor, então a frequência do $n$-ésimo termo é inversamente proporcional a sua posição $n$. Em outras palavras, o produto entre a frequência e a posição é constante.

$$
\operatorname{Freq}\left(t_{n}\right) \times n=k
$$

Em uma contagem de palavras feita com parte da coleção de texto da Reuters (em inglês), mostrou-se que as cinco primeiras palavras com maior frequência eram: the, of, to, in, said (Tabela 3.1). As frequências associadas às palavras diminuíam conforme as posições se incrementavam (Tabela 3.2).

\begin{tabular}{ccc}
\hline Posição & Termo & Frequência \\
\hline 1 & the & 12802 \\
2 & of & 6943 \\
3 & to & 6129 \\
4 & in & 4970 \\
5 & said & 4903 \\
6 & a & 4867 \\
7 & and & 4810 \\
8 & for & 2622 \\
9 & reuter & 2355 \\
10 & it & 2270 \\
\hline Tabela 3.1 - Distribuiça a o de Zipf (1-10)
\end{tabular}

\begin{tabular}{ccc}
\hline Posição & Termo & Frequência \\
\hline 10 & it & 2270 \\
$\vdots$ & $\vdots$ & $\vdots$ \\
100 & tax & 335 \\
$\vdots$ & $\vdots$ & $\vdots$ \\
5000 & measured & 4 \\
$\vdots$ & $\vdots$ & $\vdots$ \\
10000 & oates & 1 \\
$\vdots$ & $\vdots$ & $\vdots$ \\
$\vdots$ & $\vdots$ & $\vdots$ \\
15000 & unroasted & 1 \\
\hline Tabela 3.2 - Distribuição de Zipf (10-15000)
\end{tabular}

A frequência dos termos encontrados na coleção da Reuters é inversamente proporcional a sua posição

Parte da dificuldade de assimilação da linguagem natural pela máquina está relacionada com as palavras de pouca ocorrência e que são raramente faladas no dia 
a dia. No entanto, há uma linha de pesquisa usando métodos estatísticos para deduzir informações de texto sem necessariamente entrar nos detalhes das regras gramaticais.

A simples contagem de palavras pode ter aplicações diretas como, por exemplo, fornecer uma indicação do estilo do autor com base nas palavras comumente empregadas. Ainda no começo dos estudos do processamento da linguagem natural, Luhn (1958) propôs a criação automática de resumos de texto com base na frequência de palavras e sua distribuição entre as frases.

Em seu trabalho, buscavam-se as palavras-chaves que melhor representassem o conteúdo do texto. Dessa forma, os termos deveriam ter importâncias distintas. Palavras com frequências muito altas ou muito baixas não contribuíam na tarefa de discriminação de relevância e, portanto, deveriam ser desconsideradas.

Luhn estabeleceu a existência de zonas de cortes superior e inferior, determinadas empiricamente, de forma que restassem apenas as palavras relevantes (Figura 3.1). Assim, criavam-se os fundamentos para a moderna área de recuperação da informação.

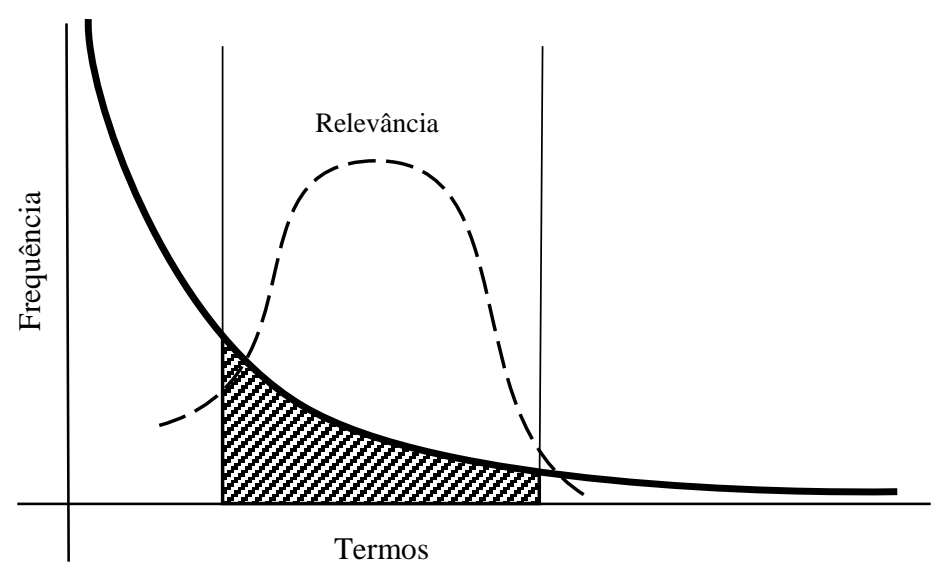

Figura 3.1 - Distribuição de termos e relevância

Os termos são ordenados por frequência. Luhn verificou que os termos mais relevantes não são aqueles que aparecem muito, nem pouco. Dessa forma, estabeleceu-se a existência de zonas de cortes para definir onde estariam as palavras mais relevantes. Essas zonas seriam determinadas através de experimentos. 


\subsection{Pré-processamento}

A etapa de pré-processamento transforma o texto bruto em uma classe relevante para ser trabalhada pela máquina. Nessa fase, são realizadas as tarefas:

- Segmentação

- Reconhecimento de termos

- Lematização

- Eliminação de termos irrelevantes

O objetivo é aumentar a quantidade de palavras relevantes, removendo as palavras com muita frequência ou pouco usadas. A seguir, descreveremos cada uma delas com mais detalhes.

\subsubsection{Segmentação}

A tarefa de segmentação obtém um conjunto de sentenças a partir do texto original. Sua função é determinar o começo e o fim das frases, reconhecendo, por exemplo, quando um ponto é um ponto final ou se faz parte de uma abreviação. Apesar da aparente facilidade dessa tarefa, a segmentação de texto se torna mais complexa em línguas que não apresentam espaço entre as palavras, tipicamente em línguas orientais.

\subsubsection{Reconhecimento de Termos}

A tarefa de reconhecimento de termos transforma uma sequência de caracteres em um conjunto de termos. Como parte da análise léxica, as palavras são separadas dos números e dos demais caracteres de pontuação. As palavras maiúsculas e minúsculas são usualmente consideradas iguais e, portanto, convertidos para uma mesma representação.

Apesar de tratarmos frequentemente o significado de "palavra" e "termo" como intercambiáveis, há uma diferença sutil entre eles. Um termo é mais amplo e pode ser uma composição de duas ou mais palavras. Existe também a flexibilidade 
de defini-los por nomes próprios. Por exemplo, "Escola Politécnica" e "Universidade de São Paulo" são termos referentes a entidades nomeadas.

\subsubsection{Lematização}

Introduzido por Lovins (1968), a tarefa de lematização (stemming) reduz a variedade de palavras ao seu significado canônico. A implementação para a língua inglesa mais difundida atualmente é a de Porter (1980), na qual ocorre a redução de sufixos, deixando apenas o radical da palavra. Por exemplo: os termos escrever, escrevi e escrevemos possuem todos a mesma raiz gramatical.

Existe a possibilidade de considerar o contexto em que o termo está inserido. Nesse caso, temos uma lematização de contexto (lemmatization), capaz de substituir palavras usando dicionários ou através de análises sintáticas. Por exemplo, andar (de carro) e digirir podem corresponder a um único significado.

\subsubsection{Eliminação de Termos Irrelevantes}

Os termos irrelevantes são aqueles que aparecem com muita frequência e se tornam desnecessários para as tarefas de busca e categorização de texto. A definição de quais são os termos irrelevantes é feita por uma lista de stop words, que seria equivalente à lista negra de palavras.

Artigos, conjunções, preposição e pronomes são ótimos exemplos de stop words. Embora sejam fundamentais na construção de sentenças, não auxiliam na discriminação de texto por aparecerem em praticamente todos os documentos. A eliminação desses termos reduz o espaço necessário de armazenamento sem afetar a qualidade do sistema (SALTON e MCGILL, 1986).

Além das stop words, são eliminadas todas as palavras que estão fora de uma zona empiricamente definida pelos cortes inferior e superior (LUHN, 1958). 


\subsection{Representação Vetorial}

No artigo intitulado "Um modelo de espaço vetorial para indexação automática", Salton (1975) introduziu a ideia de representação de documento através de vetores em um espaço de alta dimensão. As componentes do vetor-documento são calculadas com base na frequência dos termos e associadas a pesos.

Em uma coleção com $n$ documentos e $m$ palavras, representam-se os documentos $D_{1}, D_{2}, \ldots, D_{\mathrm{n}}$ como vetores $d_{1}, d_{2}, \ldots, d_{\mathrm{n}}$ no espaço $\mathbb{R}^{m}$ :

$$
d_{j}=\left(W_{1, \mathrm{j}}, W_{2, \mathrm{j}}, \ldots, W_{\mathrm{m}, \mathrm{j}}\right), \text { para } 1 \leq j \leq n
$$

Onde $W_{1, \mathrm{j}}, \ldots, W$ m,j são os pesos dos respectivos termos no documento $D_{j}$.

Nessa representação, o documento é considerado como um conjunto nãoordenado de palavras, denominado de Bag of Words (BOW). Assume-se, portanto, que a ordem relativa entre os termos no documento pode ser ignorada. Por exemplo, as sentenças "eu andei ontem" e "ontem eu andei” não apresentam diferenças. Por outro lado, as situações "fui dar um passeio de carro" e "fui dar um carro de passeio" possuem significados diferentes, embora sejam completamente idênticas no BOW.

\subsubsection{Termos}

Em um modelo de espaço vetorial, um documento-vetor é definido pelos pesos associados a seus termos. Segundo Buckley (1993), a importância de atribuir os pesos é tão grande quanto à seleção de atributos.

Uma forma simples de se atribuir pesos é usar a contagem $t_{i}$ de ocorrências dos termos no documento $d$.

$$
d=\left(t_{1}, t_{2}, \ldots, t_{\mathrm{n}}\right)
$$

Entretanto, como Luhn (1958) já havia notado, as palavras não são iguais e algumas podem servir como discriminantes de documentos, enquanto que outras, 
nem tanto. É possível que eles se sobressaiam uns sobre os outros e, se atribuirmos os pesos adequados, reforçamos esse comportamento.

Existem várias formas para definir o peso de um termo, sendo que uma das mais conhecidas e utilizadas é o TF-IDF (MANNING, RAGHAVAN e SCHÜTZE, 2008). Essa medida possui duas partes:

- TF (Term Frequency) - Essa componente corresponde ao número de vezes que o termo aparece no documento. Os termos que são frequentemente mencionados em determinados documentos podem servir como discriminantes.

- IDF (Inverse Document Frequency) - Esse fator é chamado de inverso da frequência do documento, pois desfavorece os termos presentes em todos os documentos. Quando os termos estão distribuídos em toda coleção, mas não estão concentrados em poucos documentos, então esses termos tem pouco ou nenhum poder de discriminação de relevância.

Define-se o TF-IDF como o produto das partes:

$$
\mathrm{TF}-\mathrm{IDF}=\mathrm{TF} \times \mathrm{IDF}
$$

Apesar das possíveis variações no cálculo das componentes TF e IDF (SALTON e BUCKLEY, 1988), tradicionalmente se calculam as componentes por:

$$
\begin{gathered}
\mathrm{TF}=\mathrm{tf}_{t, d} \\
\mathrm{IDF}_{\mathrm{t}}=\log \left(\frac{\mathrm{N}_{\mathrm{D}}}{\mathrm{df}_{\mathrm{t}}}\right)
\end{gathered}
$$

Onde:

$$
\begin{aligned}
& \mathbf{t f}_{t, d}=\text { número de ocorrências do termo } t \text { no documento } d \\
& \mathbf{d f}_{t}=\text { número de documentos que possuem o termo } t \\
& N_{D}=\text { total de documentos }
\end{aligned}
$$


Portanto, podemos calcular os pesos do termo $t$ no documento $d$ por:

$$
\mathrm{w}_{\mathrm{t}, \mathrm{d}}=\mathrm{tf}_{\mathrm{t}, \mathrm{d}} \cdot \log \left(\frac{\mathrm{N}_{\mathrm{D}}}{\mathrm{df}_{\mathrm{t}}}\right)
$$

Observamos que o comportamento do peso TF-IDF:

- Aumenta quando o termo ocorre várias vezes em poucos documentos

- Diminui quando a frequência do termo é baixa

- Diminui quando o termo ocorre em muitos documentos

- Torna-se nulo quando ocorre em todos os documentos

\subsubsection{Normalização}

Documentos longos possuem mais termos e, como consequência, valores mais altos. Por isso, após a atribuição dos pesos aos termos e documentos, existe a possibilidade de multiplicar por um terceiro fator de correção: a componente de normalização (SALTON e BUCKLEY, 1988; SINGHAL, SALTON, et al., 1996).

$$
\mathrm{TF}-\mathrm{IDF}=(\mathrm{TF} \times \mathrm{IDF}) \times \mathrm{c}
$$

Esse fator minimiza os problemas relacionados a documentos:

- Muito extensos e que cobrem múltiplos tópicos distintos

- Longos e repetitivos sobre o mesmo tópico

Uma decisão comum é transformar o documento em um vetor unitário, ou seja, adotando o fator de multiplicação $c$ igual ao inverso do módulo de $d_{j}$.

$$
c\left(d_{j}\right)=\frac{1}{\sqrt{w_{1, j}+w_{2, j}+\cdots+w_{n, j}}}
$$

Essa normalização facilitaria o cálculo de similaridade (MANNING, RAGHAVAN e SCHÜTZE, 2008), conforme veremos logo a seguir. 


\subsubsection{Similaridade}

Os documentos em uma coleção de texto são vistos como um conjunto de vetores de dimensão $n$. O grau de similaridade entre os documentos $d_{i}$ e $d_{j}$ é dado pelo cosseno do ângulo formado pelos vetores correspondentes:

$$
\begin{aligned}
\operatorname{similar}(i, j) & =\cos \left(d_{i}, d_{j}\right) \\
& =\frac{d_{i} \cdot d_{j}}{\left\|d_{i}\right\|\left\|d_{j}\right\|} \\
& =\frac{\sum w_{t, i} w_{t, j}}{\sqrt{\sum w_{t, i}^{2}} \sqrt{\sum w_{t, j}^{2}}}
\end{aligned}
$$

Quando os documentos estão normalizados, os vetores apresentam módulo unitário e o cálculo de similaridade se torna igual ao produto escalar.

$$
\operatorname{similar}(i, j)=\sum_{t=1}^{n} w_{t, i} w_{t, j}
$$

Quando todos os pesos atribuídos $W_{t, i} \geq 0$, temos que:

$$
\operatorname{similar}(i, j) \geq 0
$$

O grau máximo de similaridade é 1 , que corresponde a vetores de mesmo sentido e direção.

\subsection{Espaço Semântico}

A análise da semântica latente (Latent Semantic Analysis, LSA) busca uma relação entre os termos e os conceitos ocultos, ou seja, uma "semântica latente" que permita relacionar os documentos por uma similaridade não restrita somente aos termos presentes (DUMAIS, FURNAS, et al., 1988; DEERWESTER, DUMAIS, et al., 1990; LANDAUER e DUMAIS, 1997). A ideia de conceitos ocultos se originou a 
partir do fato de que todas as palavras estão conectadas indiretamente pelo contexto em que se encontram.

Considere o exemplo abaixo, nos quais são apresentados os termos e suas componentes. Não há dúvida de que os termos carro e automóvel estão relacionados.

$$
\begin{aligned}
\text { CARRO } & =(\text { MOTORISTA }, \text { RODAS }, \text { PORTAS }, \text { MOTOR }) \\
\text { AUTOMÓVEL } & =(\text { MOTORISTA }, \text { RODAS }, \text { PORTAS }, \text { MOTOR })
\end{aligned}
$$

Esse tipo de relação não muda mesmo se fosse uma palavra desconhecida ou escrita de forma diferente.

$$
\text { XPTO }=(\text { MOTORISTA }, \text { RODAS }, \text { PORTAS }, \text { MOTOR })
$$

Deduzimos, sem ajuda externa ou de dicionários, que o tópico continua descrevendo carro ou automóvel. Poderia ser qualquer outra palavra no lugar de xpto, com qualquer grafia, e a conclusão seria a mesma. As componentes (motorista, rodas, portas e motor) evidenciam tal semelhança.

Em uma comparação de frases, a relação estaria mais escondida e não seria tão trivial vincular os termos carro e automóvel por suas componentes:

- O motorista ligou o $\underline{\text { motor }}$, sem fechar a porta do carro.

- Automóvel novo: rodas de liga leve, 4 portas e motor 2.0.

Uma forma de determinar a conexão entre os termos seria identificar palavras específicas do texto ou presentes somente naquele tópico. Os termos motorista, rodas, porta e motor aparecem frequentemente em assuntos relacionados a carro e automóvel. Esses termos estariam, portanto, ligados por alguma "semântica latente" (LANDAUER e DUMAIS, 1997).

Em uma representação no modelo de espaço vetorial (SALTON, WONG e YANG, 1975), as palavras são representadas por vetores. A Figura 3.2 fornece uma ideia de como seria esse espaço com os termos distribuídos. 


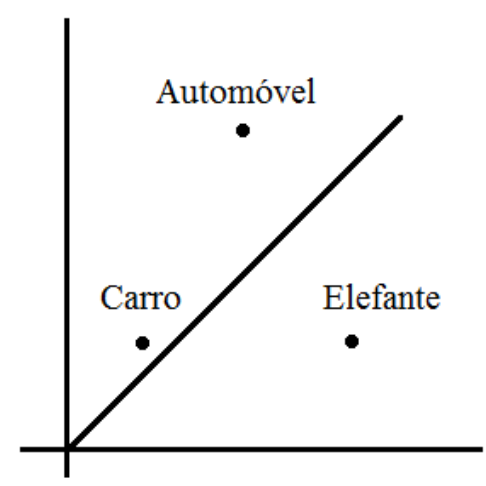

Figura 3.2 - Representação de termos no espaço vetorial

Os termos ficam dispersos no espaço, sem uma relação aparente entre eles

Assim como no primeiro exemplo, o objetivo é identificar as componentes que evidenciem as semelhanças entre os termos. A estratégia seria executar uma transformação do espaço, na qual os vetores sejam levados a outro conjunto de coordenadas. Nessa nova perspectiva, os termos mais próximos serão agrupados, enquanto que os tópicos distintos se afastarão um dos outros.

A análise da semântica latente é uma técnica que projeta os vetores em um espaço de menor dimensão. Esse espaço de dimensão reduzida é denominado de espaço semântico, pois palavras similares ou relacionadas seriam projetadas em uma mesma dimensão do espaço. Indicativos formais foram apresentados por Papadimitriou (1998).

A projeção dos vetores-documentos em um espaço semântico agrupa os termos e documentos automaticamente por similaridade, criando relacionamentos indiretos. Assim, a Figura 3.3 mantém os termos carro e automóvel próximos, distanciando-os do termo elefante.

A análise da semântica latente é baseada na decomposição de matrizes em valores singulares (DEERWESTER, DUMAIS, et al., 1990). A ideia é eliminar as dimensões irrelevantes, reduzindo a dimensão do espaço. Selecionando os vetores mais significativos, é possível reduzir um espaço com milhares de dimensões para um espaço semântico com 100 a 500 dimensões (DUMAIS, 1991). 


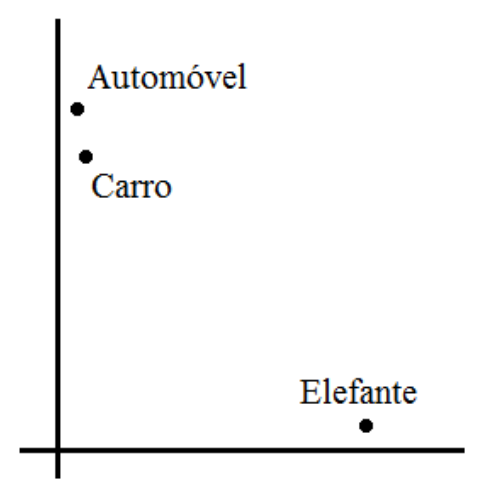

Figura 3.3 - Representação de termos no espaço semântico

Após a projeção no espaço semântico, os termos e documentos ficam agrupados por similaridade. Os termos automóvel e carro estão próximos um do outro.

A criação do espaço semântico é feita em etapas:

1. Conversão dos vetores-documentos em uma matriz termo-documento

2. Decomposição da matriz em valores singulares

3. Cálculo da aproximação da matriz de dimensão reduzida

4. Conversão da matriz aproximada para os vetores-documentos

\subsubsection{Matriz Termo-Documento}

É dada uma coleção de texto composta por $m$ termos distintos e $n$ documentos $D_{i}$, onde cada documento é representado pelo vetor coluna $d_{i}$ no espaço vetorial $\mathbb{R}^{m}$. Definimos a matriz $A$ de tamanho $m \times n$ através da justaposição dos vetores:

$$
A=\left[\begin{array}{llll}
d_{1} & d_{2} & \ldots & d_{n}
\end{array}\right]
$$

Essa matriz $A$ é chamada de Termo-Documento. 


\subsubsection{Decomposição em Valores Singulares}

Dada uma matriz $A$ de tamanho $m \times n$, com pelo menos um valor não nulo, podemos decompor no produto das matrizes $U, \Sigma$ e $V$.

$$
A=U \Sigma V^{T}
$$

Onde:

$$
\begin{aligned}
& U \text { é uma matriz } m \times r \text {, tal que } U^{\mathrm{T}} U=I_{\mathrm{r}} \\
& V \text { é uma matriz } n \times r \text {, tal que } V^{\mathrm{T}} V=I_{\mathrm{r}} \\
& \Sigma \text { é uma matriz diagonal } r \times r \text {, tal que } \Sigma=\operatorname{diag}\left(\sigma_{1}, \ldots, \sigma_{\mathrm{r}}\right) . \\
& \sigma_{1}, \ldots, \sigma_{\mathrm{r}} \text { são os valores singulares, tal que } \sigma_{\mathrm{i}} \in \mathbb{R}^{+} \\
& \mathbf{r} \text { corresponde ao número de valores singulares de } A
\end{aligned}
$$

Essa decomposição matricial é única quando os valores singulares estão em ordem decrescente.

$$
\sigma_{1} \geq \sigma_{2} \geq \cdots \geq \sigma_{\mathrm{n}}
$$

Definimos o posto da matriz por:

$$
\operatorname{rank}(A)=\text { número de valores singulares }
$$

A biblioteca SVDPACKC (BERRY, KRISHNA e VARADHAN, 1993) implementa a decomposição em valores singulares usando o algoritmo de Lanczos em matrizes esparsas. O custo desse cálculo é da ordem de $\mathrm{O}(m n c)$, onde $c$ é o número médio de valores não-nulos por linha (PAPADIMITRIOU, TAMAKI, et al., 1998).

\subsubsection{Aproximação de Matrizes}

É dada uma matriz A de tamanho $m \times n$, posto $r=\operatorname{rank}(A)$. As matrizes $U, \Sigma$ e $V$ são resultados da decomposição em valores singulares de $A$. Podemos construir uma aproximação de $A$ usando $k$ valores singulares, $O<k<r$. 
Definimos as matrizes:

$U_{0}$ é a matriz $U$ truncada de tamanho $m \times k$

$\Sigma_{0}$ é a matriz $\Sigma$ truncada de tamanho $k \times k$

$V_{0}^{\mathrm{T}}$ é a matriz $V^{\mathrm{T}}$ truncada de tamanho $k \times n$

Visualmente, as matrizes $U, \Sigma$ e $V$ são "cortadas" (Figura 3.4).

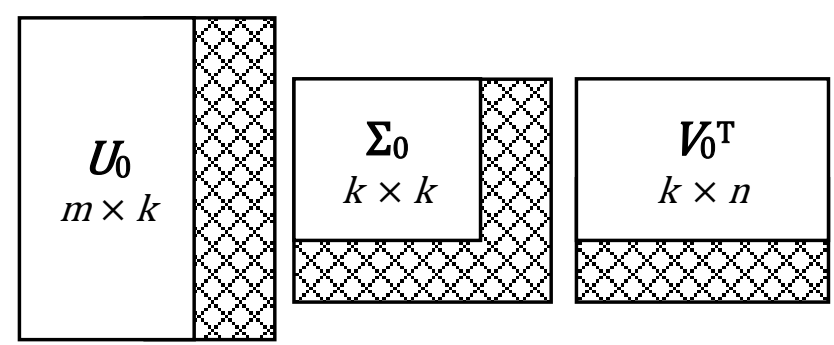

Figura 3.4-As matrizes truncadas $U_{0}, \Sigma_{0} e V_{0}$

Calculamos a matriz aproximada $A_{0}$ por:

$$
A_{0}=U_{0} \Sigma_{0} V_{0}^{T}
$$

Podemos definir o erro pela norma de Frobenius para uma matriz $M$ de tamanho $m \times n$ e posto $k$ por:

$$
\text { Erro }=\|A-M\|^{2}
$$

Pelo Teorema de Eckart-Young, o erro mínimo ocorre quando os valores singulares da matriz $M$ são exatamente igual aos $k$ maiores valores singulares da matriz $A$ (BERRY, KRISHNA e VARADHAN, 1993).

Logo, o erro mínimo ocorre quando $M=A_{0}$ e será dado por:

$$
\|A-M\|^{2} \geq\left\|A-A_{0}\right\|^{2}=\left(\sigma_{\mathrm{k}+1}\right)^{2}+\left(\sigma_{\mathrm{k}+2}\right)^{2}+\cdots+\left(\sigma_{\mathrm{r}}\right)^{2}
$$




\subsubsection{Projeção no espaço semântico}

A matriz aproximada $A_{0}$ corresponde à reconstrução da matriz termo-documento usando $k$ valores singulares. Podemos representar os documentos $D_{i}$ em um novo espaço através dos vetores $\hat{d}_{i}$, que correspondem às colunas de $A_{0}$.

$$
\left[\begin{array}{llll}
\hat{d}_{1} & \hat{d}_{2} & \ldots & \hat{d}_{n}
\end{array}\right]=\left[\begin{array}{ll}
A_{0} \\
\end{array}\right.
$$

Os vetores $\hat{d}_{i}$ são projeções dos vetores $d_{i}$ em um espaço de menor dimensão. No espaço semântico, as palavras similares ou relacionadas estão próximas entre si.

\subsection{Corpus}

Corpus é uma coletânea de texto acerca de um tema ou com uma finalidade específica. Nesse trabalho, adotamos o conjunto de artigos da Reuters conhecido como Reuters 21578 (LEWIS, 1997). A coleção contém um total de 21578 notícias do ano de 1987, que estão classificadas em 135 categorias de forma não uniforme. Os temas abordados são tópicos de economia e, em alguns casos, possuem sobreposição entre eles como, por exemplo, grãos e milho.

\subsubsection{Reuters 21578}

O corpus Reuters 21578 é frequentemente adotado como base de comparação entre classificadores de texto (JOACHIMS, 1998; DEBOLE e SEBASTIANI, 2004). É composto por 21 arquivos no formato SGML para descrever as informações adicionais ao corpo do texto.

Cada artigo é descrito no formato apresentado a seguir: 


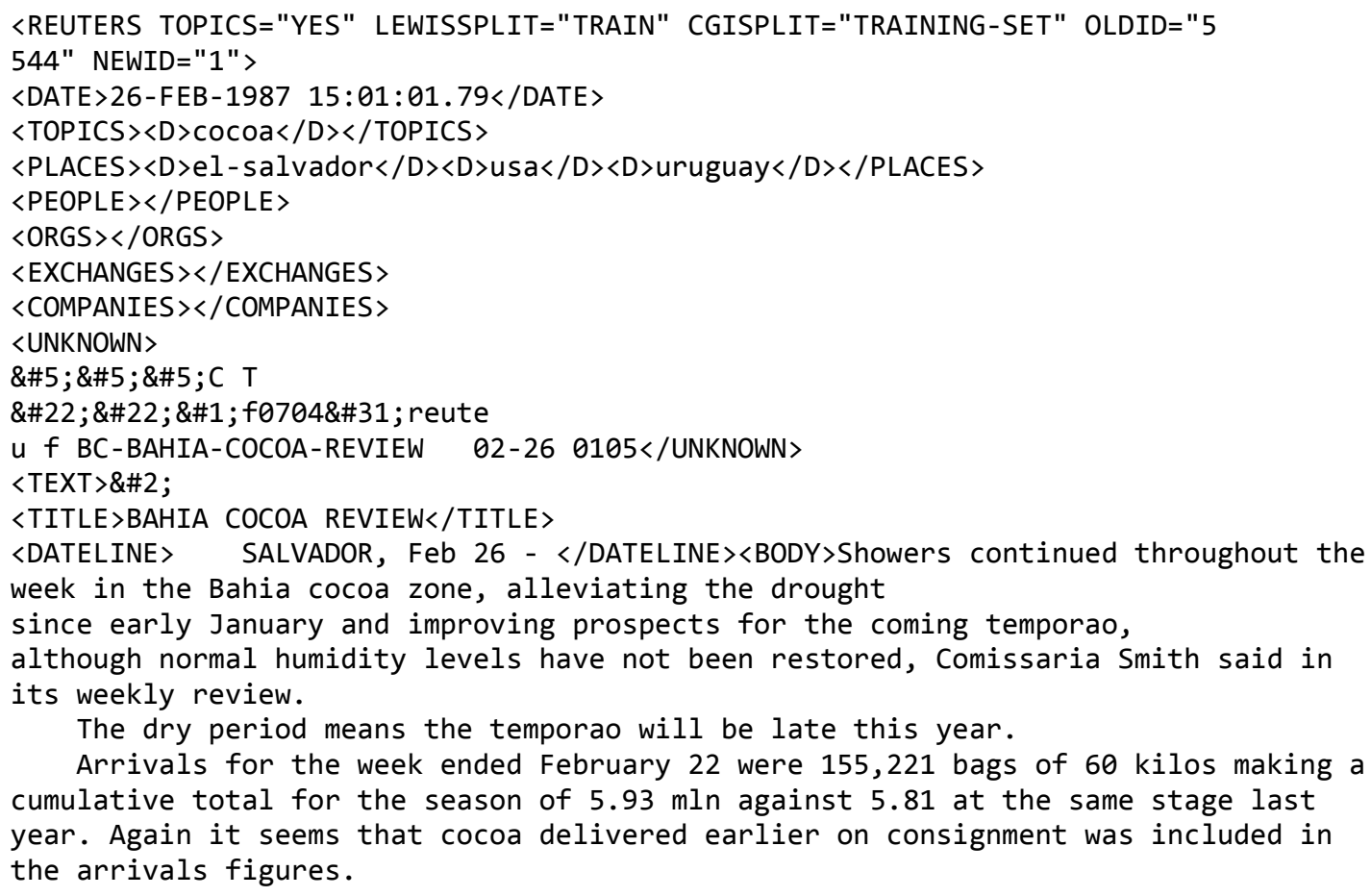

Os primeiros 21 arquivos (REUT2-000.SGM, ..., REUT2-020.SGM) contém 1000 documentos cada e o último arquivo (REUT2-021.SGM) possui outros 578 documentos.

A organização do corpus apresenta uma separação padrão conhecida por ModApté, adotada frequentemente pelos pesquisadores para identificar os conjuntos de treinamento e de teste. Nessa divisão, há 9603 exemplos de treino e 3299 provas de teste. Além disso, existem adicionalmente 8676 documentos sem uso direto para classificação, mas que podem ser usados para obter informação estatística sobre os atributos ou sobre a linguagem empregada.

Esse corpus possui documentos completamente fora de padrão como, por exemplo, artigos compostos apenas pela sentença "blah blah blah". A listagem abaixo apresenta um documento da classe “acq" com o título “TAFT BROADCASTING REJECTS 145 DLR PER SHARE BUYOUT OFFER FROM THETA CORP”. Observamos, entretanto, que o corpo do artigo não possui nenhuma informação relevante. 


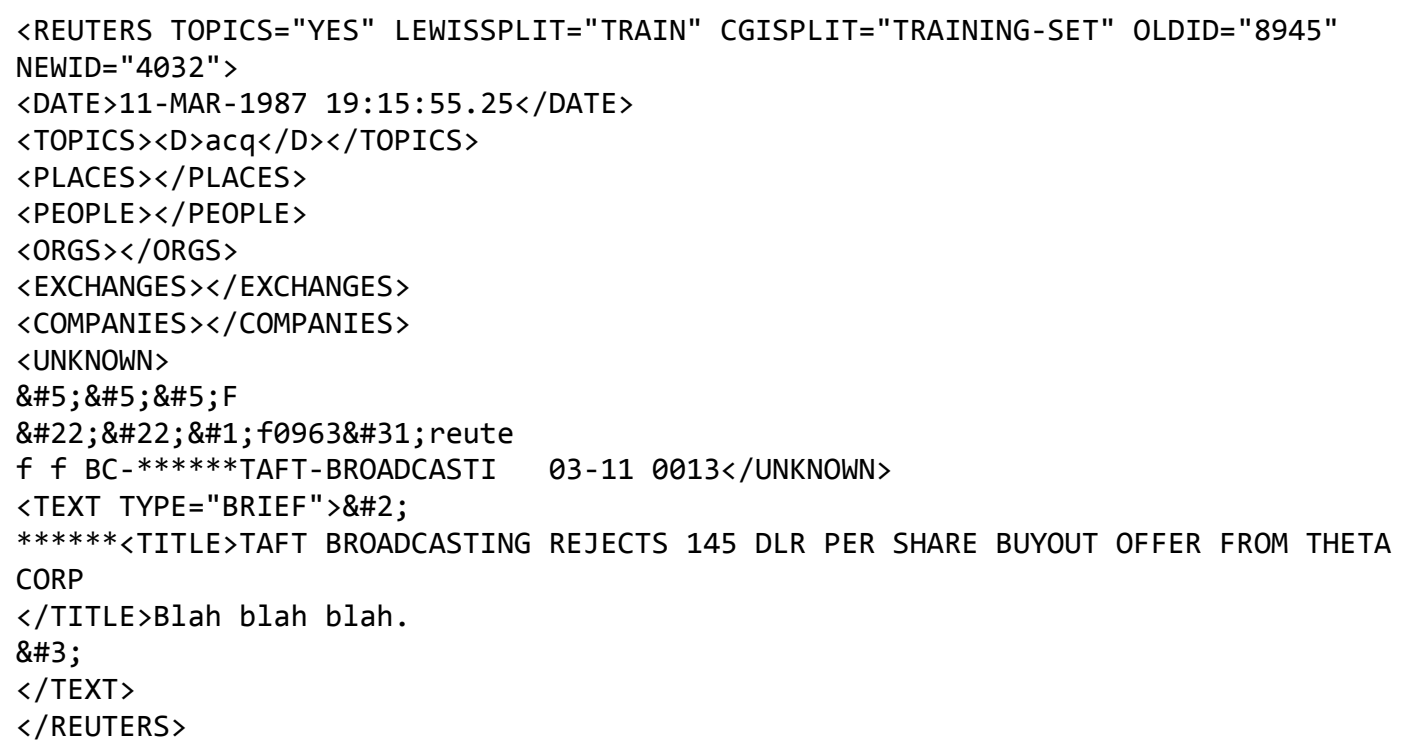

Realizamos um levantamento estatístico sobre o corpus e identificamos:

- 2108 documentos sem categorias

- 9133 documentos com uma única categoria

- 1199 documentos com exatamente duas categorias

- 462 documentos com três ou mais categorias

- 1131 documentos apenas com título, sem corpo

- 941 documentos apenas com a sentença "blah blah blah"

- 68 documentos sem título

\subsubsection{Experimentos}

Notamos que o corpus Reuters-21578 apresenta diversas formas de refinamento. Debole e Sebastiani (2004) exaltam a preocupação com relação à possibilidade de escolha de subconjuntos diferentes, pois isso dificultaria a comparação entre os resultados de diferentes autores. No entanto, acreditamos que a porcentagem de documentos inadequados é muito grande e, por isso, adotamos os subconjuntos conhecidos por R8 e R135. 
O subconjunto R135 é definido pelos documentos classificados em pelo menos uma categoria, totalizando 9805 documentos. Se limitarmos a apenas os documentos com uma única categoria, temos um total de 5946 exemplos de treino e 2347 provas de teste seguindo a divisão padrão ModApté.

O subconjunto R8 é definido pelos documentos pertencentes às oito maiores categorias. A divisão de documentos com uma única categoria é apresentada na Tabela 3.3.

\begin{tabular}{|c|c|c|}
\hline Categoria & Treino & Teste \\
\hline earn & 2695 & 1040 \\
\hline acq & 1505 & 620 \\
\hline crude & 257 & 98 \\
\hline trade & 260 & 73 \\
\hline money-fx & 190 & 69 \\
\hline interest & 154 & 57 \\
\hline ship & 121 & 35 \\
\hline grain & 38 & 7 \\
\hline
\end{tabular}

Tabela 3.3 - Distribuição de documentos no corpus $R 8$

Além dos subconjuntos R8 e R135, selecionamos subconjuntos de dados composto por apenas dois arquivos cada. Definimos as amostras de dados denominadas de P1, P2, P3, P4 e P5 para serem usadas nos testes preliminares do experimento. $\mathrm{O}$ objetivo era obter resultados mais rápidos antes de submeter a uma massa maior de dados.

- Amostra P1: REUT2-004.SGM e REUT2-019.SGM

- Amostra P2: REUT2-005.SGM e REUT2-018.SGM

- Amostra P3: REUT2-006.SGM e REUT2-017.SGM

- Amostra P4: REUT2-007.SGM e REUT2-016.SGM

- Amostra P5: REUT2-008.SGM e REUT2-015.SGM

Todas essas amostras estavam divididas em conjuntos de treinamento e de teste, seguindo a distribuição padrão ModApté. Em alguns experimentos, observamos que a separação padrão estava influenciando nos resultados. Por isso, redistribuímos aleatoriamente os documentos de forma proporcional ao tamanho dos conjuntos de treinamento e de teste dessas amostras. 
Assim, as amostras de dados: P1-A, P2-A, P3-A, P4-A, P5-A seguem a separação ModApté, enquanto que as variantes $\mathrm{B}, \mathrm{C}, \mathrm{D}$ e E correspondem às divisões selecionando dados aleatórios ou "embaralhados". 


\section{EXTENSÃo DA MATRIZ TERMO- DOCUMENTO}

Se todos os documentos estivessem previamente categorizados, não haveria a necessidade de classificação automática. O problema nasce quando existem documentos sem classificação prévia. Com base nas informações conhecidas, a máquina é capaz de iniciar o processo de aprendizagem e assimilação de conceitos.

Não há dúvidas da importância dos exemplos iniciais. Quanto maior for o tamanho da amostra de treinamento, melhores serão as chances de produzir um classificador de boa qualidade. É crucial ter as informações sobre classificação expostas de forma precisa.

O algoritmo de análise da semântica latente é indiferente à categoria. Em seu processo, todos os documentos são organizados em uma matriz termo-documento que será decomposta nas matrizes $U, \Sigma$ e $V$. O espaço semântico corresponde à reconstrução aproximada da matriz termo-documento usando as matrizes truncadas. Somente depois, teremos liberdade para escolher o classificador a ser usado para treinamento. Em outras palavras, os passos anteriores ignoram completamente as informações referentes à categoria.

A motivação desse experimento é inserir a discriminação das categorias logo no início do processo, o quanto antes possível. Dessa forma, a informação será trabalhada durante toda fase de treinamento.

\subsection{Proposta}

O objetivo desse experimento é incluir as informações referentes às categorias antes da geração do espaço semântico, ou seja, antes da decomposição da matriz termo- 
documento em valores singulares. As categorias podem ser inseridas como parte da matriz na forma de linhas. A expectativa é que a análise da semântica latente determine as nuances entre documentos e categoria, gerando um espaço semântico mais adequado à tarefa de classificação.

Dado o conjunto de documentos $D_{i}$ classificados nas categorias $C_{j}$, definimos a matriz categoria-documento de tamanho $c \times n$, denominada $K$, por:

$$
K_{j i}= \begin{cases}1, & \text { se o documento } D_{i} \in C_{j} \\ 0, & \text { caso contrário }\end{cases}
$$

Um elemento da matriz $K$ apresenta valor unitário apenas quando o documento pertence a uma determinada categoria. No caso particular dos dados de teste, assumimos que $K_{j i}=0$ para todos os documentos cuja categoria é desconhecida.

Se $A$ é a matriz termo-documento de tamanho $m \times n$, podemos estendê-la como uma matriz $A^{\prime}$ por meio da construção:

$$
A^{\prime}=\left(\begin{array}{l}
A \\
K
\end{array}\right)
$$

A nova matriz $A^{\prime}$ de tamanho $(m+c) \times n$ combina as matrizes termodocumento e categoria-documento. Ela será usada como matriz de entrada para a geração do espaço semântico. A hipótese é que a análise da semântica latente apresente melhores resultados com a inclusão das categorias junto aos termos. Quando as informações são fornecidas para o algoritmo, aumenta-se a possibilidade de assimilar as relações entre os documentos de mesma categoria.

\subsection{Experimento}

Nesse experimento, generalizamos a definição da matriz $K$. Note que a proposta inicial equivale ao caso $\lambda=1$.

$$
K_{j i}= \begin{cases}\lambda, & \text { se o documento } d_{i} \in C_{j} \\ 0, & \text { caso contrário }\end{cases}
$$


O conjunto de treinamentos possui os dados categorizados, permitindo a definição da matriz categoria-documento. Entretanto, os valores são todos nulos para os documentos do conjunto de teste.

O experimento é inicialmente realizado com as amostras de dados P1, P2, P3, P4, P5. Além disso, adotamos Reuters R8 para validar uma coleção com muitos textos. A taxa de acerto é usada para determinar o ganho ao se estender a matriz termo-documento. O cálculo é direto e corresponde a porcentagem de documentos classificados corretamente.

$$
t_{\text {acerto }}=\frac{\text { documentos classificados corretamente }}{\text { total de documentos }}
$$

Nesse novo modelo, a análise da semântica latente considera os documentos, os termos e as categorias. Dessa forma, consideram-se as informações relevantes desde o início do processo.

\subsection{Resultados}

Logo no início do experimento, verificamos que houve uma degradação significativa de $5 \%$ a $10 \%$ na taxa de acerto para as amostras de dados P1 a P5. A conclusão é que a parametrização $\lambda=1$ estava completamente inadequada, forçando-nos a repetir os testes.

Realizamos uma série de tentativas e determinamos que $\lambda=0,03$ era mais apropriado. A discussão sobre o parâmetro $\lambda$ será feita adiante. Nesse momento, apresentamos uma comparação entre os desempenhos da análise da semântica latente usando diretamente a matriz termo-documento e a matriz estendida com a inclusão de categoria (Tabela 4.1).

O experimento foi conduzido para as dimensões $k=100,200,400$, usando uma grande variedade de amostras de dados. Observamos que as 100 dimensões apresentaram os melhores desempenhos nas amostras de dados P1 e P3, enquanto que 400 dimensões foram mais adequadas para o conjunto P5. 


\begin{tabular}{|c|c|c|c|c|c|c|}
\hline \multirow[t]{2}{*}{ Amostra de Dados } & \multicolumn{3}{|c|}{$\begin{array}{c}\text { Matriz } \\
\text { Termo x Documento }\end{array}$} & \multicolumn{3}{|c|}{$\begin{array}{c}\text { Matriz Estendida }(\lambda=\mathbf{0 , 0 3}) \\
\text { Termo+Categoria } x \text { Documento }\end{array}$} \\
\hline & $k=100$ & $k=200$ & $k=400$ & $k=100$ & $\mathbf{k}=\mathbf{2 0 0}$ & $k=400$ \\
\hline P1-A & 79,3 & 76,5 & 74,5 & 79,6 & 76,2 & 74,5 \\
\hline P1-B & 84,4 & 86,4 & 85,4 & 84,7 & 86,4 & 85,4 \\
\hline P1-C & 83,7 & 82,7 & 81,0 & 83,0 & 82,7 & 80,6 \\
\hline P1-D & 81,6 & 83,0 & 82,0 & 81,6 & 83,0 & 81,6 \\
\hline P1-E & 85,0 & 83,7 & 83,3 & 86,1 & 83,7 & 83,7 \\
\hline P2-A & 64,8 & 65,5 & 65,9 & 65,5 & 65,5 & 65,5 \\
\hline P2-B & 71,6 & 79,3 & 80,5 & 72,0 & 79,3 & 80,5 \\
\hline P2-C & 73,9 & 82,8 & 82,0 & 74,3 & 82,8 & 82,0 \\
\hline P2-D & 74,7 & 77,8 & 77,8 & 75,1 & 77,8 & 77,8 \\
\hline P2-E & 73,6 & 80,1 & 78,9 & 73,9 & 79,7 & 78,5 \\
\hline P3-A & 72,4 & 68,7 & 72,4 & 73,3 & 69,1 & 72,8 \\
\hline P3-B & 84,3 & 80,6 & 82,9 & 84,3 & 81,1 & 82,5 \\
\hline P3-C & 81,1 & 77,4 & 77,9 & 81,6 & 77,9 & 77,4 \\
\hline P3-D & 82,5 & 82,9 & 81,6 & 83,4 & 82,9 & 82,0 \\
\hline P3-E & 83,4 & 82,0 & 82,9 & 84.3 & 82,5 & 82,9 \\
\hline P4-A & 78,2 & 76,6 & 77,7 & 78,2 & 76,6 & 77,5 \\
\hline P4-B & 79,1 & 79,5 & 78,8 & 80,2 & 79,3 & 78,8 \\
\hline P4-C & 73,9 & 75,7 & 77,0 & 74,8 & 75,7 & 77,0 \\
\hline P4-D & 78,6 & 78,4 & 77,7 & 78,6 & 78,2 & 77,7 \\
\hline P4-E & 79,1 & 79,5 & 80,0 & 81,1 & 79,7 & 79,7 \\
\hline P5-A & 73,7 & 71,6 & 71,3 & 73,5 & 71,6 & 71,3 \\
\hline P5-B & 77,0 & 78,9 & 78,4 & 77,7 & 78,9 & 78,2 \\
\hline P5-C & 75,8 & 79,4 & 79,1 & 75,8 & 79,4 & 79,1 \\
\hline P5-D & 76,1 & 79,1 & 80,8 & 76,5 & 79,6 & 80,8 \\
\hline P5-E & 74,6 & 76,8 & 77,7 & 74,6 & 76,5 & 77,7 \\
\hline Reuters R8 & 95,2 & 94,5 & 93,9 & 95,5 & 94,6 & 94,1 \\
\hline
\end{tabular}

Tabela 4.1 - Comparativo de desempenho da matriz estendida

A taxa de acerto resultante da matriz estendida (combinação da matriz TermoDocumento com a Categoria-Documento) é ligeiramente melhor. A tabela apresenta os resultados variando-se o número de dimensões usados na análise da semântica latente em relação a cada conjunto de amostra de dados.

O número de dimensões influencia diretamente os resultados da análise da semântica latente. Uma sugestão de Deerwester (1990) era utilizar em torno 100 dimensões. Em um trabalho mais recente elaborado por Bradford (2008), chegou-se ao número de 300 a 500 dimensões para uma coleção com milhões de documentos.

Além do parâmetro de dimensões $k$, nesse experimento precisamos ajustar $\lambda$. Verificamos que a proposta inicial $\lambda=1$ apresentou uma degradação entre $5 \%$ a $10 \%$, sendo completamente inadequado para prosseguir com os testes. Conforme se aumentava $\lambda$, mais o resultado se degradava. $\mathrm{O}$ melhor resultado foi obtido com $\lambda=0,03$, que ficou ligeiramente melhor do que a matriz termo-documento. Valores muito baixos não modificavam o resultado. 
Ressaltamos que a matriz estendida com $\lambda=0$ corresponde exatamente ao mesmo cenário que a matriz termo-documento sem nenhuma informação de categoria.

\subsection{Conclusão}

O objetivo do experimento era agregar informações relevantes às categorias antes da decomposição da matriz termo-documento em valores singulares. Assim, decidiu-se estender a matriz com as linhas da matriz categoria-documento.

A mudança de comportamento foi significativa quando houve o ajuste no número de dimensões (parâmetro $k$ ) tanto para a matriz termo-documento como para a matriz estendida. Por outro lado, as variações do parâmetro $\lambda$ não trouxeram ganhos significativos que justificassem sua utilização.

Seria interessante rever a definição da matriz categoria-documento:

- Atualmente a matriz categoria-documento é muito simplificada e todos os elementos são nulos ou iguais a uma constante. Entre os possíveis problemas, destacamos que sua definição não leva em consideração o tamanho do documento.

- Os elementos com categoria desconhecida são preenchidos com valores nulos. Isso pode afetar negativamente o desempenho, pois é um valor arbitrário e sem nenhum embasamento matemático. Talvez se aumentarmos a proporção de amostras de treinamento em relação ao conjunto de teste, então esse fator seria menos relevante.

Uma possibilidade seria considerar somente os exemplos de treino para obter os vetores singulares, que seriam usados para projetar os documentos de testes. Essa é uma forma de determinar a categoria por regressão linear, na qual existem trabalhos semelhantes que adotaram essa abordagem (YANG, ZHANG e KISIEL, 2003; CHAKRABORTI, LOTHIAN, et al., 2006). 


\section{ESPAÇOS SEMÂNTICOS POR Categoria}

No jargão da informática, a expressão “copiar e colar" possui um significado diferente do literal. Essa variação de significado é similar a quando alguém manda "fechar a janela" (de um aplicativo de computador), mas não por causa da chuva (condição meteorológica). Algumas palavras estão associadas a diferentes contextos e podem ter significados específicos, assim como existem os jargões do futebol, da informática, médico, etc.

Em geral, os documentos que abordam um único tema possuem semelhanças no estilo da escrita: abreviações, nomes, termos específico da área ou vocabulário em geral. Por exemplo, um texto com a palavra "equação" provavelmente, e com grande chance, apontaria para um artigo de "matemática" ao invés de uma receita de "culinária".

Nesse experimento, a motivação é representar os documentos como vetores e mapear as categorias em subespaços independentes. Podemos definir o grau de afinidade com qualquer documento através da projeção do vetor no subespaço correspondente. Essa seria uma medida de proximidade, na qual se avalia o quanto um documento está inserido em uma categoria.

Ao projetar o vetor-documento em todos os subespaços, determinamos aquele que apresenta o valor máximo e, portanto, possui maior afinidade. Logo, podemos classificar os documentos desconhecidos usando uma métrica bem definida. 


\subsection{Proposta}

Geralmente os documentos do mesmo tópico possuem semelhanças de forma e conteúdo. O objetivo do experimento é tratar as categorias de forma independente e extrair um conjunto de características únicas, como uma assinatura.

O primeiro passo é definir as categorias como subespaços a partir do conjunto de treinamento. Assumindo que não haja documentos repetidos e que os vetores sejam linearmente independentes, podemos definir um subespaço através de $n$ vetores ortogonais e unitários em uma categoria com $n$ documentos. Em um conjunto de textos classificados em $c$ categorias, teremos um total de $c$ subespaços diferentes. Cada categoria terá seu próprio conjunto de vetores de base, que será independente das demais.

A tarefa de classificação de dados prevê, com base nos dados de treinamento, a qual classe o documento pertence. Isso equivale a medir o quanto um documento está inserido em uma categoria, ou seja, mediremos a semelhança entre o vetordocumento e os subespaços.

A hipótese é que um documento $d$ está relacionado à categoria na qual sua projeção seja máxima. Se definirmos o subespaço $S$ através do conjunto de vetores unitários e ortogonais $\left\{s_{1}, s_{2}, \ldots, s_{j}\right\}$, então calculamos a projeção do documento $d$ por:

$$
\operatorname{proj}(d)=\left\|\sum_{i}\left(d \cdot s_{i}\right) \overrightarrow{s_{\imath}}\right\|
$$

Essa técnica será denominada de Classificação por Projeção. Podemos resumir os passos em:

1) Agrupar os documentos por categoria

2) Definir o subespaço para cada categoria, usando as amostras correspondentes

3) Obter os vetores base, unitários e ortogonais, de cada subespaço

4) Calcular a projeção do vetor $d$ para cada subespaço

5) Classificar o documento de acordo com sua projeção máxima 
É comum aplicarmos a representação vetorial de documentos para realizar a tarefa de classificação. O modelo de espaço vetorial transforma textos em vetores, permitindo manipular matrizes ao invés de sequência de palavras (SALTON, WONG e YANG, 1975). Entretanto, podemos aplicar a decomposição de valores singulares para reduzir a dimensão da matriz. Em uma matriz de menor dimensionalidade, as relações entre documentos ficam mais expostas (DEERWESTER, DUMAIS, et al., 1990).

A análise da semântica latente é uma técnica que se propõe a identificar as relações escondidas entre documentos com base na co-ocorrência de termos. Como cada categoria possui um subespaço correspondente, então a técnica é aplicada individualmente. O resultado será, para cada categoria, a geração de um espaço semântico.

Neste caso, uma categoria corresponde ao subespaço de dimensão reduzida. O fato de existirem múltiplos espaços semânticos independentes possui vantagens quando há palavras com mais de um significado. Por exemplo, consideramos a palavra "árvore" em diferentes contextos:

a. Árvore, planta, natureza, vento, solo, formiga

b. Árvore, estrutura de dados, grafo, elementos, busca, programa

Se considerarmos um único espaço semântico para ambos, então teríamos a relação estabelecida entre $(a)$ e $(b)$ por causa do termo comum "árvore". Assim, incorretamente, criam-se os vínculos entre: formiga e programa, estrutura de dados e vento, planta e grafos, entre outros. Assim, observamos que quando a análise da semântica latente é aplicada a um subconjunto de documentos, ao invés da coleção completa, torna-se possível atenuar o efeito da polissemia.

Além disso, cada espaço semântico pode apresentar uma dimensionalidade diferente. A escolha do número de dimensões adequado para cada um dos espaços é crucial, sendo necessário chegar a um valor balanceado:

- Uma categoria, cujo subespaço tem poucas dimensões, apresenta uma baixa taxa de recuperação de documentos, ou seja, deixará de ter a visibilidade necessária sobre quais os documentos que realmente pertencem à categoria. 
- Uma categoria, cujo subespaço possui dimensões em excesso, apresentará o fenômeno do overfitting, pois seu tamanho será maior do que é realmente. A taxa de recuperação será alta, mas sem precisão.

Essa técnica será denominada de Espaços Semânticos por Categoria (ESC) e pode ser resumida nas etapas:

1) Agrupar os documentos por categoria

2) Definir o subespaço para cada categoria, usando as amostras correspondentes

3) Aplicar a análise da semântica latente com $k$ dimensões

4) Calcular a projeção do vetor $d$ para cada subespaço

5) Classificar o documento no subespaço de acordo com sua projeção máxima

O processo segue praticamente os mesmos passos que a categorização por projeção, exceto pelo terceiro item.

\subsection{Metodologia}

O experimento avalia a precisão do Classificador por projeção e dos Espaços semânticos por categoria (ESC), comparando com os resultados fornecidos pela análise da semântica latente. A métrica usada é a taxa de acerto, que corresponde à porcentagem de documentos classificados corretamente.

Separamos os documentos de treinamento e os agrupamos por categoria. No experimento com espaços semânticos por categoria, o número de dimensão $k$ é um parâmetro fornecido previamente.

Adotamos os conjuntos menores P1, P2, P3, P4 e P5 para uma avaliação preliminar do desempenho do classificador e, se obtivermos resultados positivos, prosseguimos os testes com uma massa de dados maior: Reuters R8 e R135. 


\subsection{Resultados}

Representamos cada categoria como um subespaço do modelo vetorial, no qual podemos avaliar a similaridade entre documentos e categorias. Esse grau de semelhança é dado pela projeção do vetor e, assim, temos a Classificação por projeção.

Conduzimos uma série de testes usando os conjuntos de dados P1 a P5. A Tabela 5.1 compara a taxa de acerto da análise da semântica latente e da categorização por projeção.

\begin{tabular}{|c|c|c|c|c|}
\hline \multirow{2}{*}{ Amostra de dados } & \multicolumn{2}{|c|}{ Análise da Semântica Latente } & \multirow{2}{*}{$\begin{array}{c}\text { Classificação } \\
\text { por Projeção }\end{array}$} \\
\cline { 2 - 4 } & $\mathbf{k = 1 0 0}$ & $\mathbf{k = 2 0 0}$ & $\mathbf{k = 4 0 0}$ & 65,3 \\
\hline P1 & 79,3 & 76,5 & 74,5 & 55,6 \\
\hline P2 & 64,8 & 65,5 & 65,9 & 65,9 \\
\hline P3 & 72,4 & 68,7 & 72,4 & 74,3 \\
\hline P4 & 78,2 & 76,6 & 77,7 & 70,1 \\
\hline P5 & 73,7 & 71,6 & 71,3 & \\
\hline
\end{tabular}

Tabela 5.1 - Desempenho da técnica Categorização por projeção

Em todos os testes realizados, a técnica de categorização por projeção apresentou uma precisão inferior em comparação com a análise da semântica latente.

O resultado demonstra um desempenho significativamente inferior com diferença de 3-10\%. Uma possível explicação para esse comportamento é o overfitting. A categorização por projeção cria um subespaço usando uma combinação linear de todos os documentos encontrados no conjunto de treinamento e que pertencem à categoria.

Vamos supor que existam documentos de treinamento incorretamente classificados. A simples presença de um elemento adiciona uma dimensão inexistente ao subespaço da categoria, estendendo o tamanho para cobrir regiões que não pertencem à categoria. Por exemplo, se houver um documento eclético, misturando vocabulários de diversos temas distintos, então o espaço semântico crescerá para todas as direções.

Uma forma de evitar o overfitting é diminuindo a dimensionalidade das matrizes. Por isso, a técnica dos Espaços semânticos por categoria surge como uma solução natural para classificar os documentos. A Tabela 5.2 apresenta um resumo dos resultados e a Tabela 5.3 possui os detalhes com todos os conjuntos de dados. 


\begin{tabular}{|c|c|c|c|c|}
\hline \multirow{2}{*}{ Amostra de dados } & \multicolumn{3}{|c|}{ Análise da Semântica Latente } & $\begin{array}{c}\text { Espaço Semântico } \\
\text { por Categoria }\end{array}$ \\
\cline { 2 - 4 } & $\mathbf{k = 1 0 0}$ & $\mathbf{k = 2 0 0}$ & $\mathbf{k = 4 0 0}$ & $\mathbf{k = 5 0}$ \\
\hline P1-A & 79,3 & 76,5 & 74,5 & 81,6 \\
\hline P2-A & 64,8 & 65,5 & 65,9 & 71,3 \\
\hline P3-A & 72,4 & 68,7 & 72,4 & 79,3 \\
\hline P4-A & 78,2 & 76,6 & 77,7 & 82,2 \\
\hline P5-A & 73,7 & 71,6 & 71,3 & 77,7 \\
\hline Tabelay
\end{tabular}

Tabela 5.2 - Desempenho do Espaço Semântico por Categoria (Resumo)

\begin{tabular}{|c|c|c|c|c|c|}
\hline \multirow{2}{*}{ Amostra de Dados } & \multicolumn{3}{|c|}{$\begin{array}{c}\text { Análise da Semântica } \\
\text { Latente }\end{array}$} & \multicolumn{2}{|c|}{$\begin{array}{l}\text { Espaço Semântico } \\
\text { por Categoria }\end{array}$} \\
\hline & $k=100$ & $k=200$ & $k=400$ & $k=10$ & $k=50$ \\
\hline \multirow{5}{*}{$\begin{array}{l}\text { P1-A } \\
\text { P1-B } \\
\text { P1-C } \\
\text { P1-D } \\
\text { P1-E }\end{array}$} & 79,3 & 76,5 & 74,5 & 79,6 & 81,6 \\
\hline & 84,4 & 86,4 & 85,4 & 85,4 & 88,1 \\
\hline & 83,7 & 82,7 & 81,0 & 82,3 & 85,4 \\
\hline & 81,6 & 83,0 & 82,0 & 81,0 & 87,1 \\
\hline & 85,0 & 83,7 & 83,3 & 84,0 & 85,7 \\
\hline \multirow{5}{*}{$\begin{array}{l}\text { P2-A } \\
\text { P2-B } \\
\text { P2-C } \\
\text { P2-D } \\
\text { P2-E }\end{array}$} & 64,8 & 65,5 & 65,9 & 75,5 & 71,3 \\
\hline & 71,6 & 79,3 & 80,5 & 79,3 & 81,2 \\
\hline & 73,9 & 82,8 & 82,0 & 84,7 & 87,7 \\
\hline & 74,7 & 77,8 & 77,8 & 80,5 & 78,2 \\
\hline & 73,6 & 80,1 & 78,9 & 80,1 & 84,3 \\
\hline \multirow{5}{*}{$\begin{array}{l}\text { P3-A } \\
\text { P3-B } \\
\text { P3-C } \\
\text { P3-D } \\
\text { P3-E }\end{array}$} & 72,4 & 68,7 & 72,4 & 79,7 & 79,3 \\
\hline & 84,3 & 80,6 & 82,9 & 82,0 & 85,3 \\
\hline & 81,1 & 77,4 & 77,9 & 78,3 & 80,6 \\
\hline & 82,5 & 82,9 & 81,6 & 82,5 & 85,3 \\
\hline & 83,4 & 82,0 & 82,9 & 87,6 & 88,0 \\
\hline \multirow{5}{*}{$\begin{array}{l}\text { P4-A } \\
\text { P4-B } \\
\text { P4-C } \\
\text { P4-D } \\
\text { P4-E }\end{array}$} & 78,2 & 76,6 & 77,7 & 80,9 & 82,2 \\
\hline & 79,1 & 79,5 & 78,8 & 81,3 & 84,7 \\
\hline & 73,9 & 75,7 & 77,0 & 80,4 & 84,7 \\
\hline & 78,6 & 78,4 & 77,7 & 82,4 & 84,7 \\
\hline & 79,1 & 79,5 & 80,0 & 80,0 & 84,5 \\
\hline \multirow{5}{*}{$\begin{array}{l}\text { P5-A } \\
\text { P5-B } \\
\text { P5-C } \\
\text { P5-D } \\
\text { P5-E }\end{array}$} & 73,7 & 71,6 & 71,3 & 76,8 & 77,7 \\
\hline & 77,0 & 78,9 & 78,4 & 80,6 & 81,8 \\
\hline & 75,8 & 79,4 & 79,1 & 82,5 & 82,0 \\
\hline & 76,1 & 79,1 & 80,8 & 81,8 & 83,2 \\
\hline & 74,6 & 76,8 & 77,7 & 79,9 & 79,6 \\
\hline
\end{tabular}

Tabela 5.3 - Detalhamento do desempenho do Espaço Semântico por Categoria

O desempenho da técnica de Espaço semântico por categoria (ESC) foi superior a $80 \%$ de precisão na maioria dos testes realizados.

Ao reduzirmos o número de dimensão dos subespaços, observamos um ganho significativo no desempenho do classificador. A técnica de espaço semântico por categoria apresentou uma precisão de 2 a $7 \%$ melhor, sendo superior em todas as 
amostras de dados (Tabela 5.3) exceto na P3-C. No geral, atingiu resultados acima de $80 \%$ de precisão.

Após validar o desempenho do espaço semântico por categoria no conjunto de dados P1 a P5, repetimos o experimento usando uma massa de dados maior. Nesse caso, utilizamos os corpus da Reuters R8 e R135. Ao contrário do esperado, a técnica de espaço semântico por categoria (ESC) apresentou um desempenho ligeiramente inferior à análise da semântica latente (Tabela 5.4). O classificador ESC ficou aproximadamente $0,5 \%$ abaixo na comparação.

\begin{tabular}{|c|ccc|ccc|}
\hline & \multicolumn{3}{|c|}{$\begin{array}{c}\text { Análise da Semântica } \\
\text { Latente }\end{array}$} & \multicolumn{3}{c|}{$\begin{array}{c}\text { Espaço Semântico por } \\
\text { Categoria }\end{array}$} \\
\cline { 2 - 7 } & $\mathbf{k}=\mathbf{1 0 0}$ & $\mathbf{k}=\mathbf{2 0 0}$ & $\mathbf{k}=\mathbf{4 0 0}$ & $\mathbf{k}=\mathbf{1 0}$ & $\mathbf{k}=\mathbf{5 0}$ & $\mathbf{k = 1 0 0}$ \\
\hline $\mathbf{R 8}$ & 95,2 & 94,5 & 93,9 & $\mathbf{9 4 , 5}$ & $\mathbf{9 3 , 4}$ & $\mathbf{9 3 , 1}$ \\
\hline $\mathbf{R 1 3 5}$ & 88,3 & 89,2 & 88,5 & $\mathbf{8 7 , 3}$ & $\mathbf{8 8 , 7}$ & $\mathbf{8 8 , 7}$ \\
\hline
\end{tabular}

Tabela 5.4 - Comparação de desempenho do Espaço semântico por categoria

A taxa de acertos do espaço semântico por categoria, que são espaços semânticos independentes, ficou abaixo do desempenho da análise da semântica latente. Os testes foram realizados na coleção de documentos Reuters R8 e R135.

\subsection{Conclusão}

O classificador por projeção apresentou resultados com precisão abaixo dos demais classificadores, ficando de 3 a 10\% abaixo no comparativo. Isso serviu como uma evidência de como o fenômeno de overfitting afeta o desempenho dos dispositivos.

O classificador de espaço semântico por categoria (ESC) mostrou-se como uma evolução natural, visto que as dimensões são reduzidas. Em todos os experimentos envolvendo pouca quantidade de documentos, seu desempenho foi superior à análise da semântica latente (LSA) e ficou acima de $80 \%$.

Nos experimentos com o corpus Reuters R8 e R135, observamos uma mudança no comportamento do LSA. Com o aumento da massa de dados, o desempenho médio que estava próximo a $77 \%$ subiu para acima de $88 \%$. Nesses casos, a precisão do classificador LSA se mostrou melhor do que a do ESC. 


\section{Reuters R8}
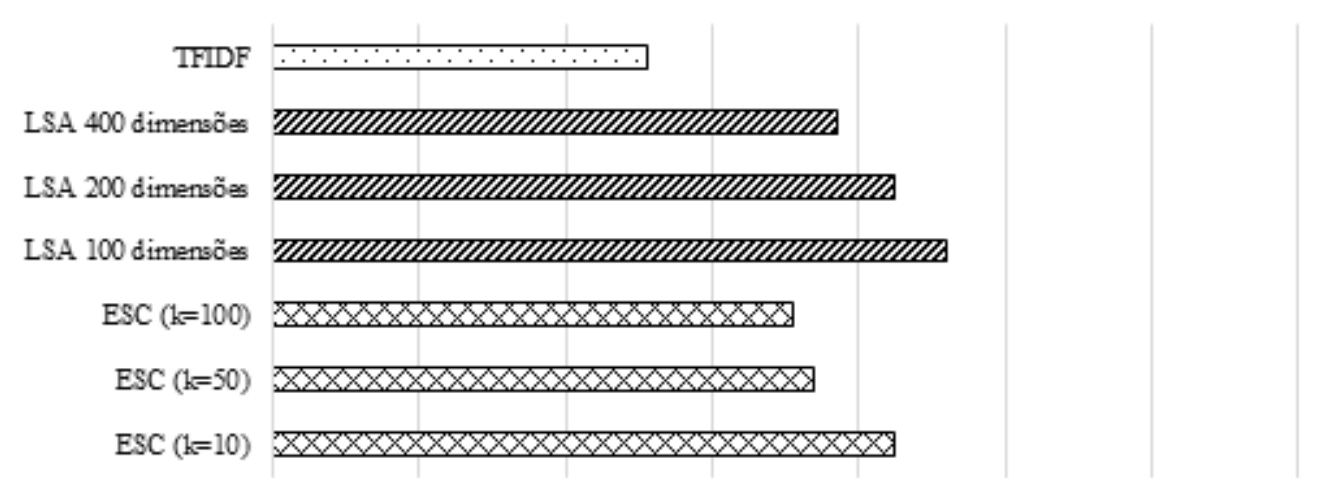

\begin{tabular}{lllllllllll}
$86 \%$ & $88 \%$ & $90 \%$ & $92 \%$ & $94 \%$ & $96 \%$ & $98 \%$ & $100 \%$ \\
\hline
\end{tabular}

\section{Reuters R135}

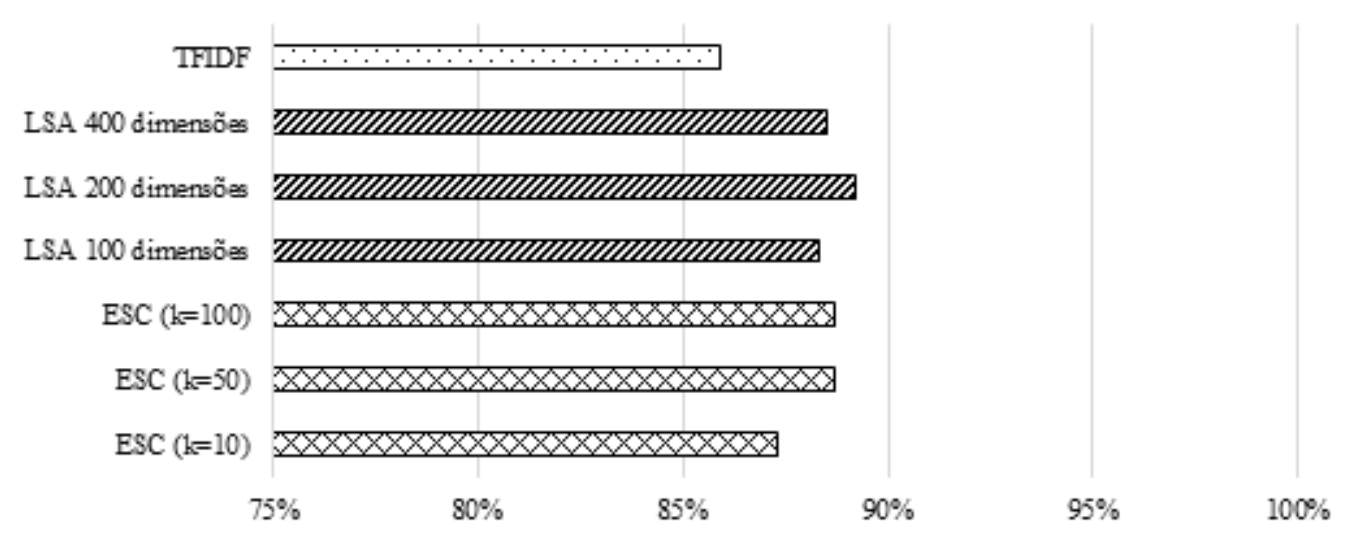

Figura 5.1 - Comparação entre o ESC e os diferentes métodos

Comparação dos modelos de espaço vetorial (TFIDF), a análise da semântica latente (LSA) e o espaço semântico por categoria (ESC)

A Figura 5.1 apresenta uma comparação do desempenho dos modelos:

- TFIDF: Modelo de espaço vetorial e com pesos TF-IDF

- LSA: Análise da semântica latente para as dimensões 100, 200 e 400

- ESC: Espaço semântico por categoria para as dimensões 10, 50 e 100

Ressaltamos que o classificador ESC apresentou um comportamento balanceado entre precisão e tempo de processamento. A taxa de acerto atingiu valores muito próximos à da análise da semântica latente, enquanto que o tempo gasto de processamento foi inferior devido ao número reduzido de dimensões $(k=10,50$ e 100$)$. 
Uma das limitações do classificador ESC se deve ao fato de que as categorias não são ortogonais entre si. Por exemplo, um documento da classe "earn" foi incorretamente classificado como "crude". Ao analisar os valores das projeções, observamos que o vetor estava projetado em todos os subespaços (Tabela 5.5).

Quando diminuímos a dimensionalidade, os espaços ficam mais "próximos" e, consequentemente, um documento passa a ter projeções em todas as categorias ou em nenhuma delas. Se os espaços semânticos fossem ortogonais, então esse problema não existiria. Essa seria uma linha de investigação futura.

\begin{tabular}{|l|l|}
\hline Categoria & Proj \\
\hline Earn & 0,753 \\
\hline Acq & 0,622 \\
\hline Crude & 0,820 \\
\hline Trade & 0,748 \\
\hline Money-fx & 0,507 \\
\hline Interest & 0,696 \\
\hline Ship & 0,717 \\
\hline Grain & 0,416 \\
\hline
\end{tabular}

Tabela 5.5 - Projeção de um documento da classe "earn"

Um documento da classe "earn" foi projetado em todas as categorias. Observamos que os subespaços são independentes, mas não são ortogonais entre si. Por isso, a projeção ocorreu em todas as categorias, com maior projeção em "crude". 


\section{DIMENSÃO IDEAL}

Landauer (1998) aplicou a técnica da análise da semântica latente em um experimento com 80 questões da prova de inglês ETS Test of English as a Foreign Language (TOEFL). As questões selecionadas avaliavam o conhecimento dos candidatos em determinar os sinônimos das palavras. O conhecimento da máquina foi construído com o conteúdo composto por jornais disponibilizados pela Associated Press, trechos da enciclopédia Grolier's Academic American e textos de conteúdo infantil.

O objetivo era encontrar os relacionamentos entre palavras no espaço semântico, ou seja, através da redução de dimensionalidade do espaço vetorial. Em seu experimento, Landauer variou o número de dimensões (parâmetro $k$ ) entre 2 a 1032, obtendo a melhor taxa de acerto com 300 dimensões (Figura 6.1).

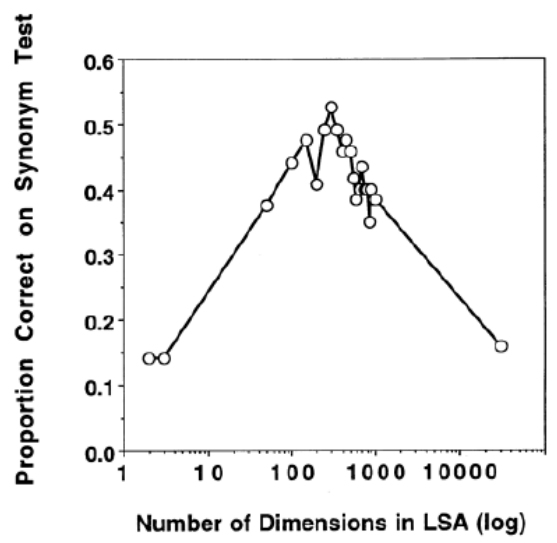

Figura 6.1 - Influência do número de dimensões

A influência do parâmetro $\mathrm{k}$ no experimento de da prova TOEFL. Esse gráfico ressalta a importância da escolha adequada do número de dimensões. Existe um valor ideal.

Quando se altera o número de dimensões, há variações nas taxas de recuperação e de precisão. Dumais (1991) sugere a utilização de um espaço composto por 200 a 300 dimensões, pois observou que, a partir de um determinado 
valor, o aumento do valor do parâmetro $k$ passa a degradar o resultado. Em uma pesquisa bibliográfica, o artigo mais recente encontrado sobre essa discussão foi um estudo empírico do número de dimensões (BRADFORD, 2008). Nesse artigo, os melhores resultados foram obtidos empiricamente com $k$ entre 300 a 500 . Entretanto, em experimentos com o conjunto de documentos médicos (MED), Deerwester (1990) reportou que o melhor desempenho ocorreu com 100 dimensões.

Em uma série de outros experimentos do Text Retrieval Conference (TREC), os resultados foram diversos. Na primeira edição da conferência, foram utilizadas 235 e 250, enquanto que, no TREC-2, empregaram-se 199 e 204 dimensões. Na versão seguinte, TREC-3, o experimento rodou com maior variação do parâmetro $k$ : 199, 250, 300 e 346 dimensões (DUMAIS, 1993; DUMAIS, 1994; DUMAIS, 1995).

O número de dimensões é o principal parâmetro da análise da semântica latente. Entretanto, não há um consenso sobre o como ajustar o número ideal para o modelo.

\subsection{Proposta}

O objetivo desse trabalho é dimensionar o parâmetro $k$, que determina o número de dimensões usadas na análise da semântica latente. A variação desse parâmetro afeta diretamente a precisão e a quantidade de documentos recuperados. Apesar da sua importância, não foi encontrada nenhuma referência sobre como determinar o valor ideal para a tarefa de categorização de documentos.

Durante a fase de treinamento, todos os documentos são considerados, independente se são de treinamento ou teste. Através da decomposição em valores singulares, encontramos um conjunto de vetores unitários e ortogonais, que vão compor a base do subespaço representado. Em nenhum momento, a categoria é levada em consideração e, por isso, o algoritmo é caracterizado como uma aprendizagem não-supervisionada (TORKKOLA, 2001). 


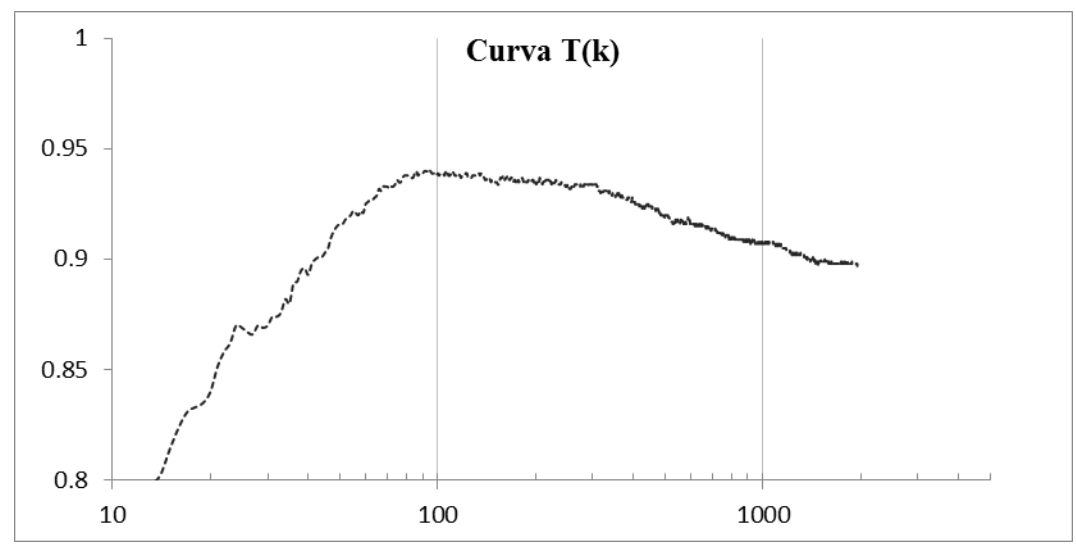

Figura 6.2 - Taxa de acerto $T(k)$ do conjunto de treinamento

A determinação da curva $\mathrm{T}(\mathrm{k})$ é um processo iterativo. Usando um modelo com $\mathrm{k}$ valores singulares, calculamos a precisão do classificador usando os documentos de treinamento. Repetimos o processo para todos os valores de $\mathrm{k}$.

Podemos transformá-lo em um algoritmo semi-supervisionado. Durante a fase de inicial, variamos o parâmetro $k$ em um intervalo de valores e calculamos a taxa de acerto correspondente aos documentos de treinamento. Esses dados representam a curva $T(k)$ : taxa de acerto conforme aumentamos o número de dimensões (Figura 6.2).

Seja $P(k)$ uma função correspondente à taxa de acerto do modelo contra os dados finais de teste na dimensão $k$. Assumindo que os conjuntos de teste e treinamento sejam aleatórios, podemos inferir que o modelo trará resultados semelhantes a ambos. Criamos nossa hipótese de que:

$$
T(k)=P(k)
$$

Quando essa hipótese é válida, os dados de treinamento podem calibrar o parâmetro $k$ e ajustá-lo para a dimensão ideal. $\mathrm{O}$ valor ideal de $k$ é aquele que maximiza o número de acertos $T(k)$.

\subsection{Experimento}

Os termos extraídos dos documentos são transformados em vetores usando pesos TFIDF. Após o pré-processamento de texto, os vetores correspondentes aos documentos 
são colocados em uma matriz termo-documento de tamanho $m \times n$. Através da decomposição em valores singulares, obtêm-se as matrizes $U, S$ e $V$. Os vetores singulares são, então, truncados e o espaço, reduzido à somente $k$ dimensões.

Assim chegamos às matrizes $U_{k}, S_{k}, V_{k}$ e a matriz $A_{k}$ :

$$
A_{k}=U_{k} S_{k} V_{k}^{T}
$$

$A_{k}$ é uma aproximação de posto $k$ da matriz termo-documento e será usada como um espaço semântico para predição. Ainda na fase de treinamento, realizamos uma prévia da classificação usando o cálculo de similaridade com os documentos de treinamento. A similaridade é dada pelo cosseno do ângulo formado entre os vetores.

Ao repetir o processo variando o número de dimensão $k$ entre 2 e 1000, obtemos a curva $T(k)$ : acertos x dimensão. Selecionamos o parâmetro $k_{\text {ideal }}$ igual ao pico máximo da curva $T(k)$ e a fase de treinamento do modelo é encerrada

Com o objetivo de medir a precisão do método, calculamos a taxa de acerto $P$ associada ao conjunto de teste. Ao utilizar o mesmo método variando o número de dimensões $k$, traça-se uma nova curva $P(k)$ que, por hipótese, é igual a $T(k)$.

\subsection{Resultados Preliminares}

O experimento foi conduzido com as amostras de dados P1, P2 e P3. O objetivo é avaliar se, a partir dos dados de treinamento, é possível calibrar o parâmetro $k$, correspondente ao número de dimensões ou de vetores singulares do modelo.

O algoritmo é iterativo e inicia com $k$ igual ao número mínimo de dimensões. Calcula-se a taxa de acerto dos documentos de treinamento usando o espaço semântico definido por $k$ valores singulares. O parâmetro k é incrementado até o número máximo de dimensões. Traçamos, então, a curva $T(k)$. Em seguida, repete-se o algoritmo usando os dados de teste para encontrar a curva $P(k)$. 
A Figura 6.3 apresenta as taxas de acerto $T(k)$ e $P(k)$ referente ao conjunto de dados $\mathrm{P} 1$, com variação de $k$ entre 10 a 600. A escala do eixo X é logarítmica e a escala $\mathrm{Y}$, taxa de acerto, foi fixada de 0.50 a 1.00 .

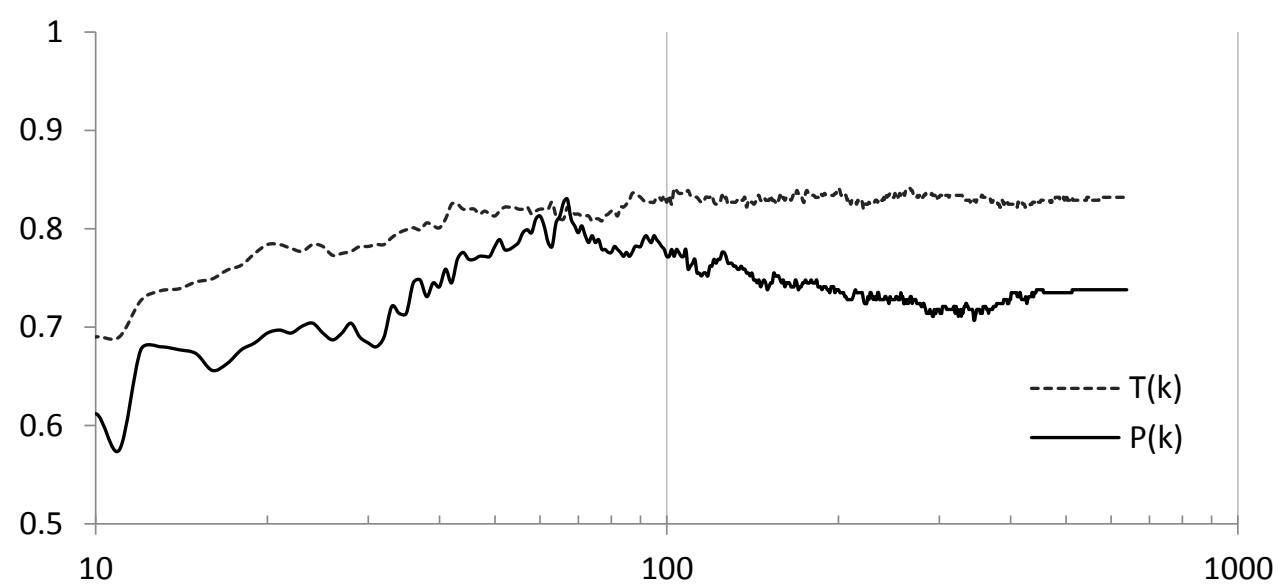

Figura 6.3 - Curvas $T(k)$ e $P(k)$ em relação aos dados $P 1$

No experimento usando o conjunto de dados $\mathrm{P} 1$, as curvas $\mathrm{T}(\mathrm{k})$ e $\mathrm{P}(\mathrm{k})$ apresentaram divergência no comportamento. $\mathrm{T}(\mathrm{k})$ teve um comportamento de crescimento constante e estabilizando após 100 dimensões. $\mathrm{P}(\mathrm{k})$ apresentou um pico de máximo em $\mathrm{k}=67$.

Apesar da hipótese de equivalência de $T(k)$ e $P(k)$, as curvas apresentaram uma divergência significativa. Repetimos o experimento usando os conjuntos de dados P2 e P3 para validar se esse resultado foi um caso específico relacionado a P1. Os resultados complementares estão apresentados no gráfico da Figura 6.4, no qual observamos novamente uma divergência entre o comportamento das curvas $T(k)$ e $P(k)$.

A explicação para essa diferença está relacionada aos conjuntos de treinamento e teste. Analisando manualmente a distribuição de categorias do conjunto de dados P1 (Tabela 6.1), observamos que os conjuntos de treinamento e de teste não possuem distribuições de dados semelhantes. A categoria "acq" representa $47 \%$ dos documentos de treinamento, mas corresponde a apenas $21 \%$ do conjunto de teste. A categoria "earn", por outro lado, é maioria no conjunto final de testes com $46 \%$ dos documentos, enquanto que compõe $23 \%$ dos dados de treinamento. As distribuições de documentos em P2 (Tabela 6.2) e P3 (Tabela 6.3) exibem a mesma irregularidade.

Portanto, identificamos um problema na forma de como os conjuntos de dados foram construídos e como isso afeta esse experimento. Os conjuntos de dados 


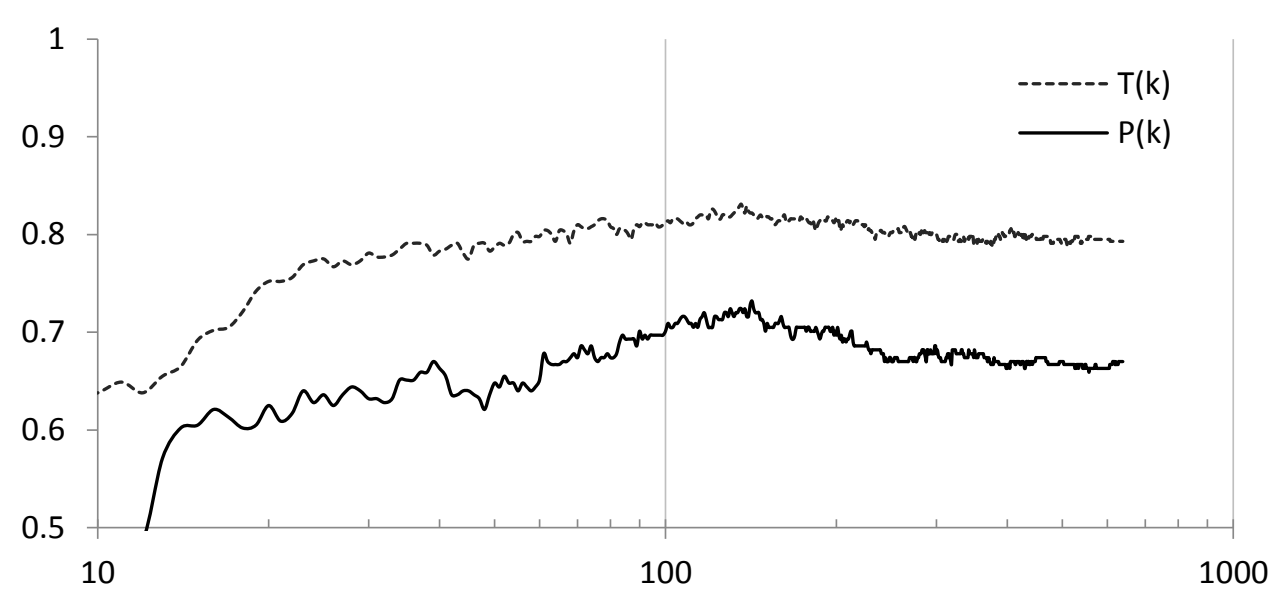

(a) Conjunto de dados P2

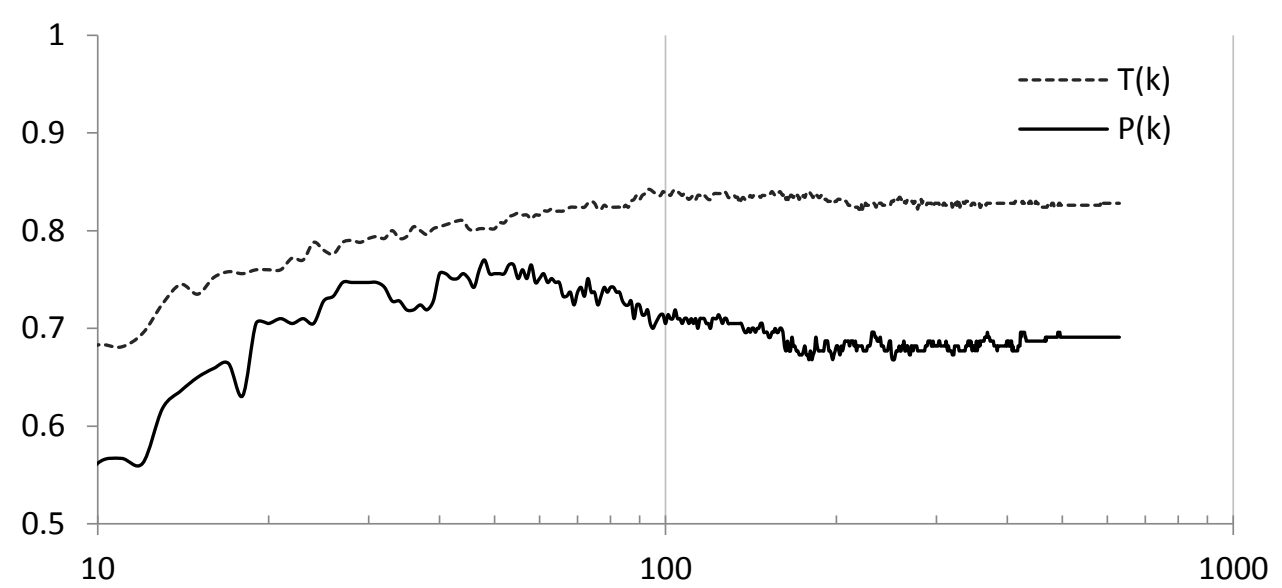

(b) Conjunto de dados P3

Figura 6.4 - Curvas $T(k)$ e $P(k)$ em relação aos dados $P 2$ e P3

As curvas $\mathrm{T}(\mathrm{k})$ e $\mathrm{P}(\mathrm{k})$ apresentaram divergência no comportamento. $\mathrm{T}(\mathrm{k})$ teve um comportamento de crescimento em ambos os gráficos. (a) A curva $\mathrm{P}(\mathrm{k})$ apresentou um valores abaixo de 0,72 e atingiu o ponto de máximo em $\mathrm{k}=117$. (b) $\mathrm{O}$ comportamento de $\mathrm{P}(\mathrm{k})$ foi completamente diferente de $\mathrm{T}(\mathrm{k})$, atingindo o ponto de máximo antes das 100 dimensões.

P1, P2 e P3 foram obtidos a partir dos arquivos selecionados do corpus Reuters 21578 e seguem a divisão padrão ModApté. A escolha de arquivos, no entanto, não seguiu nenhuma diretiva específica para garantir a mesma distribuição de categoria entre os conjuntos de treinamento e teste. 


\begin{tabular}{|c|c|c|}
\hline Categoria & Treinamento & Teste final \\
\hline Acq & $47 \%$ & $21 \%$ \\
\hline Earn & $23 \%$ & $46 \%$ \\
\hline Crude & $6 \%$ & $8 \%$ \\
\hline Trade & $4 \%$ & $5 \%$ \\
\hline Outros & $20 \%$ & $20 \%$ \\
\hline
\end{tabular}

Tabela 6.1 - Distribuição de documentos por assunto (P1)

\begin{tabular}{|c|c|c|}
\hline Categoria & Treinamento & Teste final \\
\hline Acq & $23 \%$ & $31 \%$ \\
\hline Earn & $45 \%$ & $22 \%$ \\
\hline Crude & $2 \%$ & $8 \%$ \\
\hline Trade & $5 \%$ & $4 \%$ \\
\hline Outros & $25 \%$ & $35 \%$ \\
\hline
\end{tabular}

Tabela 6.2 - Distribuição de documentos por assunto (P2)

\begin{tabular}{|c|c|c|}
\hline Categoria & Treinamento & Teste final \\
\hline Acq & $47 \%$ & $21 \%$ \\
\hline Earn & $23 \%$ & $46 \%$ \\
\hline Crude & $6 \%$ & $8 \%$ \\
\hline Trade & $4 \%$ & $5 \%$ \\
\hline Outros & $20 \%$ & $20 \%$ \\
\hline
\end{tabular}

Tabela 6.3 - Distribuição de documentos por assunto (P3)

Podemos provar que a diferença na distribuição de categorias afetou o resultado do experimento. Adotamos os conjuntos de dados P1-E, P2-E e P3-E como variações de P1, P2 e P3. A diferença é que os documentos foram misturados e embaralhados, logo depois, foram divididos em conjuntos de treinamento e de teste. Os resultados dos experimentos estão na Figura 6.5. Com exatamente os mesmos documentos, porém redistribuídos aleatoriamente entre treinamento e teste, as curvas $T(k)$ e $P(k)$ apresentam o mesmo padrão.

A conclusão é que o experimento requer que os conjuntos de treinamento e de teste sejam conjuntos aleatórios. Uma definição mais clara de aleatório é considerar que ambos foram obtidos por amostragens a partir de uma coleção de documentos. Devido à forma de construção aleatória dos subconjuntos, eles devem possuir distribuições semelhantes. Quando os documentos de treinamento não refletem os dados de teste, então o resultado pode ser inadequado. 


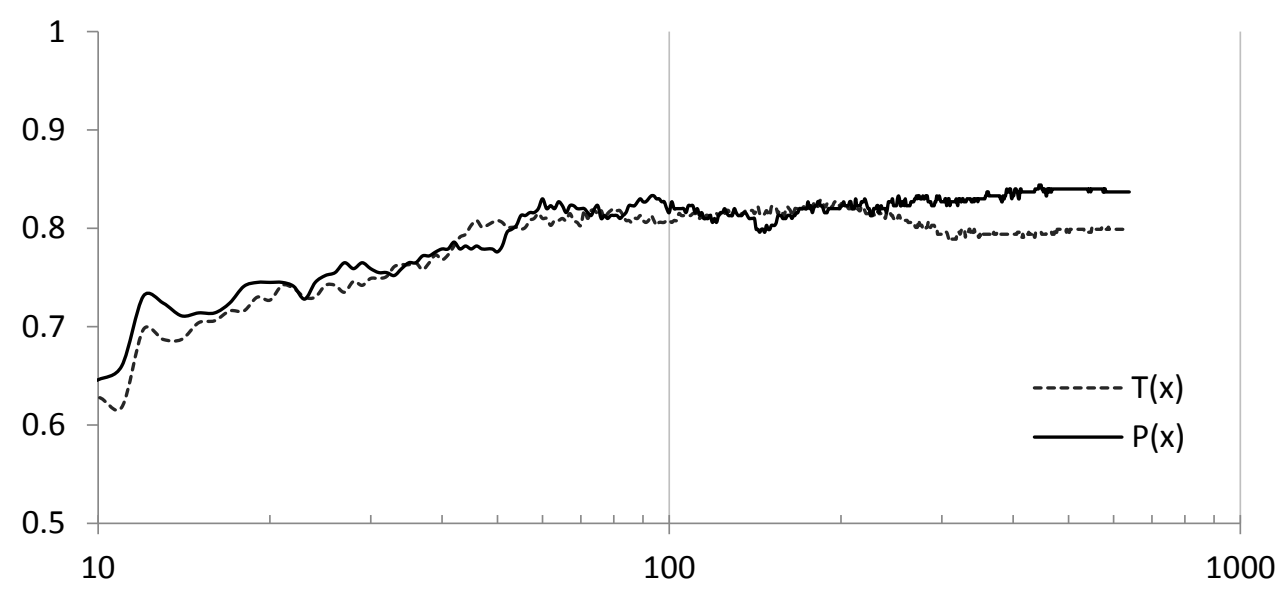

(a) Conjunto de dados P1-E (embaralhado)

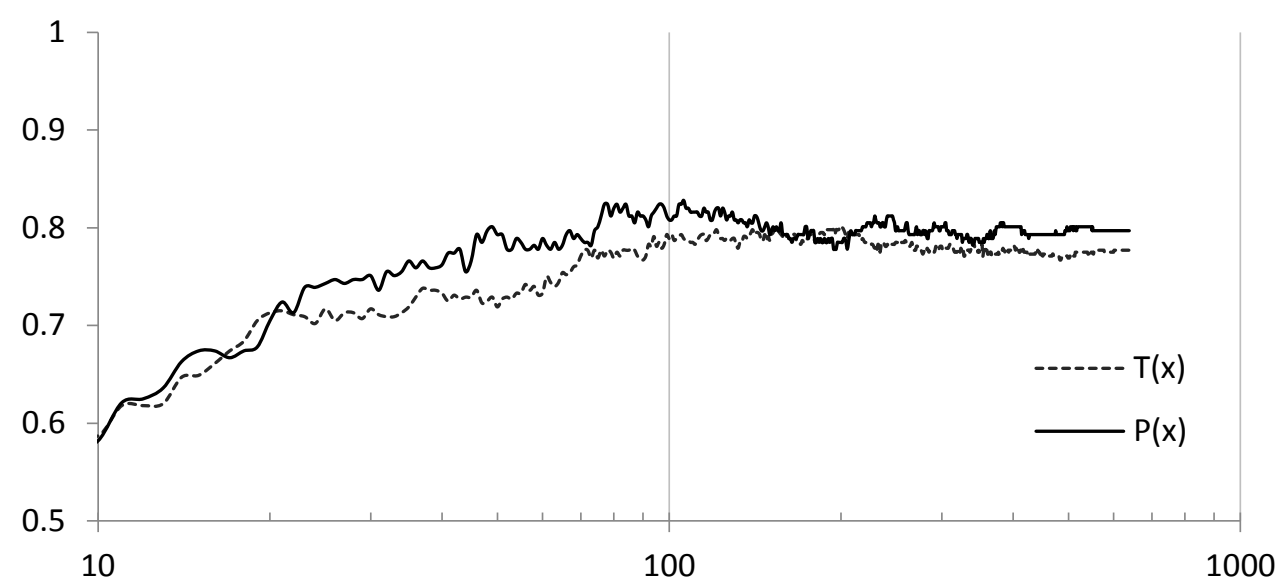

(b) Conjunto de dados P2-E (embaralhado)

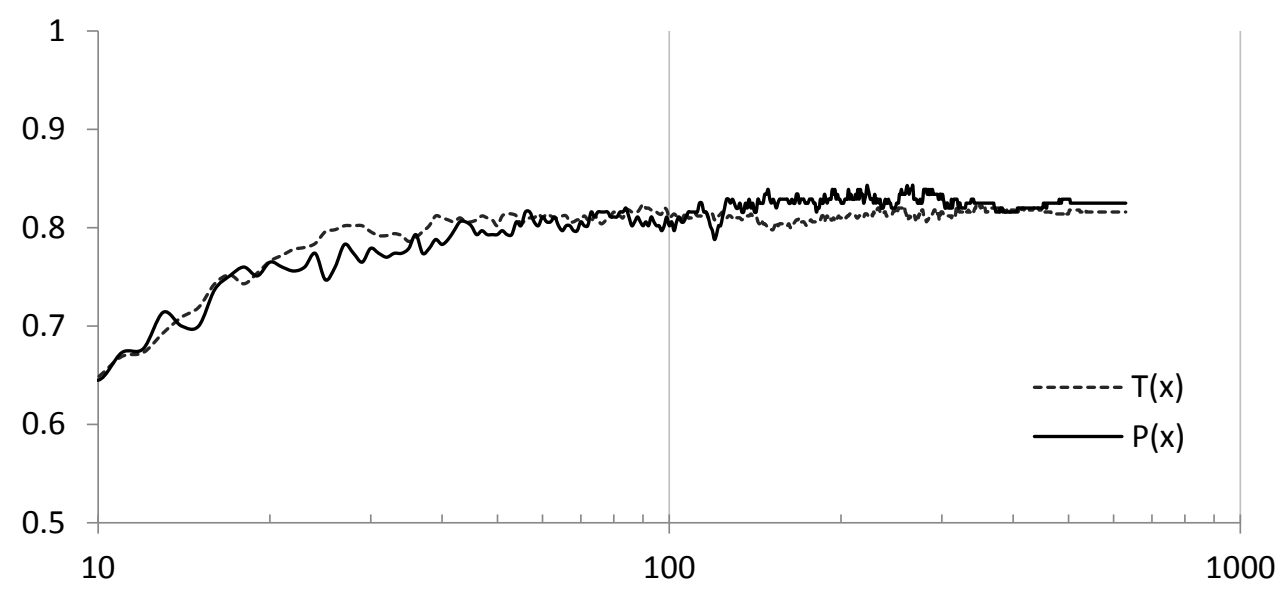

(c) Conjunto de dados P3-E (embaralhado)

Figura 6.5 - Desempenho dos conjuntos de dados com distribuição aleatória

Para cada a amostra de dados, os conjuntos de treinamento e teste foram misturadas e depois separadas de forma aleatória em dois novos conjuntos. A esses novos conjuntos de dados, denominamos de P1-E, P2-E e P3-E. Como as categorias estão distribuídas igualmente entre treinamento e testes, os resultados (a), (b) e (c) foram dentro da expectativa. 


\subsection{Resultados Finais}

A coleção de texto Reuters $\mathrm{R} 8$, em número de documentos, é significativamente maior do que os conjuntos $\mathrm{P} 1$ a P5, porém, limitado às oito categorias mais comuns. A partir das amostras previamente classificadas, aplicamos o algoritmo para traçar a curva $T(k)$, conforme ilustrado na Figura 6.6.

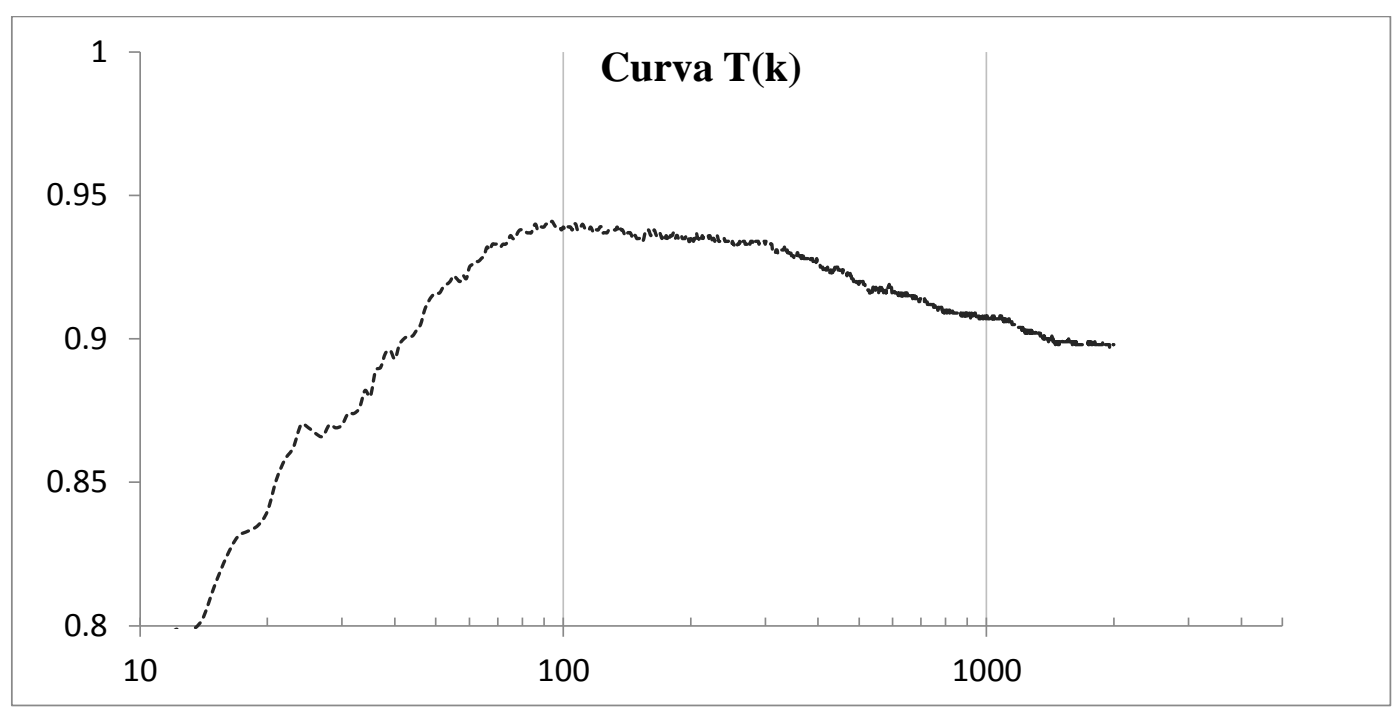

Figura 6.6 - Taxa de acerto $T(k)$ do Reuters $R 8$

A curva $\mathrm{T}(\mathrm{k})$ representa a quantidade de acertos obtidos com os documentos de treinamento no modelo, enquanto se varia o parâmetro de dimensão k

Segundo as análises realizadas nos experimentos anteriores (Tabela 6.4), a dimensão $k=100$ apresentou o melhor desempenho na tarefa de classificação do conjunto Reuters R8. Esse é um indicativo positivo de que a curva tem relação com o desempenho experimental. Na Figura 6.7, comparamos, em seguida, as curvas $T(k)$ e $P(k)$.

$\begin{array}{ccc}\mathbf{k}=\mathbf{1 0 0} & \mathbf{k}=\mathbf{2 0 0} & \mathbf{k}=\mathbf{4 0 0} \\ 95,2 & 94,5 & 93,9\end{array}$

Tabela 6.4 - Desempenho da classificação do Reuters R8 usando LSA

Os documentos foram classificados através da análise semântica latente usando diferentes valores para o parâmetro $\mathrm{k}$. A melhor taxa de acerto foi para k=100 com $95,2 \%$ de precisão. 
A fim de avaliar o efeito da aleatoriedade, criamos conjuntos aleatórios para um novo experimento. Os documentos usados são exatamente os mesmos do Reuters R8, sendo divididos em textos para treinamento e teste proporcionalmente ao tamanho original. A seleção de documento para esse novo conjunto de dados, denominado R8-E, foi feita de forma aleatória. O resultado está apresentado na Figura 6.8.

A diferença percentual entre $T(k)$ e $P(k)$ foi menor do que 2,5\% (Figura 6.9) e claramente menor do que nos experimentos preliminares com os conjuntos de dados P1, P2 e P3. Uma possível explicação para esse comportamento é o aumento no número de documentos utilizados. Como os conjuntos de treinamento e teste são maiores, o erro associado diminui.

\subsection{Conclusão}

A escolha do número de dimensão $k$ afeta diretamente o desempenho do classificador de texto. Utilizar valores abaixo ou acima do ideal pode degradar o resultado final. A proposta do trabalho foi utilizar os dados de treinamento para apoiar na decisão do $k$ ideal, transformando o algoritmo da análise da semântica latente em uma aprendizagem semi-supervisionada.

No experimento, observamos o comportamento de quando os conjuntos não apresentam a mesma distribuição de categorias entre eles. A hipótese de igualdade entre $T(k)$ e $P(k)$ se torna inválida. Nesse caso, torna-se inviável utilizar a técnica proposta.

Assumimos que a distribuição de dados entre os documentos de treinamento e teste são semelhantes. Nesse caso, a hipótese foi válida e $T(k)=P(k)$. No caso do conjunto R8, o erro foi inferior a $2,5 \%$ e poderia ser menor se aumentássemos a quantidade de dados. A proposta do experimento foi validada e demonstrou-se uma forma de determinar o parâmetro $k$ ideal com apenas os dados de treinamento. 


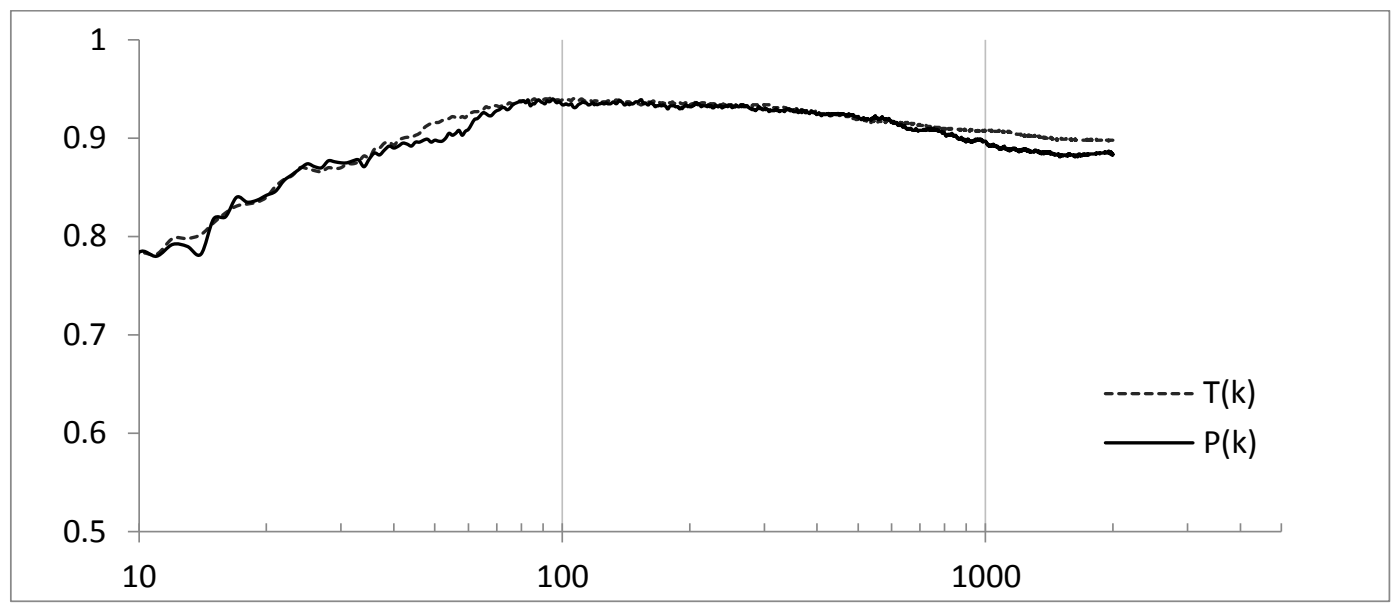

Figura 6.7 - Determinando a dimensão ideal em Reuters $R 8$

As curvas $\mathrm{T}(\mathrm{k})$ e $\mathrm{P}(\mathrm{k})$ seguem próximas uma da outra. Isso confirma a hipótese de que é possível determinar a dimensão ideal do modelo com base em $\mathrm{T}(\mathrm{k})$.

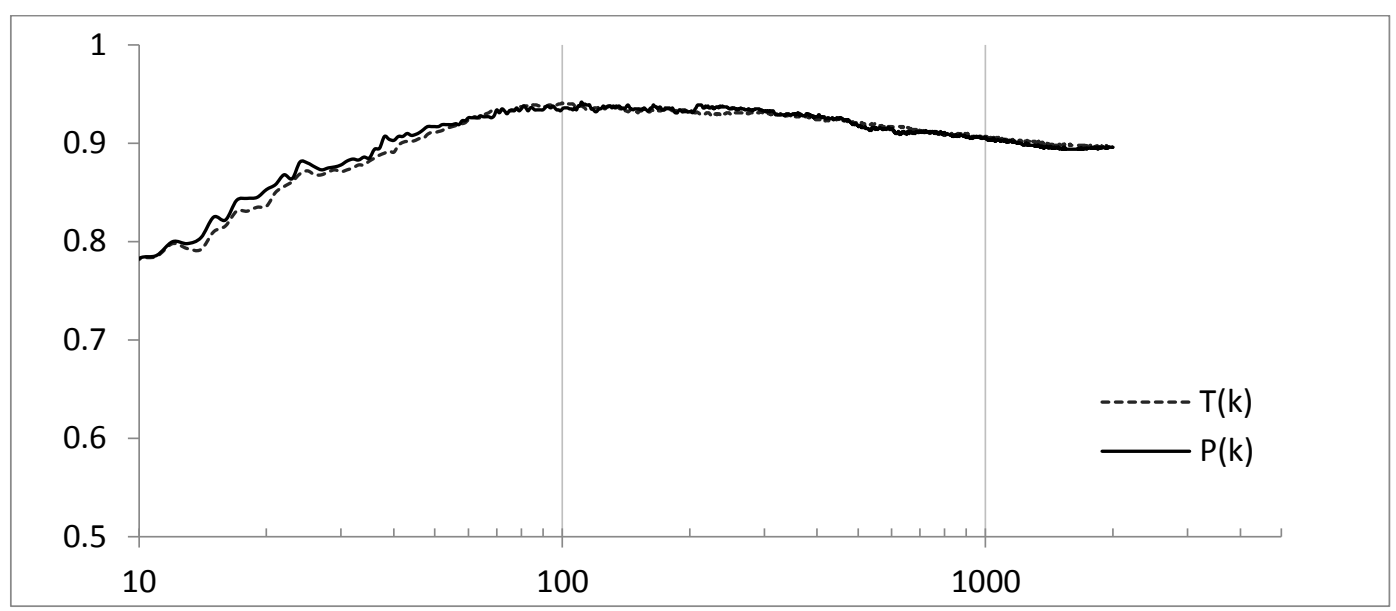

Figura 6.8 - Avaliação da aleatoriedade usando os dados R8-E

$\mathrm{O}$ experimento de determinação de dimensão foi repetido para o conjunto Reuters R8. Entretanto, dessa vez redistribuímos os documentos entre treinamento e teste de forma aleatória. As curvas $\mathrm{T}(\mathrm{k})$ e $\mathrm{P}(\mathrm{k})$ estão muito próximas.

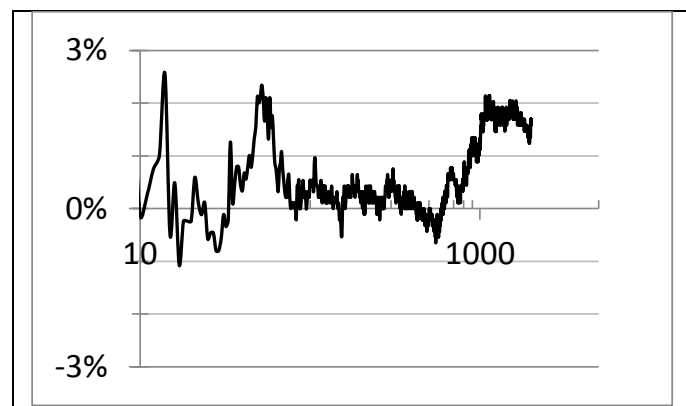

(a) Reuters R8

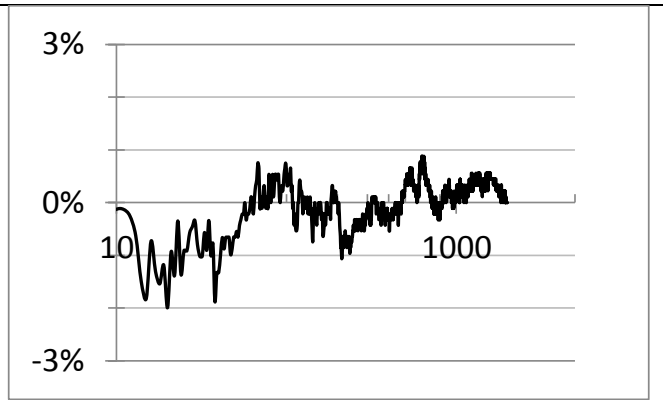

(b) R8-E

Figura 6.9 - Diferença percentual entre $T(k)$ e P $(k)$ em Reuters $R 8$

A diferença percentual entre as curvas $\mathrm{T}(\mathrm{k})$ e $\mathrm{P}(\mathrm{k})$ é menor do que 2,5\%. Uma explicação para a pequena diferença percentual é o aumento no número de documentos utilizados para treinamento e teste. 


\section{Algoritmo Mais EfiCIENTE}

A análise da semântica latente (Latent Semantic Analysis, LSA) é uma técnica capaz de determinar relações indiretas entre palavras e documentos. Como já foi observado nas coleções de texto do Text REtrieval Context (DUMAIS, 1993) e sua influência na prova de sinônimos do ETS Test of English as a Foreign Language (TOEFL) (LANDAUER, FOLTZ e LAHAM, 1998), a escolha do número de dimensões (parâmetro $k$ ) afeta diretamente as taxas de precisão e de recuperação.

Uma das propostas desse trabalho foi utilizar os dados de treinamento para apoiar na decisão do $k$ ideal (Algoritmo 7.1), que projeta todos os documentos em uma dimensão reduzida. O processo é iterativo, variando-se o parâmetro $k$ e percorrendo todas as dimensões. Em cada projeção, o conjunto de treinamento é usado para estimar a taxa de acertos referente àquele modelo. A escolha de $k$ é feita com base nessas avaliações.

Apesar dos resultados favoráveis em relação à funcionalidade do algoritmo, o tempo de processamento aumentou significativamente. A execução se tornou extremamente mais lenta em relação a outras técnicas. Utilizando uma massa de dados composta por apenas 1000 documentos, o processo de determinação de $k$ demorou 25 minutos. Por outro lado, esses mesmos documentos foram processados em apenas 11 segundos pelo LSA com 300 dimensões. A diferença foi de 136 vezes.

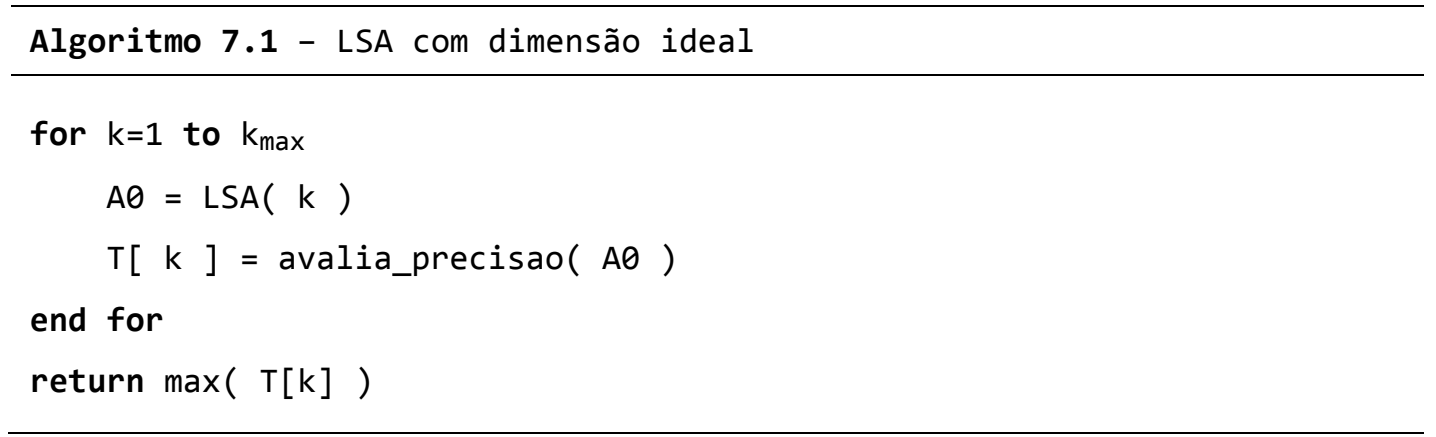




\subsection{Proposta}

O problema é rapidamente compreendido ao rever a lógica do algoritmo. A cada iteração de $k=1,2, \ldots, n$, realizam-se os cálculos de decomposição em valores singulares, multiplicação matricial e produto escalar. Esses cálculos são repetidos $n$ vezes ao longo do processo. O objetivo do experimento é transformar esse processo em uma sequência de passos incrementais, de forma que o processo reaproveite as informações calculadas nas etapas anteriores.

\subsubsection{Cálculo Único do SVD}

A decomposição em valores singulares (Singular Value Decomposition, SVD) de matrizes utiliza as funções da biblioteca SVDPACKC (BERRY, 1993). A determinação dos valores singulares é feita através do método iterativo de Lanczos. A cada iteração $k=1,2, \ldots, n$, repetimos o cálculo de decomposição de matriz, que internamente realizam operações custosas de multiplicação de matrizes. Se modificarmos o algoritmo atual para minimizar o número de chamadas à biblioteca SVDPACKC, o tempo total de processamento irá diminuir.

O cálculo único do SVD é realizado usando a maior dimensão necessária $k_{\max }$ e, depois, o resultado é mantido em memória para ser reaproveitado. A cada iteração, a decomposição de matriz é obtida ao se truncar os $k$ maiores valores singulares da matriz em memória, evitando chamar novamente a biblioteca matemática. Apesar de ser uma alteração simples (Algoritmo 7.2), o tempo economizado foi significativo.

\subsubsection{Projeção da Matriz Termo-Documento}

A decomposição de matriz em valores singulares desempenha um papel central na análise da semântica latente. A matriz termo-documento $A$ pode ser escrita como o produto de matrizes:

$$
A=U \Sigma V^{T}
$$




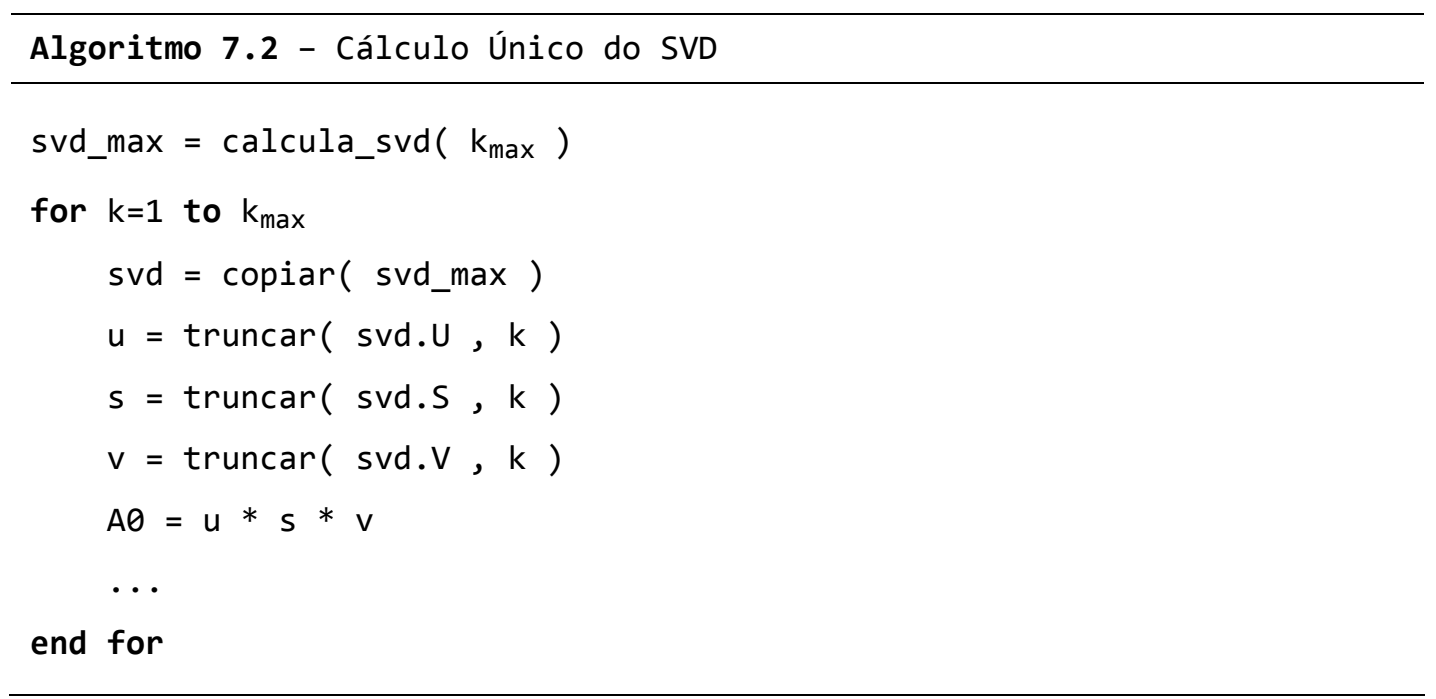

Truncando as matriz $U, \Sigma, V$ com os $k$ maiores valores singulares, obtemos uma aproximação $A_{0}$ da matriz $A$ :

$$
A_{0}=U_{0} \Sigma_{0} V_{0}^{T}
$$

Nesse espaço, podemos calcular a similaridade pelo cosseno do ângulo formado entre os vetores:

$$
\begin{aligned}
& \operatorname{similar}(i, j)=\cos \left(\widehat{d}_{\imath}, \widehat{d}_{J}\right) \\
& \operatorname{similar}(i, j)=\frac{\widehat{d}_{\imath} \cdot \widehat{d}_{J}}{\left\|\widehat{d}_{\imath}\right\| \cdot\left\|\widehat{d}_{J}\right\|}
\end{aligned}
$$

Onde $\widehat{d}_{\iota}$ e $\widehat{d}_{\jmath}$ são colunas de $A_{0}$ correspondentes aos documentos.

Ao invés de trabalharmos com as colunas de $A_{0}$, aplicaremos uma transformação linear para projetar em outro espaço. Definimos a matriz $B$ como a multiplicação da transposta da matriz $U \operatorname{com}$ a matriz $A$ :

$$
\begin{aligned}
B & =U^{T} A \\
& =U^{T}\left(U \Sigma V^{T}\right) \\
& =\left(U^{T} U\right) \Sigma V^{T}
\end{aligned}
$$

A matriz $U^{T}$ é unitária e ortogonal, ou seja, $U^{T} U=I$. Logo, 


$$
\begin{aligned}
B & =I \Sigma V^{T} \\
& =\Sigma V^{T}
\end{aligned}
$$

Tomamos os documentos como colunas da matriz $B$.

Essa é uma proposição diferente da exposta por Berry (1995), na qual os documentos são as linhas da matriz $V$. Uma das diferenças é que os espaços $A$ e $B$ são isométricos, ou seja, a distância entre pontos, o produto escalar e o cosseno se mantém após a projeção. Podemos interpretar a multiplicação por $U^{T}$ como uma rotação de vetores. Assim, podemos calcular a similaridade de forma análoga usando os vetores projetados para representar os documentos:

$$
\operatorname{similar}(i, j)=\cos \left(\widehat{d}_{l}, \widehat{d}_{J}\right)=\cos \left(\widehat{b}_{l}, \widehat{b}_{J}\right)
$$

Onde $\widehat{b}_{\imath}$ e $\widehat{b_{J}}$ são colunas de $B$.

A demonstração da equivalência de similaridade será feita nos lemas 1 e 2 a seguir. Serão demonstrados que os espaços são, de fato, isométricos e mantém as propriedades de distância entre pontos e produto escalar.

Lema 1: Seja d um vetor coluna de tamanho $m$. Considere uma matriz $U$ de tamanho $m \times n$, tal que $U U^{\mathrm{T}}=I_{\mathrm{m}}$. Então, temos que $\|d\|=\left\|U^{\mathrm{T}} d\right\|$.

Demonstração: Representamos o módulo do vetor como um produto de matrizes:

$$
\begin{aligned}
\|d\| & =d^{\mathrm{T}} d \\
& =\left(d^{\mathrm{T}} I_{\mathrm{m}}\right) d \\
& =\left(d^{\mathrm{T}} U U^{\mathrm{T}}\right) d \\
& =\left(d^{\mathrm{T}} U\right)\left(U^{\mathrm{T}} d\right) \\
& =\left(d^{\mathrm{T}} U\right)\left(d^{\mathrm{T}} U\right)^{\mathrm{T}} \\
& =\left(U^{\mathrm{T}} d\right)^{\mathrm{T}}\left(U^{\mathrm{T}} d\right) \\
& =\left\|U^{\mathrm{T}} d\right\|
\end{aligned}
$$


Lema 2: Sejam A, B vetores colunas de tamanho $m$. Definimos o produto escalar dos vetores por:

$$
\operatorname{dot}(a, b)=a^{\mathrm{T}} b
$$

Dada uma matriz $U$ de tamanho $m \times n$, tal que $U U^{\mathrm{T}}=I_{\mathrm{m}}$, então:

$$
\operatorname{dot}(a, b)=\operatorname{dot}\left(U^{\mathrm{T}} a, U^{\mathrm{T}} b\right)
$$

Demonstração: Por definição, produto escalar é dado por:

$$
\begin{aligned}
\operatorname{dot}(a, b) & =a^{\mathrm{T}} b \\
& =a^{\mathrm{T}} I_{\mathrm{m}} b \\
& =a^{\mathrm{T}}\left(U U^{\mathrm{T}}\right) b \\
& =\left(a^{\mathrm{T}} U\right)\left(U^{\mathrm{T}} b\right) \\
& =\left(U^{\mathrm{T}} a\right)^{\mathrm{T}}\left(U^{\mathrm{T}} b\right) \\
& =\operatorname{dot}\left(U^{\mathrm{T}} a, U^{\mathrm{T}} b\right)
\end{aligned}
$$

Como as matrizes são isométricas e mantém as características de distância entre pontos e o produto escalar, então a similaridade apresenta a mesma fórmula e resultado:

$$
\operatorname{similar}(i, j)=\frac{\widehat{b}_{l} \cdot \widehat{b}_{J}}{\left\|\widehat{b}_{l}\right\| \cdot\left\|\widehat{b}_{J}\right\|}
$$

A matriz $B$ tem tamanho $m \times k$ e pode ser calculada facilmente pela multiplicação da matriz diagonal $\Sigma_{0}$ pela matriz $V_{0}$. Se considerar o espaço de dimensão reduzida $B$ ao invés da matriz aproximada $A_{0}=U_{0} \Sigma_{0} V_{0}{ }^{\mathrm{T}}$, evitamos uma multiplicação matricial por $U_{0}$ (Algoritmo 7.3).

$$
B=U_{0}^{\mathrm{T}} A_{0}=\Sigma_{0} V_{0}^{\mathrm{T}}
$$




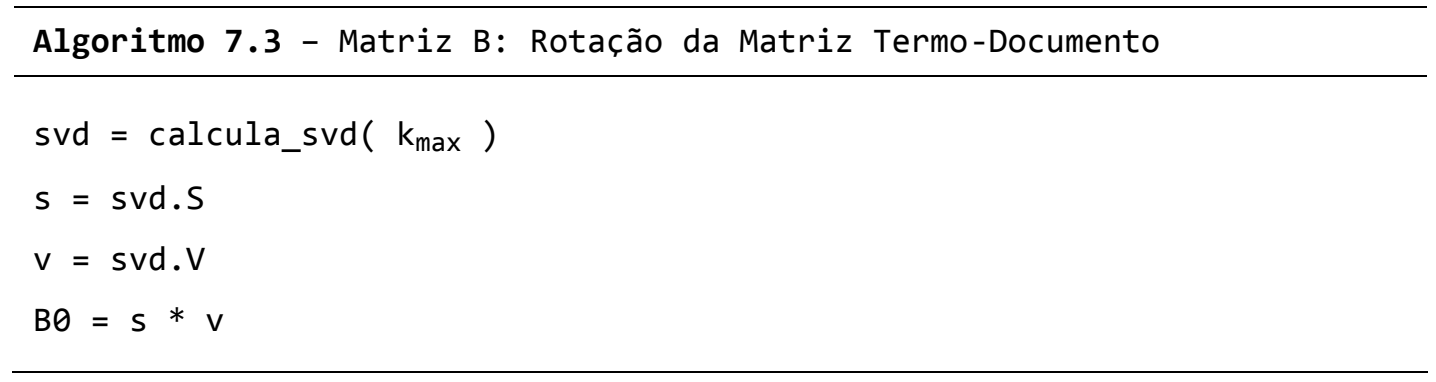

\subsubsection{Cálculo Incremental da Similaridade}

Adotamos a matriz $B$ truncada em $k$ dimensões, que equivale ao espaço semântico com parâmetro $k$. Durante a fase de treinamento, variamos o parâmetro $k$ entre 1 a $n$, com o objetivo de traçar a curva $T(k)$ e determinar o pico de máximo. A cada iteração de $k$, determinamos a similaridade dentre todos os $m$ documentos.

Considerando a representação dos documentos como $\widehat{b_{l}^{k}}=\left(b_{i 1}, b_{i 2}, \ldots, b_{i k}\right)$, um vetor de dimensão truncada em $k$, a similaridade será dada por:

$$
\operatorname{similar}(i, j, k)=\frac{\widehat{b_{l}^{k}} \cdot \widehat{b_{J}^{k}}}{\left\|\widehat{b_{l}^{k}}\right\| \cdot\left\|\widehat{b_{J}^{k}}\right\|}
$$

Onde $i$ e $j$ identificam os documentos a serem comparados.

Podemos definir as funções de produto escalar e o quadrado do módulo como somatório de produtos:

$$
\begin{gathered}
\operatorname{Prod}(i, j, k)=\widehat{b_{l}^{k}} \cdot \widehat{b_{J}^{k}}=\sum_{t}^{k} b_{i t} b_{i t} \\
\operatorname{Mods}(i, k)=\left\|\widehat{b_{l}^{k}}\right\|^{2}=\sum_{t}^{k}\left(b_{i t}\right)^{2}
\end{gathered}
$$

Assim, reescrevemos a similaridade por:

$$
\operatorname{similar}(i, j, k)=\frac{\operatorname{Prod}(i, j, k)}{\sqrt{\operatorname{Mods}(i, k) \cdot \operatorname{Mods}(j, k)}}
$$




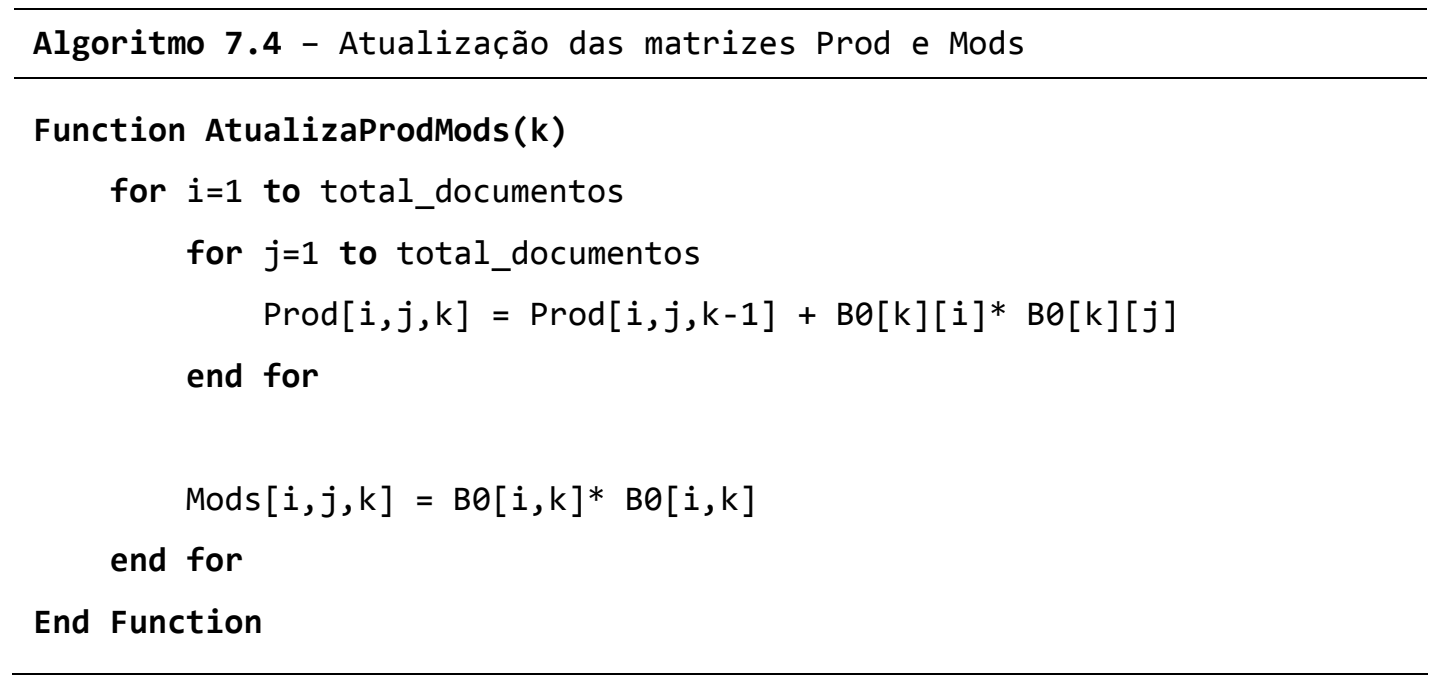

Cada operação de Prod e Mods requer $n$ operações (considerando somente multiplicação, divisão e raiz quadrada). No entanto, o ideal seria calcular a similaridade de forma incremental, conforme se aumenta o número de dimensões. Se transformarmos Prod e Mods em funções recursivas, então é possível eliminar o somatório de produtos. A cada iteração, são realizadas somente duas operações de multiplicações.

$$
\begin{gathered}
\operatorname{Prod}(i, j, k)=\operatorname{Prod}(i, j, k-1)+b_{i k} \cdot b_{j k} \\
\operatorname{Mods}(i, k)=\operatorname{Mods}(i, k-1)+\left(b_{i k}\right)^{2}
\end{gathered}
$$

O algoritmo de cálculo incremental de similaridade depende da função AtualizaProdMods, que atualiza as matrizes Prod e Mods (Algoritmo 7.4). A função recebe o parâmetro $k$ de entrada, referente à qual dimensão será atualizada. Esse é um parâmetro incremental. Utiliza-se a matriz $B_{0}{ }^{\mathrm{k}}$, calculada logo após a decomposição em valores singulares (Algoritmo 7.3), para calcular o produto escalar e o quadrado do módulo.

O cálculo da similaridade entre documentos assume que as matrizes Prod e Mods estão atualizadas na dimensão correta e retorna o grau de similaridade por cosseno (Algoritmo 7.5). 


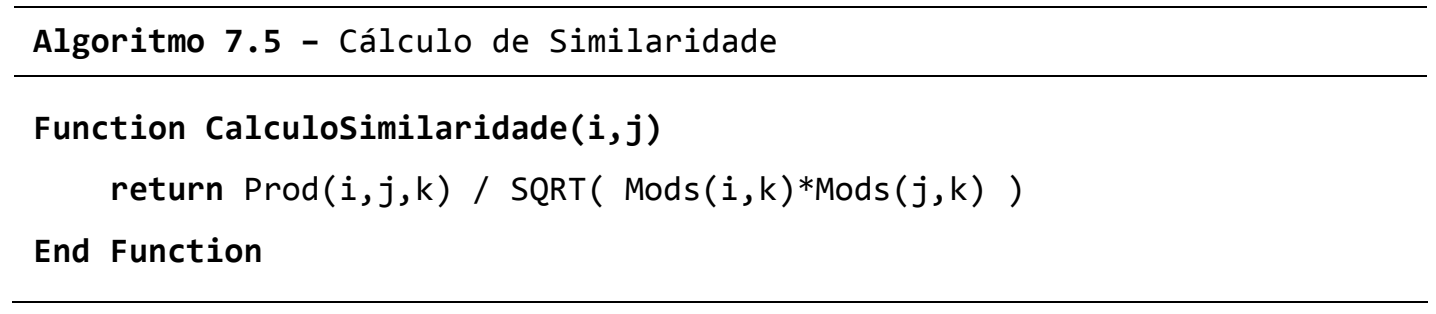

\subsection{Experimento}

Utilizamos o corpus Reuters R135 com a separação padrão conhecida por ModApté. Os vetores resultantes do conjunto de treinamento e testes foram colocados em uma matriz termo-documento de tamanho $m \times n$. A decomposição em valores singulares foi realizada por meio da biblioteca SVDPACKC usando o número máximo de dimensões $k_{\max }$. Como resultado, obtivemos as matrizes $U, \Sigma$ e $V$. Os vetores singulares foram armazenados em memória para garantir o cálculo único do SVD.

Assim chegamos às matrizes $U_{0}, \Sigma_{0}$ e $V_{0}$, podendo calcular a matriz $B_{0}$ de tamanho truncado de $m \times k$.

$$
B_{0}=\Sigma_{0} V_{0}^{\mathrm{T}}
$$

A matriz $A_{0}$, aproximação da matriz termo-documento, é calculada apenas para efeito de comparação, entretanto, não é usada na predição. Ainda na fase inicial, fazemos uma prévia da classificação usando o cálculo da similaridade com os documentos de treinamento.

O cálculo de similaridade entre documentos é feito da forma incremental. As matrizes Prods e Mods são atualizadas por uma função AtualizaProdMods, que utiliza os valores da matriz $B_{0}$ referentes à dimensão $k$. O cálculo de similaridade determina quais são os documentos de mesma categoria através da classificação pelo vizinho mais próximo. Os documentos que apresentam maior similaridade estão, portanto, na mesma categoria. Dessa forma, é possível determinar a taxa de acerto relacionada aos dados de treinamento. Nesse processo, varia-se o número de dimensão $k$ entre 2 a 2000 para obter a curva $T(k)$.

Ao final do experimento, os tempos são comparados. 


\subsection{Resultados Preliminares}

Avaliamos os tempos de processamento dos conjuntos de dados P1 a P5, quando utilizado o parâmetro máximo de dimensões $k_{\max }=100$. A diferença entre os tempos foi significativa, sendo cerca de 10 vezes mais rápido (Figura 7.1).

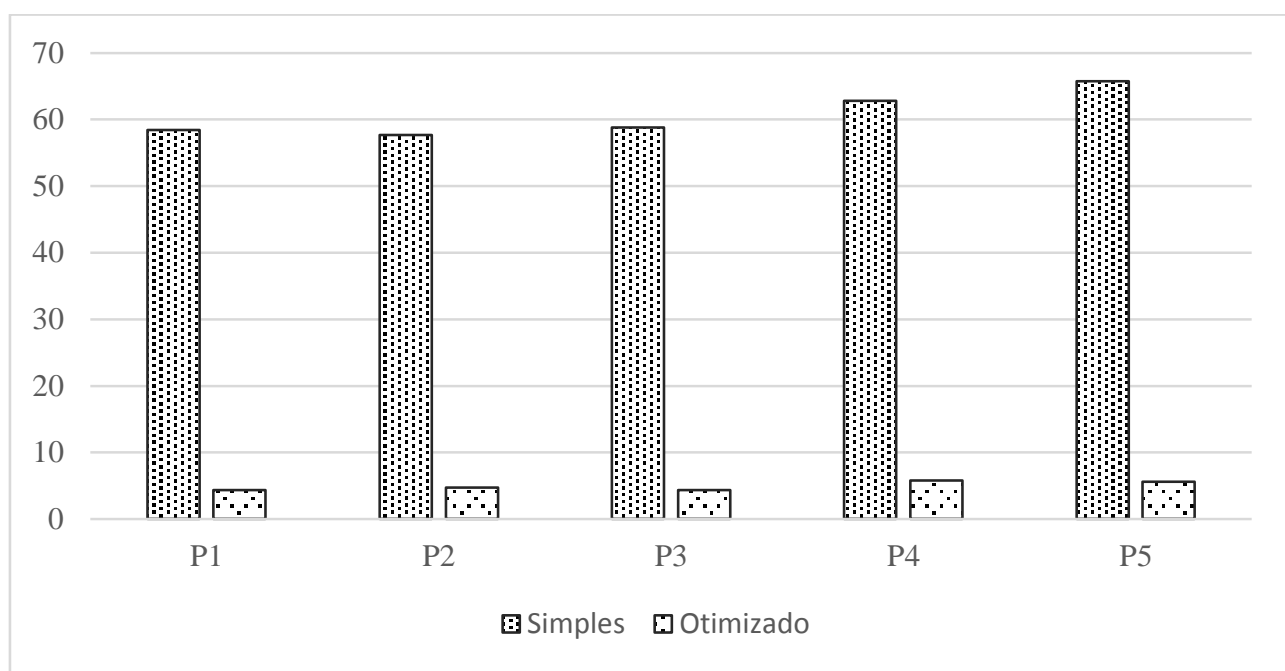

Figura 7.1 - Tempo gasto pelos métodos simples e otimizado (segundos)

Enquanto o método simples faz o cálculo completo do LSA para todas as dimensões, o método otimizado utiliza cálculos incrementais para reaproveitar os resultados obtidos nas etapas anteriores

Os tempos apresentados pelo método simples tornam o algoritmo inviável sem nenhuma otimização adicional. Foram medidos individualmente o tempo gasto entre SVD e Matriz:

- SVD - Tempo gasto durante o acesso à biblioteca SVDPACKC para decompor a matriz em valores singulares. O cálculo único do SVD tem a finalidade de reduzir esse tempo, pois as múltiplas chamadas à biblioteca serão convertidas em apenas uma.

- Matriz - Tempo gasto relacionado com multiplicação de matrizes e projeção de vetores. O cálculo incremental de similaridade evita a multiplicação das matrizes e transforma a projeção de vetores em uma função recursiva e incremental. 
Considerando que a dimensão ideal se situa entre 100 a 300, então repetimos o experimento para $k_{\max }=400$. A Tabela 7.1 apresenta os tempos gastos para o método simples e otimizado, separando entre as fases do cálculo do SVD e de multiplicação de matrizes e vetores. Além do ganho de desempenho, os tempos apresentados mostram que há um equilíbrio entre o tempo gasto nas etapas SVD e Matriz.

\begin{tabular}{|c|ccc|ccc|}
\hline Conjunto de & \multicolumn{3}{|c|}{ Simples } & \multicolumn{3}{c|}{ Otimizado } \\
\cline { 2 - 7 } Dados & SVD & Matriz & Total & SVD & Matriz & Total \\
\hline P1 & 689,2 & 689,2 & 1469 & 9,2 & 9,4 & 18 \\
P2 & 743,8 & 743,8 & 1619 & 9,5 & 8,9 & 18 \\
P3 & 742,4 & 742,4 & 1367 & 9,7 & 8,5 & 18 \\
P4 & 775,65 & 1158,8 & 1934 & 13,6 & 11,2 & 25 \\
P5 & 755,4 & 1149,6 & 1905 & 12,6 & 9,2 & 22 \\
\hline
\end{tabular}

Tabela 7.1 - Comparação de tempo dos métodos simples e otimizado

O tempo em segundos apresentado está dividido nas fases de SVD e Matriz.

\subsection{Resultados Finais}

Para validar os resultados em um conjunto maior de dados, repetimos os testes com o conjunto Reuters R135. Variou-se o número de dimensão $k$ de 10 a 400, obtendo o resultado apresentado na Tabela 7.2. Ao analisar as informações em um gráfico de escala logarítmica (Figura 7.2), observamos que os tempos do método simples e do otimizado possuem inclinação semelhante conforme se aumenta o número de dimensões $k_{\max }$.

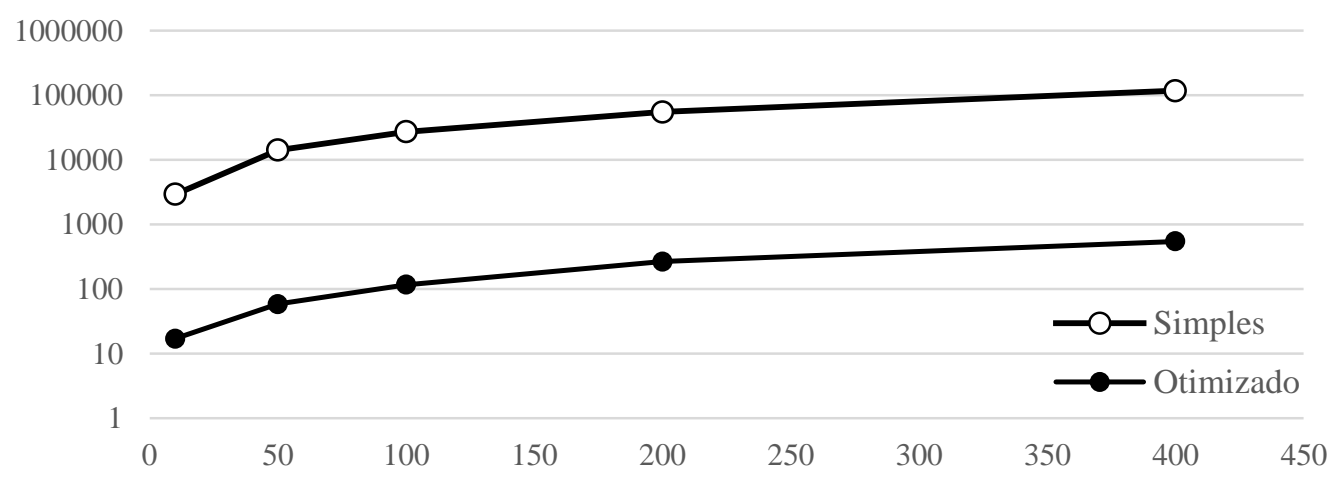

Figura 7.2 - Comparação dos tempos em escala logarítmica

$\mathrm{Na}$ escala logarítmica, fica evidente que os tempos simples e otimizado possuem um comportamento semelhante, embora haja uma grande diferença de magnitude. 


\begin{tabular}{|cccccc|}
\hline $\mathbf{k}_{\max }$ & $\mathbf{1 0}$ & $\mathbf{5 0}$ & $\mathbf{1 0 0}$ & $\mathbf{2 0 0}$ & $\mathbf{4 0 0}$ \\
\hline Simples & 2919 & 14063 & 27071 & 54695 & 117169 \\
\hline Otimizado & 17 & 58 & 116 & 265 & 544 \\
\hline
\end{tabular}

Tabela 7.2 - Tempo gasto pelos métodos simples e otimizado no Reuters R135

A diferença de tempo entre os métodos simples e otimizado é significativa.

Continuamos a investigação do tempo gasto nas etapas de SVD e Matriz usando o corpus Reuters R8 (Figura 7.3). Conforme se incrementava o número de dimensões, observamos que a porcentagem de tempo gasto em cada etapa se alterava.

Apesar do algoritmo de decomposição em valores singulares (SVD) ser custoso, o tempo de processamento relacionado às tarefas matriciais, multiplicação de matrizes e projeção de vetores, sobrepunha-se sobre o tempo de SVD. Isso está relacionado com o cálculo repetitivo necessário para traçar a curva $T(k)$, na qual todos os documentos de treinamento são avaliados em um modelo de $k$ dimensões.

Uma última ideia seria aplicar a técnica do LSA individualmente para as dimensões $k=50,100,200,400$ e traçar os pontos de $T(k)$ para esses valores. Nesse caso, o método simples demorou 779 segundos para calcular as taxas de acerto. Adaptamos o algoritmo proposto para calcular $T(k)$ nessas dimensões usando o cálculo único do SVD e o incremental de similaridade. O tempo gasto pelo método otimizado foi de 468 segundos. Portanto, podemos escolher uma forma arbitrária de incrementar $k$, não sendo necessariamente um valor unitário.

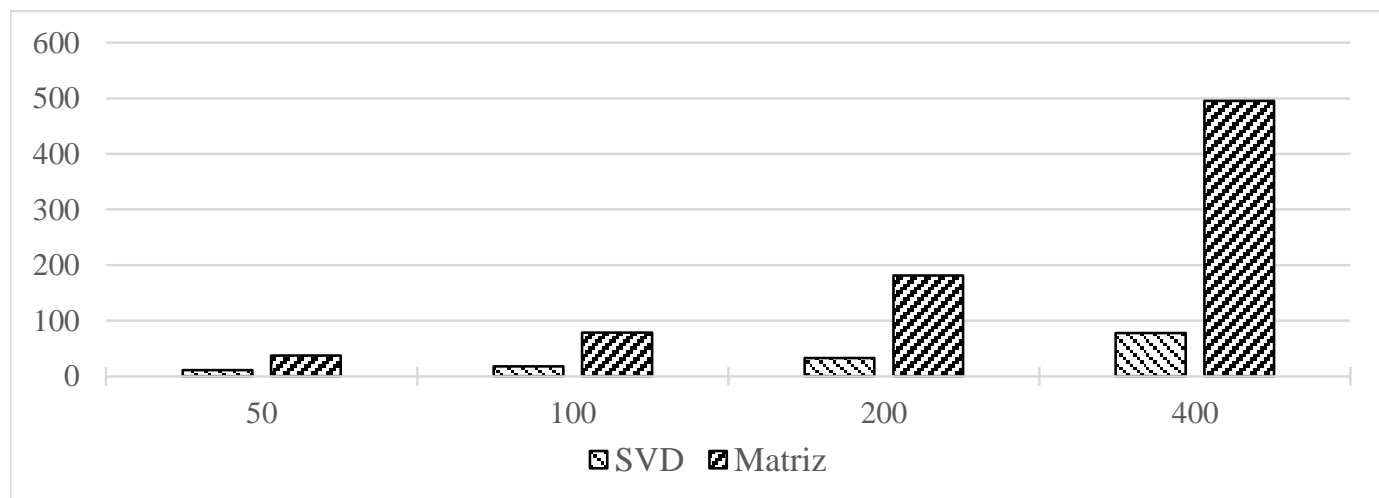

Figura 7.3 - Tempo gasto nas etapas SVD e Matriz

O tempo gasto na etapa matriz cresce consideravelmente conforme aumenta-se o número de dimensões. Esse crescimento é superior ao tempo gasto no processo de decomposição matricial (SVD). 


\subsection{Conclusão}

$\mathrm{Na}$ proposta desse experimento, apresentamos formas de aperfeiçoar o algoritmo para que rodasse dentro de um tempo aceitável: cálculo único do SVD, projeção da matriz termo-documento e cálculo incremental da similaridade. Os tempos obtidos na coleção Reuters R135 foram abaixo de 10 minutos para o máximo de 400 dimensões. Os resultados apresentados demonstram consistência na solução proposta e reforçam a aplicabilidade do algoritmo de dimensão ideal.

Apesar de ressaltarmos a melhoria dos tempos, destacamos a importância da ideia de projeção no espaço $B$. Esse espaço possui efetivamente um número menor de dimensões do que a matriz $A$ e, por ser uma transformação isométrica, todas as medidas de distância e de cosseno entre vetores são mantidas. 


\section{CONSIDERAÇÕES FINAIS}

Logo no início do trabalho, foram apresentados tópicos gerais de linguagem natural, misturando questões filosóficas e analogias ao desafio enfrentado pelas crianças nos primeiros anos para adquirir a linguagem. O ser humano possui um mecanismo de leitura robusto, que desempenha funções de inferência e define significados apropriados ao contexto. Dessa forma, deslizes gramaticais ou de sintaxe criam dificuldades, mas não impedem sua compreensão. Realizando um paralelo ao mundo da aprendizagem de máquina, foram discutidos os tópicos de modelagem de dados e o fenômeno de overfitting. Notamos que errar (um pouco) é bom e, graças a isso, é possível ler textos sem que haja toda a informação presente.

Um fundamento importante é a distribuição de Zipf e o espaço vetorial. Assim como em um jogo de caça-palavras, o principal objetivo é encontrar um padrão rapidamente. Usando os métodos tradicionais de representação de texto, é possível realizar a classificação de documentos mesmo sem entrar nas minúcias da gramática. O tema se desenvolveu para a análise da semântica latente: uma técnica baseada na álgebra linear e que, sem conhecimentos prévios, é capaz de encontrar o relacionamento entre termos.

O trabalho descreveu quatro diferentes experimentos de classificação de documento usando a coleção de texto da Reuters.

Primeiro, questiona-se o fato da análise da semântica latente ser considerada uma técnica de aprendizagem não-supervisionada. O experimento considera as informações de classificação prévia em uma matriz "categoria-documento" com o objetivo de torná-lo um mecanismo supervisionado. Entretanto, foram obtidos ganhos insignificantes frente ao trabalho adicional.

No segundo experimento, as classes são consideradas como diferentes subespaços. O grau de similaridade é dado pela projeção do vetor-documento no 
respectivo espaço, ou seja, define-se o quanto que um documento está inserido na categoria. $\mathrm{O}$ experimento apresentou ótimos resultados para amostras pequenas de dados, no entanto, o resultado ficou abaixo do esperado para um conjunto grande. Como a redução de dimensão foi feita em um contexto local, sem considerar o aspecto global, a técnica diminuiu as diferenças entre os documentos, mas não entre as classes. A conclusão é que o resultado seria melhor se houvesse uma forma de trabalhar com subespaços ortogonais.

O terceiro experimento cria uma proposta de algoritmo para determinar a dimensionalidade ideal do espaço ao invés de adotar valores empíricos. Define-se a hipótese de que o classificador apresenta o mesmo desempenho para os dados de treinamento e de teste. Portanto, é possível prever a dimensão ideal usando apenas os exemplos previamente conhecidos, que refletirá no comportamento do teste final. Quando os dados de treinamento e de teste possuem uma distribuição semelhante, observamos que essa hipótese é válida. O quarto experimento tem o objetivo de encontrar melhorias no algoritmo anterior para garantir que funcione em um tempo de processamento adequado. É proposta uma série de otimizações, reduzindo significativamente o tempo necessário. Portanto, esses dois últimos experimentos mostraram que é possível determinar a dimensão ideal do espaço semântico em um tempo adequado.

\subsection{Contribuições da Pesquisa}

A análise da semântica latente tem origem nos anos 90 e tem sido muito difundida graças a sua facilidade em encontrar termos e documentos pelo contexto. A dificuldade em ajustar o número de dimensões é vista de forma recorrente, sendo usualmente tratada como uma questão de tentativa e erro. Em geral, são adotadas 100 a 500 dimensões, procurando sempre se manter dentro dessa faixa.

A principal contribuição desse trabalho foi encarar a determinação do número de dimensões como um problema. Existe a possibilidade de utilizar o conjunto de treinamentos para calibrar o valor ideal, tornando o mecanismo em um algoritmo semi-supervisionado. A hipótese de equivalência das curvas $T$ e $P$, que 
correspondem às taxas de acerto das amostras de treinamento e de teste, pode ser verificada em qualquer dispositivo de classificação. Houve também a discussão sobre a distribuição dos dados de treinamento e de teste, mostrando contraexemplos que tornam a hipótese inválida.

A segunda grande contribuição do trabalho foi adotar uma projeção do espaço que utiliza efetivamente um menor número de dimensões do que a matriz termodocumento. Embora essa transformação seja conhecida na álgebra linear, ela não tem sido aplicada para a análise da semântica latente. Demonstra-se que o espaço projetado é isométrico, ou seja, as medidas de módulo, produto escalar e cosseno são iguais em ambos os espaços. Portanto, as similaridades entre termos e documentos são podem ser calculadas em um espaço reduzido.

O algoritmo de determinação da dimensão ideal do espaço é consequência dessas duas contribuições. Nos experimentos realizados, o tempo de processamento foi adequado e, portanto, poderia ser empregado para determinar as relações escondidas. A contribuição do algoritmo vai além da área de recuperação de informação, sendo aplicável em variantes da análise da semântica latente em outras áreas de conhecimento que utilizam a redução de dimensionalidade.

\subsection{Trabalhos Publicados}

Uma introdução sobre a classificação automática de texto usando a análise da semântica latente em conjunto com os resultados dos experimentos de investigação da dimensão ideal e de projeção de vetores no espaço isométrico foram apresentados no XVIII Congresso Argentino de Ciência da Computação em 2012.

CATAE, F.; ROCHA, R. L. A. Classificação Automática de Texto Buscando Similaridade de Palavras e Significados Ocultos. XVIII Congreso Argentino de Ciencias de la Computación CACIC 2012. Bahía Blanca: Universidad Nacional del Sur. 2012. p. 1069-1078. 
Um estudo de aprendizado usando a tecnologia adaptativa foi apresentado no Workshop de Tecnologia Adaptativa. Nesse artigo, a estrutura de árvore de decisão foi modificada para incorporar os conceitos de automodificação e reduzir o fenômeno de saturação do modelo.

CATAE, F. S.; ROCHA, R. L. A. Introdução a Árvores de Decisão Adaptativas. Memórias do WTA'2011 - Workshop de Tecnologia Adaptativa. São Paulo: EPUSP. 2011. p. 79-86.

Além das publicações realizadas, há interesse em se aprofundar na hipótese de equivalência entre as taxas de acerto T e P, que está comprovada empiricamente com os resultados apresentados nesse trabalho e em congresso. O problema precisa ser descrito algebricamente para formalizar a hipótese. Assim, abre-se a possibilidade de publicar um modelo embasado em uma representação mais clara com as limitações e os erros associados.

\subsection{Trabalhos Futuros}

Ao longo do trabalho foram identificadas diversas oportunidades de investigação a serem realizadas. Entretanto, o tempo limita a quantidade de assuntos explorados e a profundidade no tema. Como novas ideias continuam sempre surgindo sem um fim aparente, fechamos o escopo do trabalho e dedicamos o tempo para documentar os experimentos realizados. Deixamos algumas sugestões para serem investigadas em trabalhos futuros:

- O algoritmo da dimensão ideal é incremental, exceto pela primeira etapa, o cálculo da decomposição em valores singulares. Nessa fase, é fornecido um parâmetro de dimensão máxima $\left(k_{\max }\right)$ na entrada e são retornados os valores singulares na saída. A decomposição em valores singulares usando o método de Lanczos é iterativo, ou seja, todo o algoritmo poderia ser feito ao mesmo tempo que a curva $T(k)$ é determinada. Como melhoria ao algoritmo proposto, poderíamos definir uma iteração por: determinar o $k$-ésimo valor 
singular, depois encontrar a taxa de acerto $T(k)$ correspondente, incrementar $k$. Essa modificação eliminaria o parâmetro de dimensão máxima.

- O algoritmo de dimensão ideal pode ser generalizado para outras tarefas, além da classificação de texto pelo vizinho mais próximo. $\mathrm{O}$ algoritmo seria enriquecido com a combinação de outras técnicas como a máquina de vetores de suporte e entropia máxima.

- Uma linha de investigação é buscar por formas iterativas para o cálculo da decomposição de valores singulares como, por exemplo, a representação de documentos e termos através de vértices e arestas de um grafo. Dependendo da construção, pode ser criada uma matriz de adjacência corresponde à representação do espaço vetorial. Assim, reformula-se o problema na teoria dos grafos, que possui algoritmos e teoremas específicos. Um exemplo é empregar a caminhada aleatória no grafo para determinar os valores singulares (HERDAĞDELEN, ERK e BARONI, 2009).

- No experimento de espaços semânticos por categoria utilizamos um método local de redução de dimensionalidade. O ideal seria adotar um método global para identificação de categorias, de forma que a técnica maximize a discriminação entre classes. Uma possibilidade seria utilizar um mecanismo supervisionado como a máquina de vetores de suporte.

\subsection{Conclusão}

O desenvolvimento linguístico é visto de forma próxima a evolução cognitiva do ser humano, estabelecendo uma possível relação entre pensamento e linguagem. Assim, mesmo que haja um sistema que permita associar a cada palavra um significado, interpretar sentenças segue sendo um desafio. $\mathrm{O}$ conjunto de regras tem que ser finito 
e relativamente simples frente às inúmeras possibilidades de construções permitidas pelas línguas naturais.

A hipótese inicial de Chomsky é a existência de um sistema de regras compartilhado por todos os seres humanos, ou seja, um sistema que é natural a todos os indivíduos da espécie e que possibilita sua comunicação. Seu principal argumento tem como base a velocidade de aprendizado e a competência que crianças, expostas aos ambientes mais diversos, têm para aprender e usar linguagens naturais - o chamado "Paradoxo da Pobreza de Estímulo" (CHOMSKY, 1986)

A análise da semântica latente é uma das respostas ao paradoxo, no qual propõe uma técnica de processamento de linguagem natural, cujo objetivo é procurar, com base nas ocorrências de termo entre os documentos, as relações escondidas ou latentes entre eles. Uma das belezas da análise da semântica latente é que não há nenhum conhecimento prévio sobre a gramática. Por trás dessa técnica, encontra-se o simples cálculo da decomposição de matriz em valores singulares (BERRY e DUMAIS, 1995).

O espaço semântico corresponde à escolha dos $k$ maiores valores singulares do espaço vetorial. Segundo o principio da navalha de Occam, devemos buscar a simplificação. Nesse caso, a menor complexidade está relacionada à menor dimensionalidade do espaço. Compreendemos que a redução de dimensão funciona como um potente dispositivo de indução, ou seja, cria um modelo capaz de generalizar outras representações (VITANYI e LI, 2000).

Foi observado empiricamente que, embora os documentos sejam classificados em categorias distintas, ainda existe sobreposição entre essas categorias, ou seja, os subespaços associados às categorias não são ortogonais. A fim de segregar esses espaços, exploramos a possibilidade de estender a análise da semântica latente a considerar as informações relativas às categorias, não se limitando aos termos e aos documentos.

A principal contribuição desse trabalho foi encontrar um método de determinar a dimensão ideal, ou seja, o número de valores singulares que fornece a melhor representação do espaço. Foi proposto um algoritmo semi-supervisionado que aprende com as amostras previamente classificadas (dados treinamento) e ainda 
utiliza o conjunto de teste final para criar o espaço semântico. Após a decomposição em valores singulares, a matriz é projetada em um novo espaço para obter as medidas de similaridades de forma mais eficiente. Devido à isometria dos espaços, a distância Euclidiana e produto escalar são iguais, por isso, as medidas de similaridade se mantêm equivalente.

Como próximo passo, pretende-se formalizar as hipóteses através de uma descrição matemática mais rigorosa e tentar generalizar o algoritmo para outros casos e técnicas como, por exemplo, a máquina de vetores de suporte. Além disso, há a possibilidade de mudar a forma de representação do espaço vetorial para uma matriz de adjacência de grafo. 


\section{REFERÊNCIAS}

BENNETT, K. P.; CAMPBELL, C. Support vector machines: hype or hallelujah? ACM SIGKDD Explorations Newsletter, v. 2, n. 2, p. 1-13, 2000.

BERRY, M. Svdpackc (version 1.0) user's guide, 1993.

BERRY, M. Using Linear Algebra for Intelligent Information Retrieval, 1995.

BERRY, M.; DUMAIS, S. T. Using Linear Algebra for Intelligent Information Retrieval. SIAM Review, v. 37, p. 573-595, 1995.

BERRY, M.; KRISHNA, T. D. A. V.; VARADHAN, S. Svdpackc (version 1.0) user's guide. [S.1.]. 1993.

BINGHAM, E.; MANNILA, H. Random projection in dimensionality reduction: applications to image and text data. Proceedings of the seventh ACM SIGKDD international conference on Knowledge discovery and data mining. [S.1.]: ACM. 2001. p. 245-250.

BRADFORD, R. B. An empirical study of required dimensionality for large-scale latent semantic indexing applications. Proceedings of the 17th ACM conference on Information and knowledge management. [S.1.]: [s.n.]. 2008. p. 153-162.

BUCKLEY, C. The importance of proper weighting methods. Human Language Technology. [S.1.]: [s.n.]. 1993.

CATAE, F. S.; ROCHA, R. L. A. Introdução a Árvores de Decisão Adaptativas. Memórias do WTA'2011 - Workshop de Tecnologia Adaptativa. São Paulo: EPUSP. 2011. p. 79-86.

CATAE, F. S.; ROCHA, R. L. A. Classificação Automática de Texto Buscando Similaridade de Palavras e Significados Ocultos. XVIII Congreso Argentino de Ciencias de la Computación CACIC 2012. Bahía Blanca: Universidad Nacional del Sur. 2012. p. 1069-1078. 
CHAER, I. Um estudo sobre a Teoria da Predição aplicada à análise semântica de Linguagens Naturais. 2010. Dissertação (Mestrado em Sistemas Digitais) - Escola Politécnica, Universidade de São Paulo. São Paulo. 2010.

CHAKRABORTI, S. et al. Sprinkling: Supervised Latent Semantic Indexing. Advances in Information Retrieval, p. 510-514, 2006.

CHOMSKY, N. Aspects of the Theory of Syntax. Cambridge, MA, USA: MIT Press, 1965.

CHOMSKY, N. Knowledge of Language: Its Nature, Origin, and Use. Westport, CT, USA: Praeger/Greenwood, 1986.

CHOMSKY, N. Linguistics and cognitive science: Problems and mysteries. Cambridge, MA: Blackwell, 1991.

CORTES, C.; VAPNIK, V. Support-vector networks. Machine Learning, v. 20, n. 3, p. 273-297, 1995.

DEBOLE, F.; SEBASTIANI, F. An Analysis of the Relative Hardness of Reuters21578 Subsets. Journal of the American Society for Information Science and Technology, v. 56, p. 971-974, 2004.

DEERWESTER, S. et al. Indexing by Latent Semantic Analysis. Journal of the American Society for Information Science, v. 41, p. 391-407, 1990.

DIETTERICH, T. Overfitting and undercomputing in machine learning. ACM computing surveys (CSUR), v. 27, n. 3, p. 326-327, 1995.

DOMINGOS, P.; PAZZANI, M. On the optimality of the simple Bayesian classifier under zero-one loss. Machine learning, v. 29, p. 103-130, 1997.

DRUCKER, H.; WU, D.; VAPNIK, V. N. Support vector machines for spam categorization. Neural Networks, IEEE Transactions on, v. 10, n. 5, p. 1048-1054, 1999.

DUMAIS, S. T. Improving the retrieval of information from external sources. Behavior Research Methods, Instruments and Computers, v. 23, n. 2, p. 229-236, 1991.

DUMAIS, S. T. LSI meets TREC - A Status Report. In: D. Harman (Ed.), The First Text REtrieval Conference (TREC1), National Institute of Standards and Technology Special Publication. [S.1.]: [s.n.]. 1993. p. 137-152. 
DUMAIS, S. T. Latent Semantic Indexing (LSI) and TREC-2. The Second Text REtrieval Conference (TREC-2). [S.1.]: [s.n.]. 1994. p. 105-115.

DUMAIS, S. T. Latent Semantic Indexing (LSI) - TREC-3 Report. Overview of the Third Text REtrieval Conference. [S.1.]: [s.n.]. 1995. p. 219-230.

DUMAIS, S. T. et al. Using latent semantic analysis to improve access to textual information. Computer Human Interaction. [S.1.]: [s.n.]. 1988. p. 281-285.

DUMAIS, S. T. et al. Inductive learning algorithms and representations for text categorization. Proceedings of the seventh international conference on Information and knowledge management. [S.1.]: ACM. 1998. p. 148-155.

HARTER, S. P. Psychological relevance and information science. JASIS, v. 43, n. 9, p. 602-615, 1992.

HERDAĞDELEN, A.; ERK, K.; BARONI, M. Measuring semantic relatedness with vector space models and random walks. Proceedings of the 2009 Workshop on Graph-based Methods for Natural Language Processing. [S.1.]: Association for Computational Linguistics. 2009. p. 50-53.

HUANG, J.; LU, J.; LING, C. X. Comparing naive Bayes, decision trees, and SVM with AUC and accuracy. Data Mining, 2003. ICDM 2003. Third IEEE International Conference on. [S.1.]: IEEE. 2003. p. 553-556.

HULL, D. Improving text retrieval for the routing problem using latent semantic indexing. Proceedings of the 17th annual international ACM SIGIR conference on Research and development in information retrieval. New York: Springer-Verlag. 1994. p. 292-291.

HYAFIL, L.; RIVEST, R. L. Constructing optimal binary decision trees is NPComplete. Information Processing Letters, v. 5, n. 1, p. 15-17, 1976.

JAIN, S. System that learn: An introduction to learning theory. Cambridge, MA: MIT Press, 1986.

JOACHIMS, T. Text categorization with support vector machines: Learning with many relevant features. Machine learning: ECML-98, p. 137-142, 1998.

KOTSIANTIS, S. B.; ZAHARAKIS, I. D.; PINTELAS, P. E. Supervised Machine Learning: A Review of Classification Techniques. Frontiers in Artificial Intelligence and Applications, v. 160, p. 3, 2007. 
LANDAUER, T. K.; DUMAIS, S. T. A Solution to Plato's Problem: The Latent Semantic Analysis Theory of Acquisition, Induction, and Representation of Knowledge. Psychological Review, New York, NY, USA, v. 104, p. 211--240, 1997.

LANDAUER, T. K.; FOLTZ, P. W.; LAHAM, D. Introduction to Latent Semantic Analysis. Discourse processes, v. 25, p. 259-284, 1998.

LEWIS, D. D. Reuters-21578 text categorization test collection, 1997. Disponivel em: <http://www.daviddlewis.com/resources/testcollections/reuters21578>.

LEWIS, D. D. Naive (Bayes) at Forty - The Independence Assumption in Information Retrieval. Proceedings of ECML-98, 10th European Conference on Machine Learning. New York: Springer Verlag. 1998. p. 4-15.

LOVINS, J. B. Development of a stemming algorithm. [S.1.]: MIT Information Processing Group, Electronic Systems Laboratory, 1968.

LUHN, H. P. The automatic creation of literature abstracts. IBM Journal of research and development, v. 2, n. 2, p. 159-165, 1958.

MANNING, C. D.; RAGHAVAN, P.; SCHÜTZE, H. An introduction to information retrieval. [S.1.]: Cambridge University Press Cambridge, v. 1, 2008.

MANNING, C. D.; SCHÜTZE, H. Foundations of statistical natural language processing. [S.1.]: MIT press, 1999.

MINGERS, J. An Empirical Comparison of Pruning Methods for Decision Tree Induction. Machine learning, v. 4, n. 2, p. 227-243, 1989.

MITCHELL, T. M. Machine Learning. 1. ed. New York: McGraw-Hill, Inc., 1997.

NETO, J. J. Adaptive rule-driven devices - general formulation and a case study. Implementation and Application of Automata, p. 466-470, 2001.

PAPADIMITRIOU, C. H. et al. Latent semantic indexing: a probabilistic analysis. Proceedings of the seventeenth ACM SIGACT-SIGMOD-SIGART symposium on Principles of database systems. [S.1.]: ACM. 1998. p. 159-168.

PISTORI, H.; NETO, J. J.; PEREIRA, M. C. Adaptive Non-Deterministic Decision Trees: General Formulation and Case Study. INFOCOMP Journal of Computer Science, Lavras, MG, 2006.

PORTER, M. F. An algorithm for suffix stripping, 1980. 
QUINLAN, J. R. C4.5: Programs for Machine Learning. [S.l.]: Morgan kaufmann, v. $1,1993$.

ROBERTSON, S. E.; JONES, K. S. Relevance weighting of search terms. Journal American Society Information Science, v. 27, n. 3, p. 129-146, 1976.

ROCCHIO, J. J. Relevance feedback in information retrieval, 1971.

ROCHA, R. L. A.; NETO, J. J. Autômato adaptativo, limites e complexidade em comparação com máquina de Turing. Proceedings of the Second Congress of Logic Applied, p. 33-48, 2000.

SALTON, G.; BUCKLEY, C. Term-weighting approaches in automatic text retrieval. Information processing \& management, v. 24, n. 5, p. 513-523, 1988.

SALTON, G.; MCGILL, M. J. Introduction to modern information retrieval, 1986.

SALTON, G.; WONG, A.; YANG, C. S. A vector space model for automatic indexing. Commun. ACM, New York, NY, USA, v. 18, n. 11, p. 613--620, November 1975. ISSN 0001-0782.

SEBASTIANI, F. Machine learning in automated text categorization. ACM computing surveys (CSUR), v. 34, p. 1-47, 2002.

SINGHAL, A. et al. Document length normalization. Information Processing \& Management, v. 32, n. 5, p. 619-633, 1996.

TORKKOLA, K. Linear Discriminant Analysis in Document Classification. IEEE ICDM Workshop on Text Mining. [S.1.]: [s.n.]. 2001. p. 800-806.

VAN RIJSBERGEN, C. J. Information Retrieval. 2nd. ed. [S.1.]: Dept. of Computer Science, University of Glasgow, 1979.

VITANYI, P. M. B.; LI, M. Minimum description length induction, Bayesianism, and Kolmogorov complexity. IEEE Transactions on Information Theory, v. 46, n. 2, p. 446-464, 2000.

YANG, Y. An evaluation of statistical approaches to text categorization. Information retrieval, v. 1, p. 69--90, 1999.

YANG, Y.; ZHANG, J.; KISIEL, B. A scalability analysis of classifiers in text categorization. Proceedings of the 26th annual international ACM SIGIR conference on Research and development in informaion retrieval. [S.1.]: ACM. 2003. p. 96-103.

ZIPF, G. K. Human behavior and the principle of least effort, 1949. 